\title{
Uma Arquitetura Distribuída para Busca de Caminhos em Grafos Dinâmicos
}

\author{
Marcelo Luís Vinagreiro
}

\author{
DisSERTAÇÃo APRESENTADA AO \\ Instituto de MATEMÁtica E \\ EsTATÍ́STICA DA \\ Universidade de SÃo PaUlo \\ COMO PARTE DOS REQUISITOS \\ PARA OBTENÇÃO DO GRAU DE \\ Mestre em CiênCia da Computação
}

Área de Concentração: Computação Distribuída Orientador: Prof. Dr. Alfredo Goldman

- São Paulo - Janeiro de 2004 - 


\title{
Uma Arquitetura Distribuída para Busca de Caminhos em Grafos Dinâmicos
}

\author{
Este exemplar corresponde à redação final \\ da dissertação a ser apresentada \\ por Marcelo L. Vinagreiro \\ e analisada pela comissão julgadora.
}

Banca examinadora:

- Prof. Dr. Alfredo Goldman vel Lejbman - IME-USP

- Prof. Dr. Fabio M. Costa - Instituto de Informática - UFG

- Prof. Dr. José Coelho de Pina Jr. - IME-USP 
Aos meus pais Alcides e Maria

e meu irmão Carlos Eduardo 


\section{Agradecimentos}

Meus sinceros agradecimentos ao meu orientador, o Professor Alfredo Goldman, pela paciência e dedicação com que me orientou. Sempre disposto e participativo, contribuiu muito para o meu amadurecimento acadêmico, ajudando-me, sobretudo nos momentos de decisão dos rumos a serem tomados.

Agradeço também à Professora Dilma M. Silva, minha orientadora por 2 anos durante meu trabalho de Iniciação Científica com bolsa CNPq, na área de Computação Distribuída. Sua participação foi decisiva para que eu continuasse minhas atividades científicas em nível de Mestrado.

Ao Professor Carlos E. Ferreira, por ser um dos grandes exemplos de boa conduta e didática excelente, dentre os professores do Instituto de Matemática e Estatística.

Aos meus pais, Alcides e Maria, pela dedicação, incentivo e carinho. Ao meu irmão, Carlos Eduardo, pelo seu companheirismo.

Aos meus amigos, Leonardo Pinho, Luciano Kubo, Luis Endo, Shigueo Isotani, e Wagner Dias, que me apoiaram e incentivaram durante todo o decorrer da Graduação e Mestrado. 


\section{Resumo}

Este trabalho descreve um novo modelo para a computação concorrente de caminhos em um grafo dinâmico particionado em um conjunto de servidores interconectados. Aspectos dinâmicos foram bem explorados em trabalhos anteriores. Aqui, são considerados também assuntos relativos à distribuição. Os cálculos de caminhos são realizados usando o arcabouço dinâmico proposto por Narváez et al.

Este modelo pode ser usado, por exemplo, em sistemas simulando o estado de uma rede ou monitorando as condições do trânsito de uma cidade em um grafo. Nesses casos, além de aspectos naturalmente distribuídos, os clientes poderiam pedir informações sobre o melhor caminho entre dois pontos considerando aspectos dinâmicos.

Também são apresentados detalhes de modelagem e implementação de uma arquitetura para validar os conceitos e idéias apresentados neste trabalho.

Palavras-Chave: computação distribuída, roteamento, algoritmos para computação de caminhos, computação dinâmica de caminhos. 


\begin{abstract}
This work describes a new model for concurrent path computation in dynamic graphs, we also consider that the graphs are partitioned in a set of interconnected servers. Dynamic aspects in path computations were well explored in previous works. Here we take into account the distribution issues. The path calculations are performed using the dynamic framework proposed by Narváez et al.

This model can be used, for example, in systems simulating the state of a network or monitoring the traffic conditions of a city in a graph. In these cases, beside the intrinsic distribution, clients could require information concerning the best path between two points considering dynamic aspects.
\end{abstract}

We also show the main details related to the design and implementation of an architecture which was developed for validating the concepts and ideas described in this work.

Keywords: distributed computing, routing, path computation algorithms, dynamic path computation. 


\section{Sumário}

Agradecimentos ........................... 4

Resumo ........................... 5

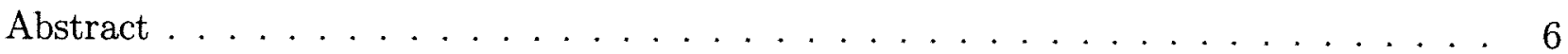

1 Introdução $\quad 14$

2 Trabalhos relacionados $\quad 16$

2.1 Algoritmos para busca de caminhos . . . . . . . . . . . . . . . 16

2.2 Algoritmos para grafos dinâmicos . . . . . . . . . . . . . . . . 17

2.2 .1 Os algoritmos RR e FMN . . . . . . . . . . . . . . . . 17

Diminuição de peso de arco . . . . . . . . . . . . . . . . . 18

Aumento de peso de arco . . . . . . . . . . . . . . . . . . . . 19

Complexidade dos algoritmos RR e FMN . . . . . . . . . . . . . . . . 19

2.3 Algoritmos para roteamento em redes . . . . . . . . . . . . . . . . . 20

2.3.1 Algoritmos baseados em vetores de distância . . . . . . . . . . . . . 20

2.3.2 Algoritmos baseados nos estados dos links . . . . . . . . . . . . . . 22

2.3 .3 Roteamento hierárquico . . . . . . . . . . . . . . . 25

2.4 Roteamento baseado em agentes móveis . . . . . . . . . . . . . . . . . . 26

$2.5 \mathrm{Um}$ exemplo de roteamento adaptativo centralizado . . . . . . . . . . . . 26

2.6 Discussão sobre as técnicas existentes . . . . . . . . . . . . . . . . . . 27

3 Um arcabouço para grafos dinâmicos $\quad 29$

3.1 Definições e notações . . . . . . . . . . . . . . . . . . . . . . . . 29

3.2 O algoritmo básico . . . . . . . . . . . . . . . . . . 30

3.3 Caminhos mínimos em grafos dinâmicos . . . . . . . . . . . . . . 30 


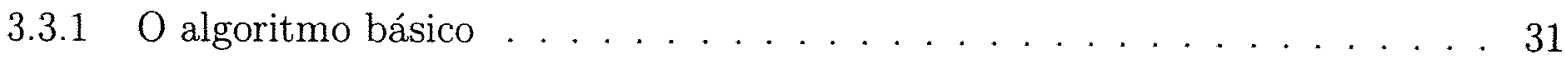

3.4 O primeiro e o segundo métodos incrementais . . . . . . . . . . . . . 33

3.5 Complexidade . . . . . . . . . . . . . . . . . . 35

3.6 Múltiplas atualizações . . . . . . . . . . . . . . . . . 35

3.7 Considerações gerais . . . . . . . . . . . . . . . . . 36

4 Uma arquitetura distribuída $\quad 37$

4.1 Considerações iniciais . . . . . . . . . . . . . . . . . . 37

4.2 Árvore pórtico . . . . . . . . . . . . . . . . . . 38

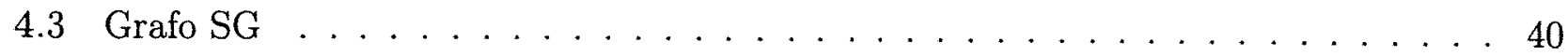

4.4 Os nós Origem e Sorvedouro . . . . . . . . . . . . . . . . . . . . 40

4.5 Árvore-modelo. . . . . . . . . . . . . . . . . . . . . 41

4.6 Roteamento adaptativo através de árvores dinâmicas . . . . . . . . . . . . . . 42

4.7 Processamento . . . . . . . . . . . . . . . . . . . . 42

4.7 .1 Processamento em $E B_{i} \ldots \ldots \ldots \ldots \ldots \ldots \ldots \ldots$

4.7 .2 Processamento em $S B_{j} \ldots \ldots \ldots \ldots \ldots \ldots$

4.8 Busca de caminhos . . . . . . . . . . . . . . . . 43

$4.8 .1 \quad$ Busca de caminhos em $E B_{i} \quad \ldots \ldots \ldots \ldots \ldots$

Procedimentos BuscaEB e BuscaInterEB . . . . . . . . . . . . . . . 44

Procedimento ConsultaPorticEB . . . . . . . . . . . . . . . . . . 46

4.8 .2 Busca de caminhos em $S B_{j} \ldots \ldots \ldots \ldots$. . . . . . . . . . 47

Procedimento BuscaSB . . . . . . . . . . . . . . . . . 47

4.9 Atualização do sistema . . . . . . . . . . . . . . . . . . . . . 48

4.10 Complexidade estimada para trocas de mensagens . . . . . . . . . . . . . . . 49

4.11 Análise do algoritmo distribuído . . . . . . . . . . . . . . . . . 50

4.12 Considerações gerais . . . . . . . . . . . . . . . . . . . 51

5 Implementação $\quad 52$

5.1 Arquiteturas computacionais distribuídas . . . . . . . . . . . . . . . 52

5.2 Serviços da arquitetura CORBA . . . . . . . . . . . . . . . 53

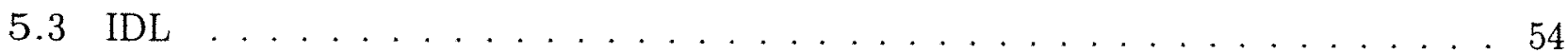

5.4 Hierarquia de classes . . . . . . . . . . . . . . . . 58 
5.4 .1 dgraph $\ldots \ldots \ldots \ldots \ldots \ldots \ldots \ldots \ldots \ldots$

5.4 .2 dgraph.ddgraphs.datastruct $\ldots \ldots \ldots \ldots \ldots \ldots \ldots$

5.4 .3 dgraph.ddgraphs.graph . . . . . . . . . . . . . . . . . 59

5.4 .4 dgraph.ddgraphs.exception . . . . . . . . . . . . . . 60

5.4 .5 dgraph.listeners . . . . . . . . . . . . . . . . . 61

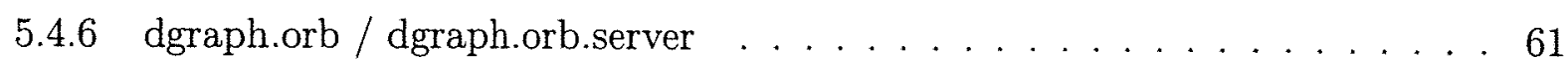

5.4 .7 dgraph.server . . . . . . . . . . . . . . . . 61

5.4 .8 dgraph.server.baseserver . . . . . . . . . . . . . . 62

5.4 .9 dgraph.server.searchserver . . . . . . . . . . . . . . 62

5.4 .10 dgraph.util . . . . . . . . . . . . . . . . 63

5.5 Uma biblioteca para grafos com acessos concorrentes . . . . . . . . . . . 63

5.6 Arquitetura das classes servidoras . . . . . . . . . . . . . . 66

5.6 .1 Classes de solicitação . . . . . . . . . . . . . . . . . 66

5.6 .2 Classes agentes . . . . . . . . . . . . . . . . 68

$5.6 .3 \quad$ BSAgents para busca de caminhos . . . . . . . . . . . . 68

$\mathrm{O}$ agente BaseServerRequestAgent $\ldots \ldots \ldots \ldots \ldots \ldots$

$\mathrm{O}$ agente FindRset2YAgent $\ldots \ldots \ldots \ldots \ldots \ldots$

$\mathrm{O}$ agente RequestSubPathAgent . . . . . . . . . . . . . . 70

5.6 .4 SSAgents para busca de caminhos . . . . . . . . . . . . . . 70

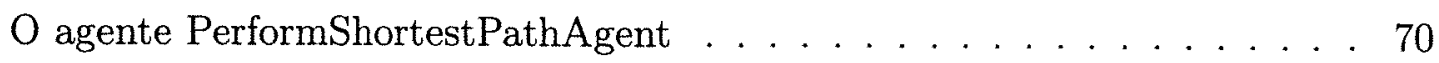

5.6.5 BSAgents para atualização de estados . . . . . . . . . . . . . . 71

$\mathrm{O}$ agente UpdateTransactionAgent $\ldots \ldots \ldots \ldots \ldots$. . . . . . . . . .

O agente UpdateRsetAgent . . . . . . . . . . . . . . . . 72

O agente CommitRsetAgent . . . . . . . . . . . . . . 72

O agente UpdateDataLinkAgent . . . . . . . . . . . . . . . . 72

5.6 .6 SSAgents para atualização de estados . . . . . . . . . . . . . . 72

O agente UpdateRwsetAgent . . . . . . . . . . . . . . . . . 72

O agente CommitRwsetAgent . . . . . . . . . . . . . . 73

5.6 .7 Classes de representação de domínios . . . . . . . . . . . . . . . . 73

5.6 .8 Classes de implementação de servidores . . . . . . . . . . . . . . . . . 73

5.6 .9 Classes adaptadoras . . . . . . . . . . . . . . . . . 76 
5.7 Remoção de estados . . . . . . . . . . . . . . . . . . 76

5.8 Considerações gerais . . . . . . . . . . . . . . . . . . 77

6 Testes $\quad 78$

6.1 Ambiente computacional . . . . . . . . . . . . . . . 78

6.2 Visão geral . . . . . . . . . . . . . . . . . . . . . . 78

6.3 Influência do Conjunto Raízes . . . . . . . . . . . . . . . . . . . . 79

6.3 .1 Atualização . . . . . . . . . . . . . . . . . 79

6.3 .2 Buscas de caminhos . . . . . . . . . . . . . . 83

6.4 Arcos afetados . . . . . . . . . . . . . . . . . . . . 84

6.5 Influência do grau . . . . . . . . . . . . . . . . . 86

6.6 Qualidade da solução . . . . . . . . . . . . . . . . . . . 87

6.7 Desempenho em função do tamanho do grafo de domínio . . . . . . . . . . . . 89

6.8 Número de acessos de clientes . . . . . . . . . . . . . . . . . . . . . . 91

6.9 Considerações gerais . . . . . . . . . . . . . . . . . 92

7 Considerações Finais $\quad 95$

7.1 Trabalhos futuros . . . . . . . . . . . . . . . . . . . 96

$\begin{array}{ll}\text { A Alguns detalhes da implementação } & 97\end{array}$

A.1 Classes para implementação de algoritmos de busca . . . . . . . . . . . . . . . 97

A.2 Arquivos de configuração de servidores . . . . . . . . . . . . . . . . . . . 101

A.3 Formatos de entrada para criação de grafos . . . . . . . . . . . . . . . . . . . . 102

A.3.1 Formato do arquivo usado na propriedade dgraph.graphpath . . . . . . 103

A.3.2 Formato do arquivo usado na propriedade dgraph.serverarea . . . . . . . 103

A.4 Classes clientes . . . . . . . . . . . . . . . . . . . . . 103 


\section{Lista de Figuras}

2.1 Grafo para exemplificar algoritmos baseados em vetores de distância . . . . . . . . 21

2.2 Grafo exemplo para ilustrar problema "count to infinity" . . . . . . . . . . . . 21

2.3 Grafo representando uma rede de interconexão . . . . . . . . . . . . . . . . 23

2.4 Roteamento hierárquico em 2 níveis . . . . . . . . . . . . . . . . 25

3.1 Definições e notações do arcabouço dinâmico. . . . . . . . . . . . . . . 30

4.1 Topologia de um domínio de aplicação sob a cobertura de duas EBs adjacentes. . 38

4.2 Conjunto raízes e tabela custos de caminhos entre raízes de $G_{i} \ldots \ldots$. . . . . . 39

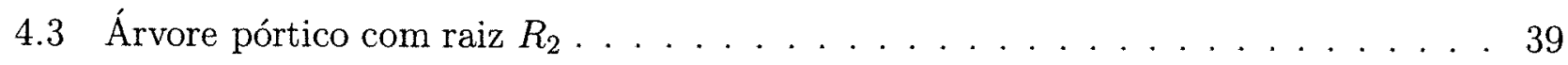

4.4 Exemplo de grafo SG. . . . . . . . . . . . . . . . . . . . . 40

4.5 Vértices especiais origem e sorvedouro. . . . . . . . . . . . . . . 41

4.6 Processo de atualização do sistema para o estado $k+1 \ldots \ldots$. . . . . . . . 49

5.1 Diagrama de classes da biblioteca de grafos da arquitetura. . . . . . . . . . . 64

5.2 Diagrama de classes dos servidores da arquitetura. . . . . . . . . . . . . 67

5.3 Relação de ações e agentes em estações-base. . . . . . . . . . . . . . . . . . . 69

5.4 Relação de ações e agentes em servidores de busca. . . . . . . . . . . . . . . 69

6.1 Atualização em servidores de busca utilizando o algoritmo estático . . . . . . . . 80

6.2 Atualização em servidores de busca utilizando o algoritmo dinâmico . . . . . . . . 80

6.3 Atualização em estações-base utilizando o algoritmo estático . . . . . . . . . . . 81

6.4 Atualização em estações-base utilizando o algoritmo dinâmico . . . . . . . . . . . 81

6.5 Comparação entre algoritmos durante a atualização de estações-base . . . . . . . . 81

6.6 Comparação entre algoritmos durante a atualização de servidores de busca . . . . 82

6.7 Busca globais em função dos Conjuntos Raízes . . . . . . . . . . . . . . . . . . 83 
6.8 Buscas locais em função dos Conjuntos Raízes . . . . . . . . . . . . . . . . . . 83

6.9 Comparações entre buscas locais e buscas globais . . . . . . . . . . . . . . . 84

6.10 Variação de arcos afetados para servidores de busca usando o algoritmo estático . 85

6.11 Variação de arcos afetados para servidores de busca usando o algoritmo dinâmico 85

6.12 Variação de arcos afetados para estações-base usando o algoritmo estático . . . . . 85

6.13 Variação de arcos afetados para estações-base usando o algoritmo dinâmico . . . . 86

6.14 Buscas locais de caminhos em sistemas em função do grau . . . . . . . . . . . . 88

6.15 Atualização de servidores de busca em função do grau . . . . . . . . . . . . . . 88

6.16 Atualização de estações-base em função do grau . . . . . . . . . . . . . . . 88

6.17 Qualidade da solução variando-se os Conjuntos Raízes . . . . . . . . . . . . . . 89

6.18 Atualização em servidores de busca em função do tipo de algoritmo . . . . . . . . 90

6.19 Atualização em estações-base em função do tipo de algoritmo . . . . . . . . . . . . 90

6.20 Desempenho de buscas de caminhos globais e locais . . . . . . . . . . . . . . . 91

6.21 Tempos de buscas em função do número de clientes variando-se o número de estações-base . . . . . . . . . . . . . . . . . . . . 92

6.22 Tempos de buscas em função do número de clientes variando-se o número de servidores de busca . . . . . . . . . . . . . . . . . 93

6.23 Tempos totais de atualização de estados em função do número de estações-base . . 94 


\section{Lista de Tabelas}

2.1 Tabela de roteamento para o nó $\mathrm{J} \ldots \ldots \ldots \ldots \ldots$

2.2 Tabelas de roteamento para os nós $\mathrm{A}, \mathrm{B}, \mathrm{C}$ e $\mathrm{D} \ldots \ldots \ldots \ldots \ldots$

2.3 O problema "count to infinity" . . . . . . . . . . . . . . . . 22

2.4 Tabela de roteamento para o nó A . . . . . . . . . . . . . 23

2.5 Tabela de roteamento para o nó A usando roteamento hierárquico em 2 níveis . . 26 


\section{Capítulo 1}

\section{Introdução}

Um dos principais assuntos em Teoria de Grafos é o problema da busca de caminhos entre dois ou mais pontos de um grafo [2]. Este problema já foi bem estudado, principalmente para grafos estáticos.

No entanto, problemas práticos em geral não apresentam uma natureza estática, uma vez que podem ocorrer alterações nos pesos dos arcos, com o decorrer do tempo. Para resolver este problema, existem vários trabalhos que estendem os algoritmos de busca de caminhos em grafos estáticos, de forma a permitir mudanças no grafo, ou apenas alterações de peso nos arcos/arestas [20]. Com esta flexibilidade adicional podem ser resolvidos problemas práticos interessantes como a busca de caminhos, segundo critérios que eventualmente podem mudar durante o processamento, como por exemplo, a quantidade de fluxo.

Neste trabalho, apresentamos um modelo que permite o cálculo de estimativas de caminhos em um grafo dinâmico. Diferentemente de trabalhos similares, como o proposto por Fawcett e Robinson [7], nos quais, a computação de caminhos é realizada em um único servidor, o qual mantém o grafo completo em memória, de forma centralizada, o trabalho aqui apresentado permite que o grafo esteja particionado em um conjunto de servidores, que se comunicam através de uma rede de interconexão, a qual supostamente não está sujeita a falhas.

O principal objetivo é apresentar soluções eficientes e escaláveis que permitam manter um modelo de monitoramento das condições de algum sistema que possa ser representado na estrutura de um grafo dinâmico, como por exemplo, o monitoramento das condições do trânsito de uma dada região, como a cidade de São Paulo ou a simulação do estado de uma rede de interconexão de forma descentralizada. Um exemplo desse tipo de aplicação pode ser encontrado no sítio do projeto SIDAM ${ }^{1}$ (Sistemas de Informações Distribuídas para Agentes Móveis).

O modelo proposto também pode ser usado em áreas emergentes da Computação, como a Computação Móvel [16], uma vez que em sistemas móveis, além da existência de uma rede fixa, também há comunicação via rádio entre as unidades móveis [16] e bases de transmissão. Neste caso, as unidades móveis poderiam obter caminhos entre dois pontos de forma dinâmica, minimizando os gastos de recursos como tempo, energia, etc.

\footnotetext{
${ }^{1}$ http://www.ime.usp.br/ sidam/
} 
Conforme será visto no Capítulo 4, o modelo proposto neste trabalho denomina-se "Roteamento adaptativo através de árvores dinâmicas". Esse modelo permite que um grafo qualquer $G$ seja particionado em subconjuntos quaisquer de subgrafos $G_{i}$, distribuídos em um grupo de servidores. De uma forma geral, existem dois tipos especiais de servidores: estações-base e servidores de busca. Uma estação-base é um servidor especializado em manter um subgrafo de $G,\left(G_{i}\right)$. Esses servidores são responsáveis por receber as atualizações de pesos dos arcos que compõem o subgrafo que está sob sua responsabilidade, bem como receber requisições de clientes, solicitando caminhos. Toda solicitação cliente de um caminho de um ponto a outro é direcionada para a estação que armazena o subgrafo que contém o nó inicial, a qual calcula uma árvore de caminhos com raiz no nó inicial. Como as estações-base apenas mantêm informações do subgrafo pelo qual elas são responsáveis, para obter um caminho é necessário realizar uma consulta a algum dentre os servidores de busca do sistema. Os servidores de busca armazenam informações globais do sistema. O modelo apresentado possibilita que o estado do sistema seja atualizado com novos valores de pesos de arcos dos subgrafos que compõem o domínio de aplicação. Dada a natureza dinâmica do sistema, são utilizados algoritmos especiais para realizar a atualização de árvores de caminhos que atuam em grafos que possuem características dinâmicas. Em particular, são discutidos os detalhes do arcabouço para algoritmos de busca em grafos dinâmicos proposto por Narváez, Siu e Tzeng [18], o qual permite transformar as versões estáticas de conhecidos algoritmos de busca, como por exemplo, o algoritmo de Dijkstra [2], em suas respectivas versões dinâmicas. Como será apresentado no Capítulo 6, o modelo proposto permite aumento de escalabilidade tanto no número de clientes ativos quanto no tamanho do grafo representante do domínio de aplicação.

O modelo proposto neste trabalho foi implementado utilizando CORBA e Java. No Capítulo 5 são apresentados detalhes de implementação e no Capítulo 6 são apresentados os resultados obtidos em testes.

Este texto está organizado da seguinte maneira: no Capítulo 2 são apresentados alguns trabalhos relacionados. No Capítulo 3 é apresentado em detalhes o arcabouço proposto por Narváez et al. [18] para a atualização de árvores de caminhos em grafos dinâmicos. No Capítulo 4 são apresentados os detalhes do modelo proposto neste trabalho. A seguir, no Capítulo 5 são apresentados detalhes da implementação do modelo discutido no Capítulo 4 e no Capítulo 6 são mostrados os resultados obtidos de testes realizados. Finalmente o Capítulo 7 apresenta algumas conclusões sobre o modelo bem como possíveis trabalhos futuros. 


\section{Capítulo 2}

\section{Trabalhos relacionados}

Neste Capítulo serão abordados alguns trabalhos relacionados ao problema de busca de caminhos. Na seção 2.6, serão apresentadas algumas comparações entre as técnicas apresentadas bem como as possibilidades de uso das mesmas no problema exposto neste trabalho.

\subsection{Algoritmos para busca de caminhos}

Um dos principais assuntos em teoria de grafos é o problema do caminho mínimo (Shortest Path Problem) [2]. Nesse problema, deseja-se encontrar uma rota mais curta (se alguma existir) entre dois vértices em um grafo. Ou seja, dado um grafo orientado $G=(V, A)$, sendo $V$ o conjunto de vértices e $A$ o conjunto de arcos, associa-se uma função $w: A \rightarrow \Re$ mapeando o peso de cada arco, onde, o peso pode representar possíveis critérios de minimização. Assim, o peso de um caminho $p=\left(v_{0}, v_{1}, \ldots, v_{k}\right)$ é a soma dos pesos de seus arcos: $w(p)=\sum_{i=1}^{k} w\left(v_{i-1}, v_{i}\right)$. Um caminho de peso mínimo de um vértice $u$ a um vértice $v$ é $\min (w(p))$ se existe ao menos um caminho, e $\infty$, caso contrário.

Para resolver esse problema, existem vários algoritmos cada qual com peculiaridades próprias, por exemplo, o algoritmo de Bellman-Ford descrito na seção 24.1 de [2] resolve o problema para grafos com pesos quaisquer, com valores negativos ou não. Entretanto, se existem ciclos com peso negativo alcançáveis a partir do vértice original, nenhum caminho mínimo é retornado. Esse algoritmo é baseado em um roteamento utilizando o esquema de vetores de distância (distance vector), e foi implementado para as primeiras versões dos roteadores da rede Arpanet e implementações do protocolo RIP (Routing Information Protocol [22]). Nesse algoritmo, cada nó mantém uma tabela que lista a rota mais barata para cada outro nó da rede. Em intervalos regulares de tempo, cada nó envia as informações presentes na sua tabela para os nós vizinhos (broadcast). O cálculo de uma rota entre dois nós tem custo de $O(|V| *|A|)$, considerando-se um grafo com $V$ vértices e $A$ arcos. Usando estruturas de dados mais eficientes para as buscas, tais como, heaps, árvores B ou tabelas de espalhamento (hashtables) [2], esse custo pode ser reduzido.

Por outro lado, o algoritmo proposto por Dijkstra (descrito na seção 24.3 de [2]) admite grafos com pesos não-negativos. O custo do algoritmo é $O\left(|V|^{2}\right)$, considerando-se um grafo de 
$V$ vértices.

O algoritmo de Dijkstra é um dos mais empregados para resolver o problema de caminho mínimo e as suas melhores implementações apresentam um tempo de execução inferior ao algoritmo de Bellman-Ford.

\subsection{Algoritmos para grafos dinâmicos}

Tradicionalmente algoritmos para grafos operam em estruturas estáticas. Normalmente, um grafo é dado e um problema é resolvido sobre ele. Entretanto, uma generalização possível são os grafos dinâmicos, cujos estados não são fixos com o passar do tempo, uma vez que podem ocorrer mudanças nos seus estados internos ${ }^{1}$. Em geral, muitos problemas que envolvem grafos apresentam uma natureza dinâmica, tal como simular o estado de uma rede em um grafo, onde atualizações dos valores dos pesos bem como a inserção/remoção de arcos ocorrem freqüentemente. Dessa forma, deseja-se ter algoritmos que realizem buscas de rotas em grafos dinâmicos de uma forma eficiente.

Em geral, esses algoritmos são executados para realizar a atualização de uma árvore de caminhos após a modificação de peso dos arcos do grafo. Para isso, eles apresentam dois tipos de métodos, dependendo do tipo de alteração à qual o peso do arco foi submetida: um procedimento trata os aumentos de pesos e outro trata as diminuições.

Para tanto algoritmos propostos por Ramalingan e Reps (RR) [20], Frigioni, Marchetti e Nanni (FMN) [9] ou Narváez, Siu e Tzeng (NST) [18] têm gerado bons resultados em termos práticos, comparando-se com as melhores implementações de algoritmos de caminhos mínimos em grafos estáticos, como o algoritmo de Dijkstra implementado com filas de prioridades.

Particularmente o trabalho proposto por Narváez et al. [18] apresenta um aspecto interessante: é proposto um arcabouço básico o qual permite transformar algoritmos estáticos bem conhecidos (Dijkstra, Bellman-Ford, etc) em versões dinâmicas dos mesmos. Maiores detalhes desses algoritmos serão apresentados nas seções posteriores.

A seção a seguir apresenta uma breve descrição dos algoritmos FMN e RR. O algoritmo proposto NST é apresentado no Capítulo 3. Os motivos da escolha do arcabouço desenvolvido por Narváez et al. na implementação do modelo distribuído apresentado no Capítulo 4 são descritos na seção 2.6 .

\subsubsection{Os algoritmos RR e FMN}

A seguir é apresentada uma breve descrição das idéias presentes nos algoritmos FMN e RR.

Para tanto, considere uma grafo $G=(V, A)$ formado por um conjunto de vértices em $V$ e arcos no conjunto $A$. Assuma $s$ como o nó inicial de uma árvore de caminhos mínimos, $T(s)$, calculada com os dados do grafo $G$. Seja $(u, v)$ um arco qualquer de $G$, com nó inicial $u$ e nó

\footnotetext{
${ }^{1}$ Neste trabalho somente serão permitidas mudanças dinâmicas nos pesos dos arcos
} 
final $v$ e $w(u, v)$ o peso associado a este arco. $d(x)$ denota o custo do caminho mínimo de um nó $x$ à raiz $s$ da árvore $T(s)$. Considere também que $\operatorname{In}(x)$ representa o conjunto de arcos que têm $x$ como nó inicial e $O u t(x)$ o conjunto de arcos que tem $x$ como nó final ${ }^{2}$. Um nó é dito afetado por uma modificação de um arco se a sua distância em relação à raiz $s$ de alguma árvore $T(s)$ é modificada.

Em princípio, a idéia envolvida nos algoritmos RR e FMN é usar a técnica descrita por Edmonds e Karp [6]. Com esta técnica, é possível diminuir a complexidade da atualização de caminhos de uma árvore de $O(m . n)$ para $O(m+n \cdot \log n)$, no pior caso, após a mudança de peso de um arco no grafo com $n$ nós e $m$ arcos. A técnica apresentada em [6] pode ser resumida da seguinte maneira: após uma atualização de peso de arco, para cada arco $(z, v) \in A$, é alterado o peso $w(z, v)$ do arco $(z, v)$ para o peso reduzido $r(z, v)=d(z)+w(z, v)-d(v)$, e aplica-se uma adaptação do algoritmo de Dijkstra no grafo modificado. Os valores calculados representam as mudanças para as distâncias desde a atualização. As verdadeiras distâncias dos nós após a atualização podem ser facilmente recuperadas a partir dos pesos reduzidos. Isso permite a redução de complexidade, conforme apresentado anteriormente.

A seguir são dadas as idéias gerais dos algoritmos RR e FMN para manipular aumentos e diminuições de pesos de arcos do grafo $G$. Para maiores detalhes, ver as referências [9] e [20].

\section{Diminuição de peso de arco}

Considerando o caso de uma operação para tratar a diminuição de peso de um arco $(x, y)$, os algoritmos RR e FMN basicamente atualizam os caminhos mínimos na árvore $\mathrm{T}$ através do algoritmo de Dijkstra, com vértice inicial em $y$, de acordo com a técnica de Edmonds e Karp [6]. Durante a execução do algoritmo de Dijkstra, quando um nó $z$ é permanentemente marcado (ou seja, não sofrerá mais alteração de sua distância em relação ao nó raiz da árvore T), todos os $\operatorname{arcos}(z, h)$ são visitados e a prioridade de $h$ na fila de prioridades usada é possivelmente atualizada.

Entretanto no algoritmo FMN, a seguinte técnica é explorada para limitar o número de $\operatorname{arcos}(z, h)$ a serem visitados. Para cada nó $z$, os conjuntos $\operatorname{In}(z)$ e Out $(z)$ são particionados em dois subconjuntos como segue: para cada nó $x \in V$, In_Own(x) denota o subconjunto de In $(x)$ contendo arcos "controlados" (owned) por $x$ e, $\overline{\operatorname{In} O \text { Own }}(x)=\operatorname{In}(x)-\operatorname{In} \_O w n(x)$ denota o conjunto de arcos em In $(x)$ e que não são "controlados" por $x$. Analogamente, Out_Own $(x)$ e $\overline{\text { Out_Own }}(x)$ representam os arcos em Out $(x)$ "controlados" e não "controlados" por $x$, respectivamente. O grafo $\mathrm{G}$ admite um $k$-ownership se, para todos nós $x$, ambos conjuntos In_Own $(x) \mathrm{e}$ Out_Own $(x)$ contêm no máximo $k$ arcos (veja a referência [9] para maiores detalhes). Finalmente, os arcos $\overline{I n \_O w n}(x)\left(\overline{O u t \_O w n}(x)\right)$ são armazenados em uma fila de prioridade com ordenação crescente (uma fila de prioridade com ordenação decrescente), onde a prioridade do arco $(y, x)$ $((x, y))$ é a quantidade $d(y)+w(y, x)(d(y)-w(x, y))$. Um arco $(x, y)$ tem um "controlador" (owner) que precisa ser $x$ ou $y$, mas não ambos. A escolha de controladores é arbitrária e é feita na inicialização do algoritmo, pelo procedimento Set_OwnerShip.

Quando a nova distância de um nó $z$ é calculada, as partições permitem ao algoritmo visitar

\footnotetext{
${ }^{2} \mathrm{~A}$ nomenclatura descrita nesta seção é proposta pelos autores dos algoritmos FMN e RR.
} 
somente os $\operatorname{arcos}(z, h)$ em Out_Own $(z)$ e aqueles em $\overline{\text { Out_Own }}(z)$, tais que $h$ é nó afetado.

\section{Aumento de peso de arco}

No caso do aumento de peso de um arco $(x, y)$ de $G$ por uma quantidade positiva $\delta$, os algoritmos RR e FMN são executados em duas fases.

Primeiramente, eles encontram os nós afetados e então calculam as novas distâncias potenciais para esses nós. A segunda fase é essencialmente a mesma para ambos os algoritmos, e consiste na execução do algoritmo de Dijkstra no subgrafo de $G$ induzido pelos nós afetados, de acordo com a técnica de Edmonds e Karp [6] descrita anteriormente. As principais diferenças estão na primeira fase conforme explicado a seguir.

No algoritmo FMN, a primeira fase é realizada da seguinte forma: para cada nó afetado $z$ considerado, os $\operatorname{arcos}(h, z)$ em In_Own $(z)$ são visitados. E também são visitados os nós em $\overline{\operatorname{In\_ } O w n}(z)$, tais que $h$ é nó afetado.

Quando a nova distância de um nó $z$ é calculada, as partições permitem ao algoritmo visitar somente os $\operatorname{arcos}(z, h)$ em Out_Own $(z)$ e aqueles em $\overline{O u t \_O w n}(z)$, tais que $h$ é nó afetado.

Com respeito ao algoritmo $\mathrm{RR}$, a primeira fase é realizada mantendo-se um subconjunto $S P$ de arcos de $G$, contendo os arcos que pertencem a pelo menos um caminho mínimo a partir de $s$ para todos nós de $G$. O grafo com conjunto de nós em $V$ e arcos em $S P$ é um grafo dirigido acíclico (DAG) [2], denotado por $S P(G)$. Como consequiência, o algoritmo RR funciona somente se todos os ciclos no grafo $G$, antes e depois de qualquer atualização de peso de arco têm comprimento positivo. De fato, se ciclos de comprimento zero são permitidos, então todos estes ciclos que são alcançados a partir da raiz $s$ da árvore $T(s)$ pertencerão a $S P(G)$, o qual não será mais um grafo dirigido acíclico.

A primeira fase do algoritmo RR encontra os nós afetados como segue: é mantido um conjunto de trabalho (work set) contendo os nós que foram identificados como afetados, mas não foram ainda processados. Inicialmente, $y$ é inserido naquele conjunto, se não há arcos em $S P(G)$ que têm $y$ como nó final, após a criação de SP. Os nós no conjunto de trabalho são processados um a um. Quando o nó $u$ é processado, todos $\operatorname{arcos}(u, v)$ são removidos de $S P(G)$, e $v$ é inserido no conjunto de trabalho. Todos nós identificados como afetados durante esta fase são inseridos no conjunto de trabalho.

\section{Complexidade dos algoritmos RR e FMN}

O algoritmo RR executa em $O(|| \sigma||+|\sigma| \cdot \log |\sigma|)$ para cada atualização de arco, onde $|\sigma|$ é o número de nós afetados por uma mudança $\sigma$, e $\|\sigma\|$ é o número de nós afetados adicionado do número de arcos que tiveram ao menos um de seus nós finais afetados. Isto resulta em um tempo $O(m+n \cdot \log n)$, no pior caso.

O algoritmo proposto por Frigioni, Marchetti e Nanni [9] tem complexidade no pior caso que depende da complexidade de saída (output complexity) da operação de atualização e também de um parâmetro da estrutura do gráfico chamado $k$-ownership. No pior caso, a complexidade é 
dada por $O(k \cdot \log n)$.

$\mathrm{Na}$ seção 3.5 é mostrada a complexidade do algoritmo proposto por Narváez et al.

\subsection{Algoritmos para roteamento em redes}

Os algoritmos para roteamento são usados em redes de computadores e permitem escolher os caminhos por onde os pacotes devem ser enviados. A seguir são apresentadas as idéias presentes nos principais algoritmos de roteamento conhecidos.

\subsubsection{Algoritmos baseados em vetores de distância}

Os algoritmos baseados em vetores de distância (Distance Vector) são também conhecidos como algoritmos de roteamento Bellman-Ford [2]. Nesses algoritmos, cada roteador tem uma tabela de roteamento que mostra a melhor rota para cada um dos outros roteadores da rede. Um grafo de rede e a tabela de roteamento para o roteador $J$ são apresentados na figura 2.1 e tabela 2.1 , respectivamente.

Como a tabela mostra, se o roteador $\mathrm{J}$ deseja enviar pacotes para $\mathrm{D}$, ele deveria enviar para o roteador vizinho $\mathrm{H}$. Quando o pacote chegar em $\mathrm{H}$, o roteador $\mathrm{H}$ avalia sua tabela de roteamento, para decidir para onde enviar o pacote, tendo como destino o nó D.

Dessa maneira, em algoritmos baseados em vetores de distância, os roteadores desempenham as seguintes tarefas:

1. O roteador calcula o peso dos links diretamente conectados a ele e salva esta informação em sua tabela de roteamento;

2. Em determinados períodos de tempo, o roteador envia sua tabela de roteamento para os roteadores vizinhos (não todos os roteadores da rede) e recebe a tabela de roteamento de cada um de seus vizinhos;

3. Baseado nas informações presentes nas tabelas de roteamento de seus vizinhos e nas suas próprias informações, o roteador atualiza sua tabela de roteamentos, minimizando o valor da equação mostrada a seguir:

$$
D^{X}(Y, Z)=c(X, Z)+\min _{w}\left\{D^{Z}(Y, w)\right\}
$$

Onde $c(X, Z)$ representa o custo do link conectando os nós X e Z. $D^{X}(Y, Z)$ é a função de distância para um pacote sair do nó $X$ e chegar no nó $Y$, usando o vizinho $Z$. Dessa forma, o vizinho $\mathrm{Z}$ que minimiza a função anterior, será usado para enviar pacotes a $\mathrm{Y}$.

Um dos mais importantes problemas com algoritmos baseado em distância de vetores é o problema conhecido como "count to infinity". Para apresentar esse problema será mostrado um 


\begin{tabular}{|c|c|c|}
\hline Destino & Custo & Vizinho \\
\hline $\mathrm{A}$ & 8 & $\mathrm{~A}$ \\
\hline $\mathrm{B}$ & 20 & $\mathrm{~A}$ \\
\hline $\mathrm{C}$ & 28 & $\mathrm{~A}$ \\
\hline $\mathrm{D}$ & 20 & $\mathrm{H}$ \\
\hline $\mathrm{E}$ & 17 & $\mathrm{I}$ \\
\hline $\mathrm{F}$ & 30 & $\mathrm{I}$ \\
\hline $\mathrm{G}$ & 18 & $\mathrm{H}$ \\
\hline $\mathrm{H}$ & 12 & $\mathrm{H}$ \\
\hline $\mathrm{I}$ & 10 & $\mathrm{I}$ \\
\hline $\mathrm{J}$ & 0 & - \\
\hline $\mathrm{K}$ & 6 & $\mathrm{~K}$ \\
\hline $\mathrm{L}$ & 15 & $\mathrm{~K}$ \\
\hline
\end{tabular}

Tabela 2.1: Tabela de roteamento para o nó J

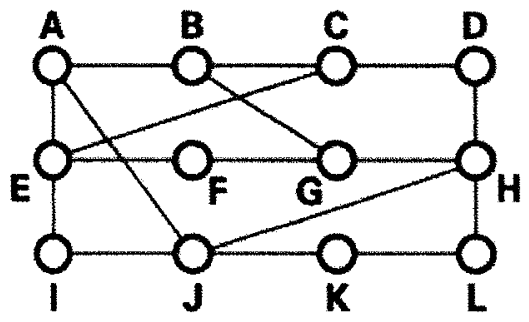

Figura 2.1: Grafo para exemplificar algoritmos baseados em vetores de distância

exemplo. Imagine uma rede com um grafo como o mostrado em 2.2. Como pode ser observado, somente há um link ligando A aos outros nós da rede. A tabela 2.2 apresenta as tabelas de roteamento para todos nós da rede.

Agora considere que o link entre A e B tornou-se indisponível. Neste momento, B corrige sua tabela de roteamento. Após um determinado período de tempo, os roteadores realizam a troca de tabelas, de forma que $\mathrm{B}$ recebe a tabela de roteamento de $\mathrm{C}$. Devido ao fato de que $\mathrm{C}$ não conhece o fato de que o link entre $\mathrm{A}$ e $\mathrm{B}$ está indisponível, a tabela de $\mathrm{C}$ diz que há um link para A com peso 2. B recebe esta tabela e "acredita" que existe um link entre C e A, tanto que corrige sua tabela de roteamento de $\infty$ para 3 (custo 1 de $\mathrm{B}$ para $\mathrm{C}$ e 2 de $\mathrm{C}$ para $\mathrm{A}$, conforme apresentado na tabela de $\mathrm{C}$ ). Novamente os roteadores trocam as tabelas de roteamento. Quando $\mathrm{C}$ recebe a tabela de roteamento de $\mathrm{B}, \mathrm{C}$ "acredita" que $\mathrm{B}$ mudou o peso de seu link a $\mathrm{A}$ de 1

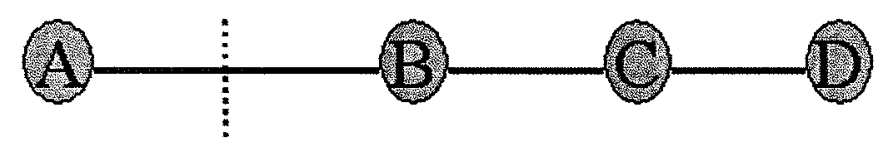

Figura 2.2: Grafo exemplo para ilustrar problema "count to infinity" 


\begin{tabular}{|c|c|c|c|c|}
\hline & $\mathrm{A}$ & $\mathrm{B}$ & $\mathrm{C}$ & $\mathrm{D}$ \\
\hline $\mathrm{A}$ & $0,-$ & $1, \mathrm{~A}$ & $2, \mathrm{~B}$ & $3, \mathrm{C}$ \\
\hline $\mathrm{B}$ & $1, \mathrm{~B}$ & $0,-$ & $1, \mathrm{~B}$ & $2, \mathrm{C}$ \\
\hline $\mathrm{C}$ & $2, \mathrm{~B}$ & $1, \mathrm{C}$ & $0,-$ & $1, \mathrm{C}$ \\
\hline $\mathrm{D}$ & $3, \mathrm{~B}$ & $2, \mathrm{C}$ & $1, \mathrm{D}$ & $0,-$ \\
\hline
\end{tabular}

Tabela 2.2: Tabelas de roteamento para os nós A,B,C e D

\begin{tabular}{|c|c|c|c|}
\hline & $\mathrm{B}$ & $\mathrm{C}$ & $\mathrm{D}$ \\
\hline Soma de peso para A após a queda do link & $\infty, \mathrm{A}$ & $2, \mathrm{~B}$ & $3, \mathrm{C}$ \\
\hline Soma de peso para A após a 1a. atualização & $3, \mathrm{C}$ & $2, \mathrm{~B}$ & $3, \mathrm{C}$ \\
\hline Soma de peso para A após a 2a. atualização & $3, \mathrm{C}$ & $4, \mathrm{~B}$ & $3, \mathrm{C}$ \\
\hline Soma de peso para A após a 3a. atualização & $5, \mathrm{C}$ & $4, \mathrm{~B}$ & $5, \mathrm{C}$ \\
\hline Soma de peso para A após a 4a. atualização & $5, \mathrm{C}$ & $6, \mathrm{~B}$ & $5, \mathrm{C}$ \\
\hline Soma de peso para A após a 5a. atualização & $7, \mathrm{C}$ & $6, \mathrm{~B}$ & $7, \mathrm{C}$ \\
\hline Soma de peso para A após a n-ésima atualização & $\ldots$ & $\ldots$ & $\ldots$ \\
\hline$\infty$ & $\infty$ & $\infty$ & $\infty$ \\
\hline
\end{tabular}

Tabela 2.3: O problema "count to infinity"

para 3, tanto que C atualiza sua tabela, mudando o custo para alcançar A para 4.

Este processo é repetido até que todos os nós descubram que o peso do link para alcançar A é $\infty$. A situação é apresentada na tabela 2.3. Por esse motivo, afirma-se que os algoritmos baseados em distância de vetores apresentam uma taxa de convergência lenta.

Uma forma de resolver o problema apresentado anteriormente é obrigar os roteadores enviar informação somente para os vizinhos que não são links exclusivos para o destino, por exemplo, C não deveria enviar qualquer informação para o nó $\mathrm{B}$ sobre $\mathrm{A}$, pois a única maneira de se chegar em A passa por B.

\subsubsection{Algoritmos baseados nos estados dos links}

Os problemas de roteamento têm sido amplamente estudados para a transmissão de datagramas ${ }^{3}$ em redes de computadores. Dentre os diversos algoritmos de roteamento em redes, destaca-se a família de algoritmos baseados nos estados dos links, Link State, dos quais o mais famoso é o New Arpanet Routing Algorithm proposto por Mcquillan [17].

Os detalhes desses algoritmos podem variar mas, em geral, eles seguem a mesma idéia: cada nó mantém um banco de dados topológico representando o estado da rede. Usualmente a base topológica é considerada como um grafo formado pelos nós da rede e os arcos representam as

\footnotetext{
${ }^{3}$ As informações que trafegam pelas redes são particionadas em unidades menores (pacotes) chamadas de datagramas. O datagrama possui informações codificadas sobre o seu destino.
} 


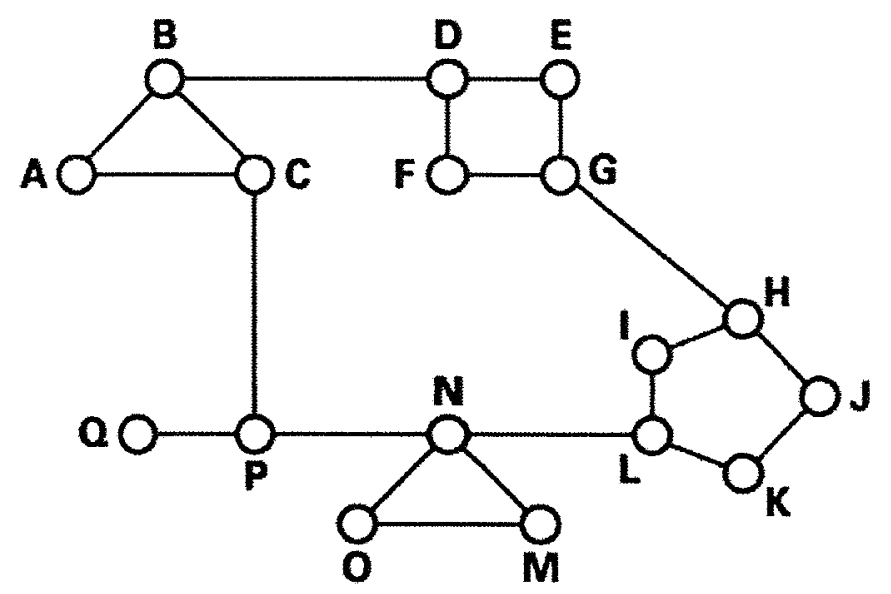

Figura 2.3: Grafo representando uma rede de interconexão

\begin{tabular}{|c|c|c|}
\hline Destino & Vizinho & Custo \\
\hline A & - & - \\
\hline B & B & 1 \\
\hline C & C & 1 \\
\hline D & B & 2 \\
\hline E & B & 3 \\
\hline F & B & 3 \\
\hline G & B & 4 \\
\hline H & B & 5 \\
\hline I & C & 5 \\
\hline J & C & 6 \\
\hline K & C & 5 \\
\hline L & C & 4 \\
\hline M & C & 4 \\
\hline N & C & 3 \\
\hline O & C & 4 \\
\hline P & C & 2 \\
\hline Q & C & 3 \\
\hline
\end{tabular}

Tabela 2.4: Tabela de roteamento para o nó A 
conexões entre os nós. Cada arco mantém a informação do seu peso, que pode ser, por exemplo, o número de pacotes trafegando naquele arco por unidade de tempo. Assim, cada nó calcula a rota mais barata partindo de si próprio para cada um dos outros nós da rede (utilizando algoritmos clássicos para encontrar caminhos de peso mínimo em grafos [2]). A partir daí, cada membro da rede constrói uma tabela de roteamento mostrando, para cada destino, qual vizinho é o primeiro ponto para a rota de menor custo. Quando as condições da rede mudam, as informações dos novos pesos de arcos são repassadas através de broadcast e as bases topológicas/tabelas de roteamento dos roteadores precisam ser atualizadas.

A figura 2.3 apresenta um grafo representando uma rede de interconexão. Os nós representam roteadores e os arcos conexões bidirecionais entre os nós. Para simplificar o exemplo, assume-se que o custo de cada arco é 1 . Nessas condições, a tabela 2.4 representa a tabela de roteamento gerada para o nó A. Nela, é apresentado o custo do caminho mínimo obtido para atingir os outros possíveis nós da rede, utilizando-se algum algoritmo de busca de caminhos mínimos, e qual é o vizinho de $\mathrm{A}$ que está no caminho mínimo calculado. Por exemplo, o melhor caminho calculado para atingir o nó $\mathrm{Q}$ tem custo 3 e o vizinho de $\mathrm{A}$ que origina tal caminho é $\mathrm{C}$, conforme pode ser visto na tabela.

Em geral, os algoritmos baseados em estados dos links realizam os seguintes passos:

1. Identifique os roteadores que estão fisicamente conectados. Para esses roteadores, é medido o tempo de espera (delay time). Para tanto, o roteador envia pacotes contendo uma mensagem especial (echo message). Quando o roteador recebe os pacotes da mensagem de resposta, ele pode calcular o tempo de espera dividindo por 2 o valor do conteúdo do campo round trip time $e^{4}$ presente no cabeçalho da mensagem;

2. Assim que um roteador tem a informação dos tempos de espera necessários para os pacotes alcançarem os vizinhos, ele envia uma mensagem de broadcast para todos os roteadores da rede, a fim de que todos os roteadores passem a ter conhecimento do novo estado da rede;

3. Em intervalos de tempo regulares, os roteadores obtém os melhores caminhos, por eles conhecidos, para enviar pacotes aos outros nós da rede. Para isso, eles utilizam um grafo descrevendo a rede, cujos arcos possuem como pesos, os tempos de espera recebidos dos nós da rede. Com os caminhos calculados, os roteadores atualizam suas tabelas de roteamento.

Apesar desses algoritmos resolverem o problema de roteamento, eles apresentam um sério inconveniente: uma vez que se faz necessário manter a informação de todos os nós da rede no caso de uma rede complexa e densa como por exemplo, a Internet ou uma WAN, essas técnicas tornam-se inviáveis.

Visando solucionar o principal problema relacionado aos primeiros algoritmos de roteamento, surgiram as idéias de roteamento hierárquico para transmissão de pacotes, ou seja, permitir que um vértice tome decisões de roteamento baseando-se em informações do estado global de um agrupamento de nós vizinhos e não no estado global de toda rede [11].

\footnotetext{
${ }^{4}$ Round trip time é uma medida do tempo corrente de espera na rede, obtido pela monitoração do tempo necessário para um pacote enviado a um servidor remoto, retornar ao servidor de origem
} 


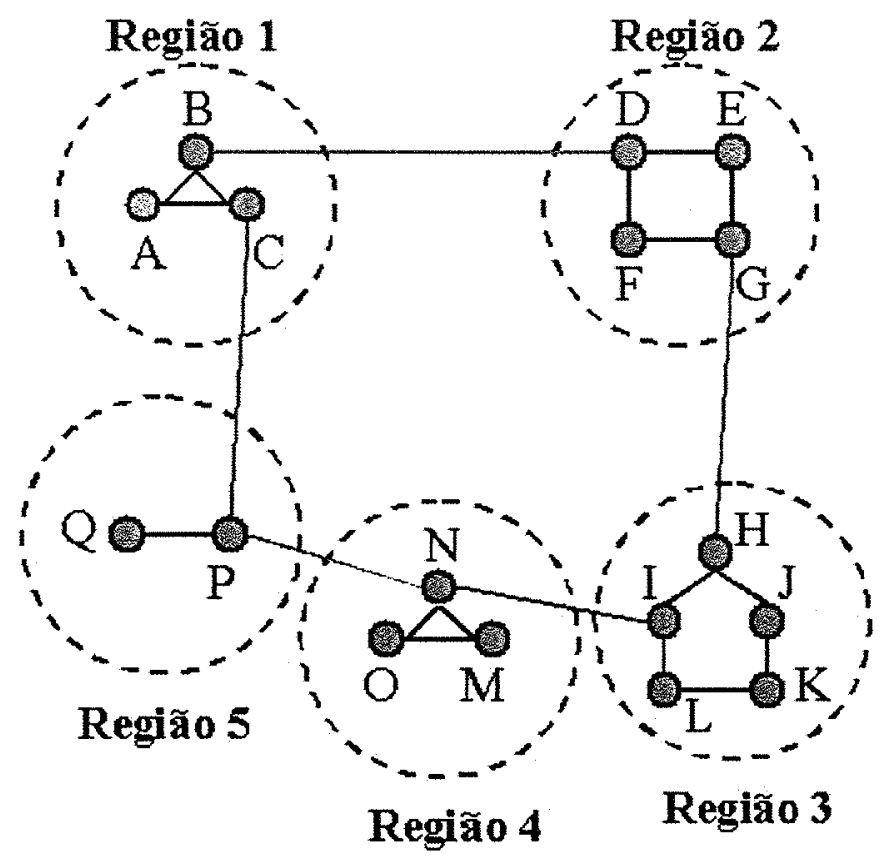

Figura 2.4: Roteamento hierárquico em 2 níveis

\subsubsection{Roteamento hierárquico}

Os algoritmos baseados em roteamento hierárquico utilizam algoritmos de busca de caminhos, por exemplo, os baseados em distância de vetores (DV), para gerar a tabela de roteamento. $\mathrm{Na}$ situação apresentada na figura 2.3, um nó X qualquer no grafo precisa guardar a tabela de roteamento com 17 registros, um para cada vértice alcançável a partir de X. A tabela 2.5 apresenta a tabela de roteamento para o nó A.

Em um roteamento hierárquico, os roteadores são classificados em grupos conhecidos como regiões. Cada roteador convencional somente guarda informação sobre os roteadores na sua região, não possuindo qualquer dado sobre outras regiões. Dessa maneira, os roteadores apenas armazenam um registro em suas tabelas de roteamento para cada região. Na figura 2.4 o domínio representado foi classificado em 5 regiões.

Dessa forma, se A deseja enviar pacotes para qualquer um dos roteadores na região 2 (D, $\mathrm{E}, \mathrm{F}$ ou $\mathrm{G}$ ), ele necessita enviar para B. Como pode ser visto, neste tipo de roteamento, as tabelas podem ser diminuídas, melhorando a eficiência da rede. O exemplo descrito na figura 2.4 apresenta um roteamento hierárquico em 2 níveis. Entretanto, também é comum o roteamento em 3 ou 4 níveis. O roteamento hierárquico é bastante usado em redes como a Internet, fazendo uso de diversos protocolos de roteamento. 


\begin{tabular}{|c|c|c|}
\hline Destino & Vizinho & Custo \\
\hline A & - & - \\
\hline B & B & 1 \\
\hline C & C & 1 \\
\hline Região 2 & B & 2 \\
\hline Região 3 & C & 2 \\
\hline Região 4 & C & 3 \\
\hline Região 5 & C & 4 \\
\hline
\end{tabular}

Tabela 2.5: Tabela de roteamento para o nó A usando roteamento hierárquico em 2 níveis

\subsection{Roteamento baseado em agentes móveis}

Uma outra forma conhecida de roteamento em redes de computadores é proveniente da comunidade de agentes móveis [23]. Sucintamente, essa técnica pode ser descrita como sendo uma coleção de agentes móveis (ants) que trafegam no interior da rede e coletam informações de cada um dos nós da rede por onde passam. Essas informações são compartilhadas com outros agentes e servem para atualizar as tabelas de roteamento dos nós da rede. Um exemplo de aplicação dessa técnica pode ser encontrado no trabalho proposto por Di Caro e Dorigo [10], conhecido por AntNet.

Uma AntNet é constituída por dois tipos especiais de agentes: forward ants (FA) e backward ants (BA). Em intervalos regulares, um determinado FA escolhe um nó destino $\mathrm{D}$ a partir do seu nó inicial S. Dessa forma, FA migra entre os nós no caminho de $\mathrm{S}$ a $\mathrm{D}$ orientando-se pelas tabelas de roteamento de cada nó que ele visita. Quando FA chega à $\mathrm{D}$, é gerado um agente $\mathrm{BA}$ que faz o caminho inverso, atualizando as tabelas de cada nó com as novas informações.

\subsection{Um exemplo de roteamento adaptativo centralizado}

A seguir, serão apresentadas as principais idéias contidas no trabalho proposto por Fawcett e Robinson [7]. Esse trabalho consiste no desenvolvimento de um sistema para o monitoramento do trânsito. Nesse trabalho, a computação de caminhos é realizada em um único servidor, o qual mantém o grafo completo, de forma centralizada. O servidor que mantém os dados é atualizado a cada 15 minutos com dados coletados de sensores que monitoram as condições do trânsito das principais vias do Reino Unido. Entre o período de duas atualizações consecutivas, o sistema utiliza interpolações matemáticas para estimar o peso de arcos.

Esse sistema utiliza um algoritmo de roteamento bastante utilizado no projeto de circuitos integrados, o algoritmo de Lee [15]. Esse algoritmo assemelha-se aos conhecidos algoritmos de busca em largura em grafos [2]. Como o sistema é dinâmico, durante o processo de cálculo de caminhos mínimos, o grafo pode ter sido atualizado, nesse caso, o modelo adotado pelos autores prevê duas fases adicionais conhecidas como trace-back e exploration. Com essas duas etapas, após um trajeto ter sido obtido, percorre-se o caminho no sentido inverso a fim de se verificar se 
mudanças ocorreram e, em caso afirmativo, corrigir o caminho obtido.

\subsection{Discussão sobre as técnicas existentes}

Conforme descrito nas seções anteriores, existem várias técnicas para efetuar roteamento. Dentre elas, destacam-se os algoritmos de roteamento em redes de computadores, como os baseados em estados dos links (Link state) [17] bem como técnicas mais apuradas, como roteamento hierárquico [11] ou o roteamento por colônias de agentes móveis [10].

A seguir serão apresentadas algumas considerações sobre a viabilidade de tais técnicas no problema proposto nesse trabalho. Essencialmente, a análise se concentrará em técnicas mais modernas de roteamento, tais como o roteamento hierárquico e o roteamento por agentes móveis, uma vez que algoritmos mais antigos como o RIP, OSPF, tornaram-se ineficientes com o crescimento das redes. Uma comparação detalhada entre a vantagem do uso de algoritmos dinâmicos em relação aos estáticos poderá ser vista no Capítulo 6 .

Um dos principais motivos para que algoritmos baseados em roteamento por hierarquias não se adequem de imediato ao problema aqui exposto reside no fato de que, normalmente, esses algoritmos conseguem agrupar vários roteadores de uma rede interna em uma mesma hierarquia, uma vez que em muitos casos, todos roteadores da rede interior trocam pacotes com o mundo exterior pelo mesmo conjunto de pontos de acesso (backbones ${ }^{5}$ ) [23]. Em geral, o número de backbones é muito inferior do que o número de nós da rede interna. Dessa forma, torna-se possível reduzir bastante o tamanho das tabelas de roteamento dos backbones, uma vez que estas últimas armazenam informações sobre os melhores caminhos para chegar aos nós que estão no mesmo nível (constituído somente por backbones). Por exemplo, para um backbone, sua tabela de roteamento apenas armazenaria informações sobre os melhores caminhos para chegar aos outros backbones da rede e não para todos os computadores da rede em que está um dado backbone.

No problema aqui exposto, generalizações desse tipo não teriam um desempenho tão vantajoso como nas redes formadas por backbones. Uma vez que, se os pontos presentes na borda (maiores detalhes na seção 4.1) de um grafo $G_{i}$, presente em um servidor $S_{i}$, fossem considerados os backbones do domínio de $S_{i}$ (como eles não necessariamente alcançam todos os pontos interiores em $S_{i}$ ), a generalização para uma estrutura de hierarquias poderia ocasionar uma sobrecarga considerável. Isso ocorre porque os pontos presentes nas bordas dos grafos presentes em outros servidores $S_{j}$ deveriam saber se um dado destino $D$ no interior do grafo $G_{i}$, presente no servidor $S_{i}$, é alcançável por um dado ponto $B_{i}$ escolhido da borda de $G_{i}$.

Os modelos que utilizam colônias de agentes móveis para roteamento em redes de computadores têm obtido bons resultados. Entretanto, a utilização de tais modelos no problema aqui exposto, em princípio, poderia ocasionar problemas de desempenho na rede de comunicação. Uma vez que ao se considerar colônias de agentes móveis para realizar roteamento, normalmente, há o seguinte cenário: os agentes escolhem os nós de origem e destino e a partir daí visitam os nós intermediários, deslocando-se ao destino em função das condições das tabelas de roteamento de cada um dos nós que visitam. Com isso, os agentes constroem a rota entre a origem e destino

\footnotetext{
${ }^{5}$ Um backbone é um nó que se comunica com outras redes.
} 
escolhidos. No caso do problema aqui apresentado, cada servidor armazena centenas ou milhares de nós em seu interior. Dessa forma, deveria existir uma grande quantidade de agentes circulando na rede interligando as estações-base, o que poderia gerar sobrecarga considerável. Para solucionar esse problema, poderia ser considerada a idéia de se reduzir o número de agentes, cada qual montando as rotas para um número maior de nós presentes em um mesmo servidor. Porém uma solução dessa natureza poderia gerar um crescimento considerável no estado dos agentes (no caso, a árvore de caminhos mínimos para os destinos escolhidos presentes em uma mesma estação-base), o qual precisa ser carregado sempre que o agente migra para outro servidor.

Algumas observações sobre limitações do número de acessos concorrentes num sistema centralizado como o descrito em 2.5 serão apresentadas no Capítulo 6, na seção 6.8 .

Como foi apresentado, o problema aqui exposto apresenta uma série de peculiaridades que se não forem consideradas podem prejudicar sobremaneira o desempenho do sistema. No Capítulo 4 é proposto um modelo alternativo para o problema.

$\mathrm{Na}$ implementação do trabalho apresentado neste texto, decidiu-se utilizar o arcabouço proposto por Narváez et al. [18] pois os resultados apresentados são tão bons quanto os melhores algoritmos de busca em grafos dinâmicos bem conhecidos. Além disso, o arcabouço permite o uso de respectivas versões dinâmicas de vários algoritmos de busca estáticos conhecidos. Maiores detalhes podem ser encontrados no Capítulo 3. 


\section{Capítulo 3}

\section{Um arcabouço para grafos dinâmicos}

Neste Capítulo é apresentado um arcabouço proposto por P. Narváez, K. Siu e H. Tzeng [18] no qual é possível adaptar algoritmos estáticos conhecidos para cálculo de caminhos mínimos, como o algoritmo de Dijkstra, para serem usados em grafos dinâmicos (ou seja, grafos cujos pesos das arestas se alteram com o decorrer do tempo).

O arcabouço proposto é constituído por um algoritmo básico (basic algorithm) o qual pode se especializar em duas modalidades: o primeiro ou o segundo método incrementais. A seguir serão apresentadas as idéias gerais do algoritmo básico proposto por Narváez et al. [18].

\subsection{Definições e notações}

Introduziremos agora algumas das notações utilizadas pelo arcabouço proposto por Narváez et al. [18].

Considere um grafo dirigido $G=(V, E)$, onde $V$ é o conjunto de vértices e $E$ é o conjunto de arcos de $G^{1}$. Considere $\operatorname{Source}(G)$ um vértice de $G$ como sendo o ponto de origem (raiz) da árvore de caminhos mínimos sendo calculada. Seja $e$ um arco dirigido do grafo, ou seja, $e \in E$. Dessa forma, assuma que $S(e)$ e $E(e)$ representam respectivamente o nó inicial e o nó final do $\operatorname{arco} e$.

Dado um conjunto $N_{V}$ de vértices de $V$, considere os conjuntos $I\left(N_{V}\right)=\left\{e \in E \mid E(e) \in N_{V}\right\}$, ou seja o conjunto de todos os arcos que incidem nos vértices contidos em $N_{V}$, analogamente, considere $O\left(N_{V}\right)=\left\{e \in E \mid S(e) \in N_{V}\right\}$, ou seja o conjunto de todos os arcos com origem nos vértices contidos em $N_{V}$.

Uma árvore $T$ é um subgrafo de $G$ tal que Source $(G)$ está em $T$, e cada nó em $T$ é alcançável de $\operatorname{Source}(G)$ através de um único caminho de arcos dirigidos. Associa-se à cada nó de $T$ os seguintes atributos: $P(n, T)$ é o nó pai do nó $n$ e $D(n, T)$ é a distância de $n$ ao $\operatorname{Source}(G)$. Particularmente, se $n=$ Source $(G)$, então $P(n, T)=$ nil e $D(n, T)=0$. Os descendentes de um

\footnotetext{
${ }^{1}$ Apesar de em geral se utilizar $A$ para denotar os arcos de $G$, decidiu-se utilizar a nomenclatura original do artigo.
} 


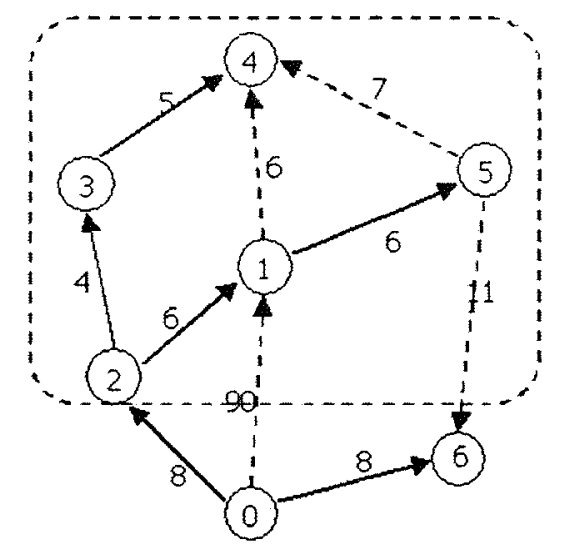

Figura 3.1: Definições e notações do arcabouço dinâmico.

nó $n \in T$ são todos os nós que são alcançáveis por $n$, chamando-se recursivamente o pai $P(n, T)$ de $n$ até a raiz $\operatorname{Source}(G)$. É usada a notação $B(n, T)$ para denotar um subconjunto que inclua $n$ e alguns descendentes de $n$ na árvore $T$. Particularmente, $B_{\max }(n, T)$ representa o conjunto máximo de descendentes de $n$ em $T$.

A figura 3.1 apresenta um grafo com 7 nós. Para esse grafo, considere uma árvore $T$ com raiz no nó 0 . Os arcos pertencentes à $T$ são mostrados na figura através de linhas contínuas. Os outros arcos do grafo (que não pertencem à $\mathrm{T}$ ) são mostrados através de linhas tracejadas. Tomando um nó $n \in T$, por exemplo, $n=1$, tem-se: $P(1, T)=2, D(1, T)=14$. O conjunto $B(2, T)=\{1,2,3,4,5\}$ está representado no retângulo pontilhado.

Assuma a existência de uma fila $Q$ com as funções de inserção (Enqueue) e extração (Extract). Um elemento $n \in T$ que está na fila $Q$ é atualizado com um novo nó pai $P^{\prime}(n, T)$ e distância $D^{\prime}(n, T)$, se a nova distância $D^{\prime}(n, T)$ for menor do que a distância atualmente calculada para $n$, conforme descrito em [18].

\subsection{O algoritmo básico}

\subsection{Caminhos mínimos em grafos dinâmicos}

Neste item é apresentado o arcabouço proposto por P. Narváez, K. Siu e H. Tzeng [18] no qual é possível adaptar algoritmos estáticos para cálculo de caminhos mínimos em grafos dinâmicos. $\mathrm{O}$ arcabouço proposto é constituído por um algoritmo básico (basic algorithm) o qual pode se especializar em duas modalidades: o primeiro método incremental ou o segundo método incremental. A seguir serão apresentadas as idéias gerais do algoritmo básico proposto por Narváez et al. [18]. 


\subsubsection{O algoritmo básico}

Considere um grafo $G=(V, E)$, onde $V$ é o conjunto de vértices e $E$ o conjunto de arcos de $G$, respectivamente. Suponha uma árvore $T$ de caminhos mínimos com raiz $r$, onde $r \in V$.

Suponha que o grafo $G$ teve o peso de um de seus arcos $e \in E$ atualizado por um valor real $\Delta$. Nessas condições o algoritmo básico pode ser chamado para atualizar a árvore $T$. O algoritmo básico é composto por 4 passos: inicialização, seleção de nós, atualização de distâncias e busca de nós.

A etapa de inicialização permite selecionar os nós que foram afetados pela mudança de peso do arco $e$. Todos os nós afetados são adicionados a uma fila $Q$. Pode-se afirmar que os algoritmos estáticos são um caso particular do algoritmo básico, pois o processamento de uma atualização em um algoritmo estático implica a adição de todos os nós do grafo $G$ a sua fila, ou seja, todos os nós do grafo são considerados afetados. Dependendo de como a fila $Q$ utilizada no algoritmo básico é implementada, o arcabouço pode se transformar em versões dinâmicas de algoritmos estáticos bem conhecidos, como o de Dijkstra.

A etapa de inicialização apresenta dois casos, dependendo se o arco $e$ teve o peso aumentado ou diminuído por $\Delta$. No caso do arco e ter seu peso incrementado por $\Delta$, é verificado se $e$ está em alguma árvore de caminhos mínimos $\mathrm{T}$, anteriormente calculada. Em caso afirmativo, seleciona-se o nó $E(e)$ e todos os seus descendentes que podem ser alcançados a partir de $E(e)$ na árvore $T$. Esses nós são inseridos no conjunto $N_{v}$. A intuição é que $N_{v}$ contém todos os nós afetados pela modificação do peso de $e$. Para cada nó final $n$ associado a um arco dentre os arcos entrando nos nós em $N_{v}$, é calculada a distância potencial newdist, adicionando-se a distância do nó pai de $n(P(n))$ e o peso do arco conectando $\mathrm{P}(\mathrm{n})$ e $\mathrm{n}$. Se newdist for menor do que a atual distância em $n, n$ é adicionado à fila $Q$.

Entretanto, se o arco $e$ teve seu peso decrementado por $\Delta$, gera-se o conjunto $N_{v}$ formado pelo nó $E(e)$ e todos os seus descendentes (os nós na árvore $T$ que podem ser alcançados a partir de $E(e))$. Assim, atualiza-se a distância dos nós em $N_{v}$, utilizando a diferença $\Delta$. Para cada arco $e$ saindo dos nós em $N_{v}$, calcula-se a distância potencial newdist de seu nó final $E(e)$, adicionando a distância do nó inicial $S(e)$ e o peso de $W(e)$. O nó $E(e)$ é adicionado à fila $Q$, se newdist é realmente menor do que a distância atual para $E(e)$.

Após a etapa de inicialização extrai-se da fila $Q$, no passo 2 , o elemento $(y)$ com a menor distância (o procedimento correto de extração é determinado pelo algoritmo específico sendo usado, por exemplo, em filas de prioridade são extraídos os elementos com menor distância). Este nó y selecionado é atualizado na árvore, caso a nova distância seja menor do que a antiga. Nesse caso, a estrutura da árvore $T$ é atualizada para refletir a nova relação pai-filho entre os nós. Também é calculado o conjunto de descendentes de $y$ em $T$, incluindo o próprio nó $y$, $B(y, T)$. Dependendo de como $B(y, T)$ é obtido, pode-se ter duas especializações do algoritmo básico: o primeiro método incremental ou o segundo método incremental. Simulações mostram que o segundo método incremental apresenta um melhor desempenho na média. Maiores detalhes sobre os dois métodos podem ser encontrados na referência [18]. Para o modelo aqui exposto, foi adotado como algoritmo dinâmico o primeiro método incremental usando filas de prioridades.

O passo 3 corrige as distâncias dos nós em $B(y, T)$ com a diferença $\Delta$. Finalmente, no passo 
4 considera-se cada nó $E(e)$ que está associado a um arco $e$ saindo dos nós em $B(y, T)$ : caso a distância potencial newdist de $E(e)$ seja menor do que a sua distância atual, então $E(e)$ é adicionado à fila $Q$, para ser selecionado posteriormente.

Os passos 2, 3 e 4 são executados ciclicamente até que a fila $Q$ fique vazia.

O algoritmo básico é mostrado a seguir:

\section{Passo 1: Inicialização - versão dinâmica}

Caso 1 - Arco e aumenta seu peso em um valor $\Delta$

$$
W(e) \leftarrow W(e)+\Delta
$$

if $e \in T$ then

$$
N_{V}=B_{\max }(E(e), T)
$$

for each $n \in N_{V}$ do

$$
D(n, T) \leftarrow D(n, T)+\Delta
$$

for each $e^{\prime} \in I\left(N_{V}\right)$ do

$$
\text { newdist } \leftarrow D\left(S\left(e^{\prime}\right), T\right)+W\left(e^{\prime}\right)
$$

if $D\left(E\left(e^{\prime}\right), T\right)>$ newdist then

Enqueue $\left(Q,\left\{E\left(e^{\prime}\right),\left(S\left(e^{\prime}\right)\right.\right.\right.$, newdist $\left.\left.)\right\}\right)$

Caso 2 - Arco e diminui seu peso em $\Delta$

$$
\begin{aligned}
& W(e) \leftarrow W(e)-\Delta \\
& \text { newdist } \leftarrow D(S(e), T)+W(e) \\
& \text { if } D(E(e), T)>n e w d i s t \text { then } \\
& \delta \leftarrow \text { newdist }-D(E(e), T) \\
& P(E(e), T) \leftarrow S(e) \\
& N_{V}=B_{\max }(E(e), T) \\
& \text { for each } n \in N_{V} \text { do } \\
& \quad D(n, T) \leftarrow D(n, T)+\delta \\
& \text { for each } e^{\prime} \in O\left(N_{V}\right) \text { do } \\
& \quad \text { newdist } \leftarrow D\left(S\left(e^{\prime}\right), T\right)+W\left(e^{\prime}\right) \\
& \quad \text { if } D\left(E\left(e^{\prime}\right), T\right)>n e w d i s t \text { then } \\
& \quad \text { Enqueue }\left(Q,\left\{E\left(e^{\prime}\right),\left(S\left(e^{\prime}\right), \text { newdist }\right)\right\}\right)
\end{aligned}
$$

Passo 2: Seleção de nós 
if $Q=\emptyset$ then End

else

$$
\begin{aligned}
& \{y,(x, d)\} \leftarrow \operatorname{Extract}(Q) \\
& \Delta \leftarrow d-D(y, T) \\
& \text { if } \Delta>0 \text { then Retornar ao passo } 2 \\
& P(y, T) \leftarrow x \\
& N_{V} \leftarrow B(y, T)
\end{aligned}
$$

Passo 3: Atualização de distâncias

for each $n \in N_{V}$ do

$$
D(n, T) \leftarrow D(n, T)+\Delta
$$

Passo 4: Busca de nós

$$
\begin{aligned}
& \text { for each } e \in O\left(N_{V}\right) \text { do } \\
& \quad \text { newdist } \leftarrow D(S(e), T)+W(e) \\
& \text { if } D(E(e), T)>\text { newdist then } \\
& \quad \text { Enqueue }(Q,\{E(e),(S(e), \text { newdist })\}) \\
& \text { Retornar para passo } 2 .
\end{aligned}
$$

\subsection{O primeiro e o segundo métodos incrementais}

De acordo com a forma como é calculado o conjunto $B(y, T)$ da fase 2 , podem-se usar duas modalidades de algoritmos descrita pelos autores: primeiro método incremental ou o segundo método incremental. A diferença entre os tipos de algoritmos está justamente no conjunto de descendentes do nó $y$ na etapa 2 do algoritmo básico.

No primeiro método incremental, $B(y, T)$ é dado pela expressão:

$$
B(y, T)=\{y\}, \forall y \in V
$$

Enquanto que no segundo método $B(y, T)$ é obtido pelo algoritmo mostrado a seguir:

$$
\begin{aligned}
& /{ }^{*} \text { a fila temporária começa com } y \text { */ } \\
& K \leftarrow\{y\}
\end{aligned}
$$


${ }^{*}$ o conjunto $N_{V}$ é inicialmente vazio */

$N_{V} \leftarrow \emptyset$

Passo 1:

${ }^{*}$ se a fila temporária é vazia */

if $K=\emptyset$ then

$/{ }^{*}$ o conjunto $N_{V}$ apresenta o conjunto desejado */

Stop

else

$/^{*}$ extrai qualquer elemento da fila */

$k \leftarrow \operatorname{Extract}(K)$

$/{ }^{*}$ adiciona $k$ ao conjunto de saída */

$N_{V} \leftarrow\left\{N_{V}, k\right\}$

\section{Passo 2:}

$I^{*}$ para todo filho imediato de $k^{*} /$

$\forall n \in B_{1}(k, T)$

${ }^{*}$ se o filho está na lista de candidatos $Q * /$

if $n \in Q$ then

${ }^{*}$ e se a nova distância disseminada é melhor */

if $D(n, T)+\Delta<=D(n, Q)$ then

${ }^{*}$ remove da fila de candidatos */

Dequeue $(Q, n)$

$I^{*}$ e adiciona $n$ à lista temporária */

$K \leftarrow\{K, k\}$

else

${ }^{*}$ e adiciona $n$ à lista temporária */

$K \leftarrow\{K, k\}$

Retornar ao passo 1 .

O segundo método incremental procura incluir o maior número possível de descendentes para o nó $y$, no passo 2 do algoritmo básico. Para efeitos de otimização somente os nós que não deveriam ser incluídos são aqueles que serão diretamente afetados por uma extração de nó da fila $Q$, ou seja, não seria útil atualizar um nó que será atualizado posteriormente por uma distância 
menor, extraida de $Q$.

O primeiro método incremental muda os atributos de somente um nó durante cada iteração. O segundo método é menos conservador, a cada iteração elementos de um conjunto inteiro de $T$ mudam seus atributos. Simulações mostram que o segundo método incremental apresenta um melhor desempenho [18]. Outra vantagem é que o segundo método incremental garante que o menor número de alterações na árvore $T$ será realizado, ou seja, um arco é removido da árvore somente se ele não pode fazer parte de nenhum caminho mínimo.

\subsection{Complexidade}

A seguir é dada uma visão geral sobre a complexidade do arcabouço proposto por Narváez et al. Para tanto, assuma $\sigma_{d}$ como o número mínimo de nós que precisam ter suas distâncias ou nós pais mudados, após a alteração de peso de um dado arco. $\mathrm{E}, \sigma_{p d}$ representa o número mínimo de nós que precisam ter suas distâncias e nós pais mudados, após uma alteração de arco. Considere que $D_{\max }$ representa o máximo grau dos nós do grafo e $\gamma$ denota um fator de redundância que indica o número médio de vezes que um nó é visitado pelo algoritmo. Neste caso, a complexidade no pior caso do primeiro método incremental implementando uma versão do algoritmo de Dijkstra que utiliza heaps é dado por $O\left(D_{\max } . \sigma_{d} \cdot \log \sigma_{d}\right)$. Para o segundo método incremental, implementando também uma versão do algoritmo de Dijkstra que utiliza heaps, a complexidade no pior caso é dada por: $O\left(\gamma \cdot D_{m a x} \cdot \sigma_{d} \cdot \log \sigma_{d}\right)$. A complexidade no pior caso para o segundo método incremental é superior à complexidade do primeiro método, uma vez que $\gamma$ é um número entre 1 e $\sigma_{p d}$, entretanto, conforme explicado no artigo [18], o segundo método incremental apresenta um desempenho melhor no caso médio.

Maiores detalhes podem ser encontrados na referência [18].

\subsection{Múltiplas atualizações}

Quando há várias mudanças de peso de arcos ocorrendo simultaneamente, é sempre possível executar o algoritmo seqüencialmente, para cada peso modificado. Entretanto, uma otimização pode ser alcançada, realizando a atualização da árvore considerando-se um conjunto maior de pesos de arcos alterados. Apesar de uma etapa de inicialização específica para cada conjunto considerado ser necessária, o corpo principal do algoritmo precisa ser executado apenas duas vezes. A seguir será descrito como tal otimização pode ser feita.

Primeiramente, serão considerados todos os arcos que tiveram pesos incrementados. Para cada arco cujo peso foi aumentado, as primeiras cinco linhas de código para o Caso 1 são executadas. Isto assegura que todos os nós afetados atualizarão suas distâncias na árvore. Assim, são executadas as próximas quatro linhas de código para um conjunto $N$, que inclui todos os nós previamente atualizados. Dessa forma, segundo os autores, garante-se que todos os nós necessários serão adicionados à fila $Q$. O restante do algoritmo (passos 2 a 4) é executado normalmente.

Após a árvore de caminhos ter sido atualizada com todos os arcos incrementados, a mesma 
será atualizada com todos os arcos que tiveram os pesos decrementados. Como anteriormente, as primeiras oito linhas de código da etapa de inicialização no Caso 2 são executadas para cada arco que teve o peso diminuído. As quatro últimas linhas de código são executadas com um conjunto $N$, o qual inclui todos nós previamente atualizados. Após a inicialização, o algoritmo (passos 2 a 4) é executado da maneira convencional.

$\mathrm{Na}$ implementação descrita no Capítulo 5 do arcabouço proposto por Narváez et al. para realizar a atualização de árvores de caminhos usadas no modelo proposto neste trabalho, é utilizado o recurso de múltiplas atualizações.

\subsection{Considerações gerais}

Este Capítulo apresentou o arcabouço dinâmico proposto por Narváez, Siu e Tzeng [18]. Conforme foi visto, o arcabouço permite transformar versões estáticas de conhecidos algoritmos de busca nas suas versões estáticas. Em geral, o arcabouço apresenta um algoritmo básico que pode se especializar tornando-se o primeiro método incremental ou o segundo método incremental. $\mathrm{O}$ primeiro método é mais conservador do que o segundo método, logo o resultado por ele obtido é melhor, embora o segundo método incremental apresente um desempenho médio superior. 


\section{Capítulo 4}

\section{Uma arquitetura distribuída}

A partir deste momento, serão apresentadas as idéias da arquitetura proposta neste trabalho. A arquitetura permite o cálculo de estimativas de caminhos entre dois pontos quaisquer de um grafo, possivelmente particionado em um conjunto finito de servidores. A denominação aqui utilizada para a arquitetura é "Roteamento adaptativo através de árvores dinâmicas", justamente pelo fato de que as principais ações envolvidas na arquitetura utilizam árvores de caminhos mínimos calculadas a partir de grafos dinâmicos, conforme será visto a seguir. Entretanto, inicialmente são mostradas algumas considerações, as quais serão úteis para a compreensão do sistema.

\subsection{Considerações iniciais}

Assuma inicialmente um domínio qualquer de aplicação que possa ser modelado na estrutura de um grafo $G$. Um exemplo de domínio de aplicação desse tipo pode ser o encontrado no cenário de aplicação descrito no Capítulo 1 . Considera-se que o grafo $G$ representando o domínio da aplicação está particionado em $N$ subgrafos $G_{i}=\left(V_{i}, A_{i}\right)$, onde $1 \leq i \leq N$.

Cada subgrafo $G_{i}$ está armazenado na memória de um servidor chamado de estação-base $\left(E B_{i}\right)$. As estações-base se comunicam através de uma rede de interconexão fixa. Todas as atualizações de pesos dos arcos contidos no subgrafo $G_{i}$ devem ser encaminhadas à estação $E B_{i}$. As estações-base também são responsáveis por receber requisições de clientes e fornecer rotas entre dois pontos de $G$.

A região de fronteira da área de cobertura de $E B_{i}$ é representada por um conjunto de vértices especiais, os quais formam a borda $\left(B\left(G_{i}\right)\right)$ de $G_{i}$. As bordas são nós de junção inter-estações, ou seja, o grafo $G$, representante do domínio completo, é formado pelo conjunto dos subgrafos $G_{i}$ colapsados pelas bordas $B\left(G_{i}\right)$. Considera-se também que a intersecção $G_{i} \cap G_{j}=B\left(G_{i}\right) \cap B\left(G_{j}\right)$, ou seja, a interseç̧ão dos vértices entre estações é dada pela intersecção dos conjuntos de nós das respectivas bordas, sem a existência de nós internos. Na figura 4.1, duas estações $E_{A}$ e $E_{B}$ são responsáveis pela cobertura de todo um domínio de aplicação $(G)$. Nesse caso: 


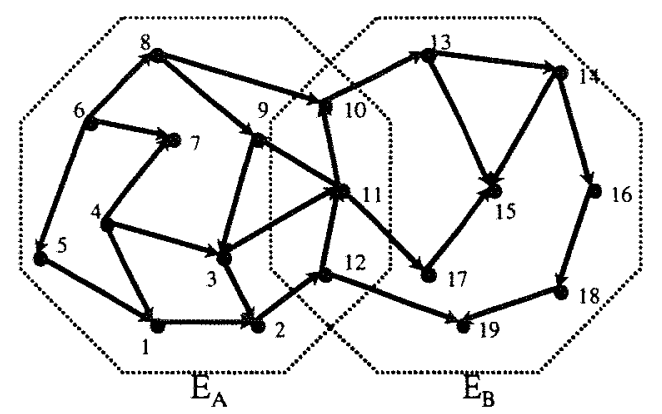

Figura 4.1: Topologia de um domínio de aplicação sob a cobertura de duas EBs adjacentes.

$$
\begin{aligned}
& B\left(G_{A}\right)=\{1,2,5,6,8,10,11,12\} \\
& B\left(G_{B}\right)=\{10,11,12,13,14,16,18,19\} \\
& B\left(G_{A}\right) \cap B\left(G_{B}\right)=\{10,11,12\}
\end{aligned}
$$

Uma estação-base somente conhece o estado do subgrafo que está contido em seu interior. Dessa forma, para calcular um caminho entre dois pontos quaisquer do domínio de aplicação, as estações se comunicam com um conjunto especial de servidores que possuem informações do estado global do sistema. Esses servidores são denominados de servidores de busca $(S B)$. Uma estação-base pode ser um servidor de busca. Assume-se que a rede interligando servidores de busca e estações-base é confiável e que as mensagens chegam aos seus destinos na ordem em que foram enviadas.

Seja o Conjunto Raizes de um grafo $G_{i}$, ou Raizes $\left(G_{i}\right)$, como um subconjunto qualquer de $B\left(G_{i}\right)$. Ou seja, Raizes $\left(G_{i}\right) \subseteq B\left(G_{i}\right)$. Nesse caso, define-se a Tabela Custos de Caminhos entre Raizes de um grafo $G_{i}$, ou TabCustRaizes $\left(G_{i}\right)$, como sendo o conjunto dos custos dos melhores caminhos conhecidos ligando todas as combinações possíveis de trajetos entre nós presentes no conjunto Raizes $\left(G_{i}\right)$.

A figura 4.2 apresenta um grafo $G_{i}$ com 4 nós em Raizes $\left(G_{i}\right)=\left\{B_{1}, B_{2}, B_{3}, B_{4}\right\}$ e um nó interno $I_{1}$. O conjunto TabCustRaizes $\left(G_{i}\right)$ é mostrado na tabela da figura 4.2 , contendo os melhores caminhos entre os pontos no Conjunto Raízes, por exemplo, de $B_{1}$ a $B_{4}$, o caminho mínimo tem custo 3 .

\section{2 Árvore pórtico}

Considere a árvore de caminhos mínimos $(T)$ com raiz $r$ calculada a partir de algum algoritmo de busca de caminhos, como o de Dijkstra [2].

Seja $r \in \operatorname{Raizes}\left(G_{i}\right)$, definimos a árvore pórtico (ou apenas pórtico) de raiz $r, \mathrm{PT}(\mathrm{r})$, como a árvore de caminhos mínimos com raiz em $r$ que contém todos os pontos de $G_{i}$ alcançáveis a partir de $r$. A figura 3 apresenta uma árvore pórtico com raiz em $R_{2}, \operatorname{PT}\left(R_{2}\right)$. 


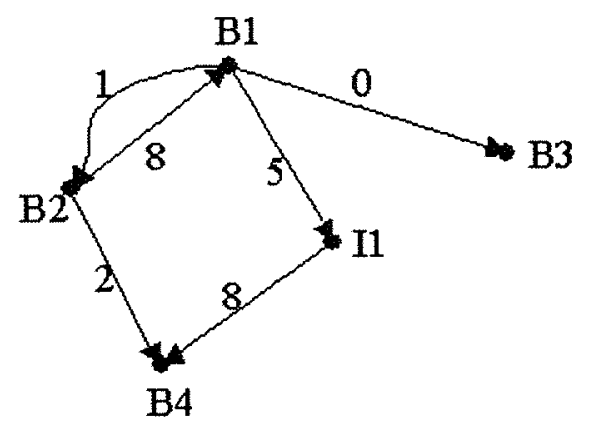

TabCustRaizes(Gi):

\begin{tabular}{|c|c|c|}
\hline Pares & $\mathrm{X}>\mathrm{Y}$ & $\mathrm{Y}>>\mathrm{X}$ \\
\hline $\mathrm{B} 1-\mathrm{B} 2$ & 1 & 8 \\
\hline B1-B3 & 0 & - \\
\hline B1-B4 & 3 & - \\
\hline B2-B4 & 2 & - \\
\hline
\end{tabular}

$E B_{i}$

Figura 4.2: Conjunto raízes e tabela custos de caminhos entre raízes de $G_{i}$
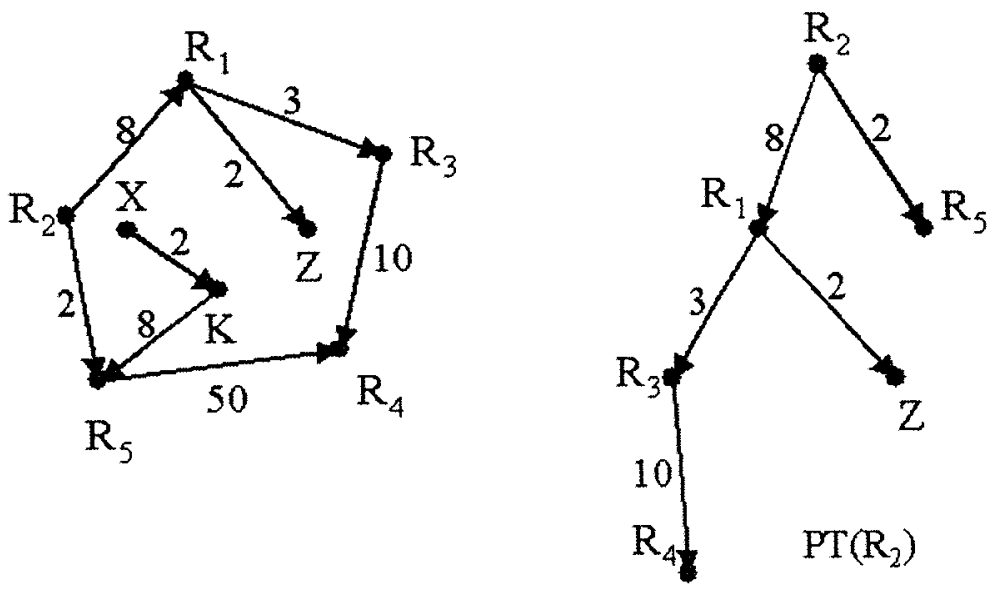

Figura 4.3: Árvore pórtico com raiz $R_{2}$ 


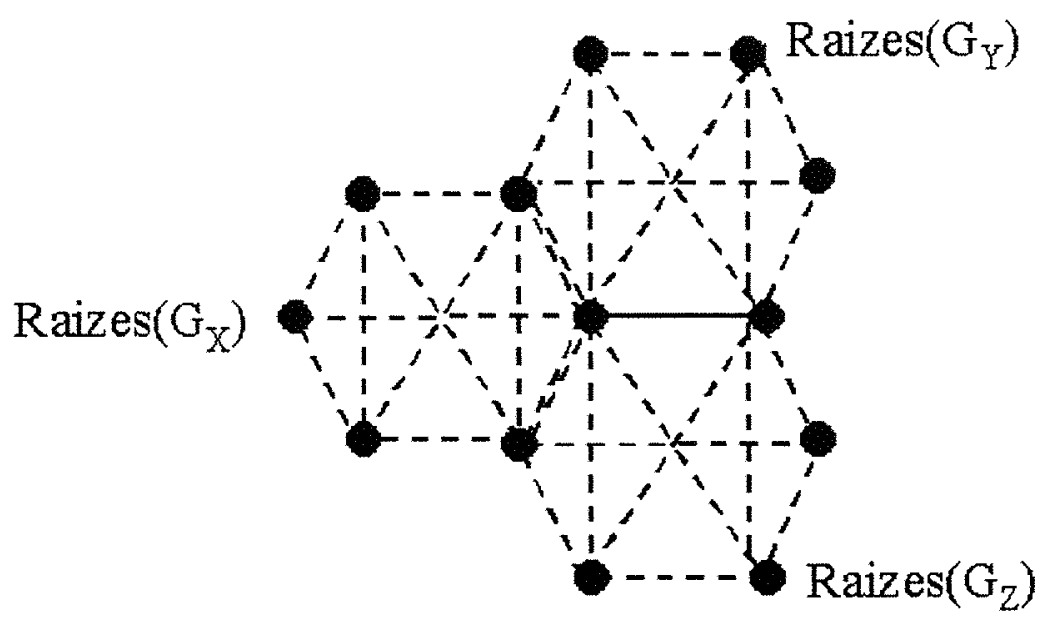

Figura 4.4: Exemplo de grafo SG.

\subsection{Grafo SG}

Os servidores de busca armazenam um grafo especial chamado $S G$ o qual permite que seja armazenada a informação contida nos conjuntos TabCustRaizes enviados pelas estações-base para um dado estado $k^{1}$.

Dessa maneira, considere um servidor de busca $S B_{j}$ e um domínio de aplicação particionado em $N$ estações-base $E B_{i}$, com $1 \leq i \leq N$. Nessa situação, $S B_{j}$ mantém um grafo $S G_{j}$ com os nós presentes em Raizes $\left(G_{i}\right)$ das estações $E B_{i}$. Os nós $u$ e $v$ em $S G_{j}$ (representando nós em Raizes $\left(G_{i}\right)$ ) tem um arco (e) de $u$ a $v$ se existe um caminho de $u$ a $v$ no grafo armazenado em $E B_{i}$. O peso de $e$, para um dado estado $k$, é dado pela informação enviada pelo conjunto TabCustRaizes $\left(G_{i}\right)^{k}$.

A figura 4.4 apresenta um exemplo de grafo SG para um domínio de aplicação particionado em 3 estações-base: X, Y e Z. As linhas pontilhadas representam arcos bidirecionais.

\subsection{Os nós Origem e Sorvedouro}

Para cada conjunto de nós em Raizes $\left(G_{i}\right)$ são criados vértices especiais $\operatorname{Origem}\left(G_{i}\right)$ e Sorvedouro $\left(G_{i}\right)$. São adicionados arcos especiais partindo de $\operatorname{Origem}\left(G_{i}\right)$ e chegando em $P$ tal que $P \in \operatorname{Raizes}\left(G_{i}\right)$. Analogamente, são inseridos $\operatorname{arcos}$ especiais de $Q$ a $\operatorname{Sorvedouro}\left(G_{i}\right)$ tal que $Q \in \operatorname{Raizes}\left(G_{i}\right)$.

O gráfico 4.5 apresenta a ilustração de um grafo $S G$ contendo vértices de 3 Conjuntos Raízes (X, Y, Z), bem como os arcos representando as ligações entre os nós dos Conjuntos Raízes. Também são apresentados os nós Origem $\left(G_{X}\right)\left(O\left(G_{X}\right)\right)$ ligando Origem $\left(G_{X}\right)$ aos nós do Conjunto Raizes $\left(G_{X}\right)$ e Sorvedouro $\left(G_{Y}\right)\left(S\left(G_{Y}\right)\right)$ ligando os nós do conjunto Raizes $\left(G_{Y}\right)$ ao

\footnotetext{
${ }^{1}$ Maiores detalhes de como os estados são obtidos estão na seção 4.9 .
} 


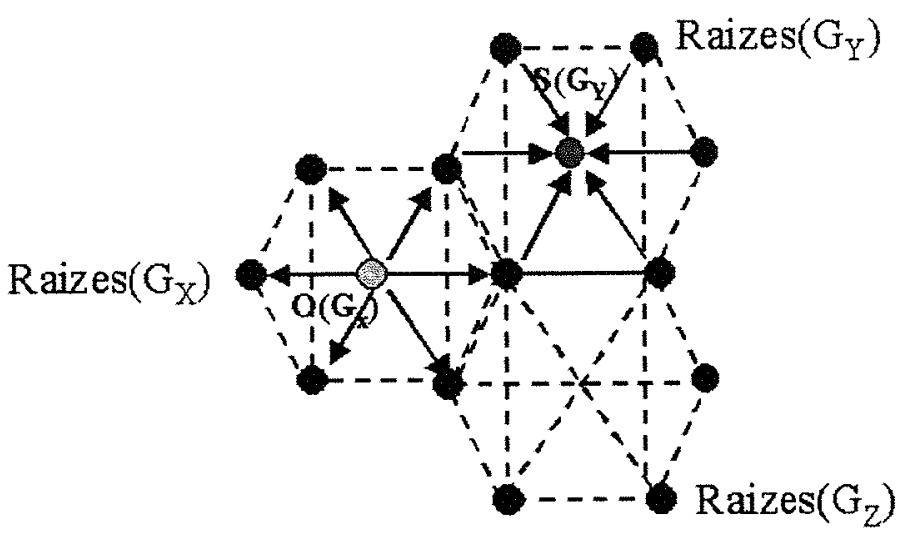

Figura 4.5: Vértices especiais origem e sorvedouro.

Sorvedouro $\left(G_{Y}\right)$. Os nós Origem $\left(G_{Y}\right)$, Origem $\left(G_{Z}\right)$, Sorvedouro $\left(G_{X}\right)$ e Sorvedouro $\left(G_{Z}\right)$ bem como os pesos dos arcos foram omitidos para não prejudicar a visualização da figura.

Os nós e arcos especiais são adicionados no momento da inicialização do grafo em $S B_{j}$. O peso atribuído aos arcos especiais é zero. Conforme será visto no Capítulo 5 , os arcos especiais permitem que vários valores de pesos sejam a eles associados, desde que apresentem um conjunto de identificadores único. Isso permite que vários processos clientes que estão realizando cálculos de caminhos possam modificar os pesos dos arcos especiais de acordo com suas necessidades.

\section{5 Árvore-modelo}

Para otimizar o tempo de cálculo de caminhos, os servidores de busca utilizam estruturas pré-calculadas, denominadas de árvores-modelo. As árvores-modelo são árvores de caminhos mantidas pelos servidores de busca com os dados de um determinado estado $k$.

Basicamente, uma árvore modelo $M T_{i}$ é a árvore de caminhos com raiz em $\operatorname{Origem}\left(G_{i}\right) \in$ $S G$. Cada servidor de busca $S B_{j}$ mantém uma árvore modelo para cada conjunto Raizes $\left(G_{i}\right)$, representando informações de $E B_{i}$. Conforme será apresentado na próxima seção, em intervalos regulares, há um processo coordenador que solicita a atualização do estado global do sistema para um dado estado $k$. Assim, considere $M T_{i}^{k}$ a árvore modelo com raiz em $\operatorname{Origem}\left(G_{i}\right)$, calculada com os dados do estado $k$.

Assim que uma solicitação de cálculo de caminhos de $X$ a $Y$ no estado $k$ chega em $S B_{j}$, onde $X \in \operatorname{Raizes}\left(G_{i}\right)$ e $Y \in \operatorname{Raizes}\left(G_{j}\right), S B_{j}$ pode utilizar a árvore $M T_{i}^{k}$ previamente calculada para acelerar procedimento de cálculo. Para isso, $S B_{j}$ necessita receber informações atualizadas dos valores dos pesos dos arcos de $\operatorname{Origem}\left(G_{i}\right)$ a $R$ tal que $R \in \operatorname{Raizes}\left(G_{i}\right)$ e de $R$ a Sorvedouro $\left(G_{j}\right)$ tal que $R \in \operatorname{Raizes}\left(G_{j}\right)$ e, com esses valores, executa o algoritmo descrito no Capítulo 3 sobre uma cópia temporária da árvore $M T_{i}^{k}$. Maiores detalhes sobre a implementação serão dados no Capítulo 5. 


\subsection{Roteamento adaptativo através de árvores dinâmicas}

Nesta seção é apresentada a arquitetura proposta neste trabalho propriamente dita. Dessa forma, podem ser definidas duas funcionalidades a serem cumpridas pelo sistema: busca de caminhos e atualização de estados. Por busca de caminhos entenda-se a capacidade de prover estimativas de rotas a clientes da aplicação. Além disso, dadas as características dinâmicas da aplicação, é necessário também proporcionar mecanismos de atualização periódica da base de informação.

O sistema apresenta, conforme descrito anteriormente, dois conjuntos de servidores: estaçõesbase e servidores de busca. De acordo com o tipo de funcionalidade a qual o servidor se destina, ele terá um conjunto definido de ações pertinentes, a serem desempenhadas. A próxima seção apresenta as idéias gerais da arquitetura, sem muita ênfase em detalhes de implementação, os quais serão tratados no Capítulo 5 .

Assuma o parâmetro k como sendo o identificador único de um dado estado global do sistema. Para os pseudo-códigos mostrados a seguir, assuma que a função RPC (server, procedure) realiza uma chamada remota do procedimento procedure no servidor server;

\subsection{Processamento}

O processamento dos servidores depende do papel que eles desempenham no sistema.

\subsubsection{Processamento em $E B_{i}$}

Cada estação-base $E B_{i}$ realiza os seguintes passos:

1. $E B_{i}$ mantém o subgrafo $G_{i}$ em memória;

2. Em intervalos regulares, $E B_{i}$ obtém/atualiza as árvores pórtico $P T(r), r \in$ Raizes $\left(G_{i}\right)$. O procedimento de atualização do estado global $(\mathrm{k})$ do sistema será discutido em maiores detalhes na seção 4.9;

3. Com os dados de $P T(r)$ para o estado k, EB $B_{i}$ gera $T a b C u s t R a i z e s\left(G_{i}\right)^{k}$ e envia para o conjunto de servidores de busca $(S B)$.

Deve-se ressaltar que na etapa 2, a atualização de $P T(r)$ é realizada com um algoritmo de busca em grafos dinâmicos [18].

O sistema permite processamento concorrente no grafo $G_{i}$ durante a execução de algoritmos para construção/atualização de árvores de caminhos mínimos, conforme será descrito no Capítulo de implementação 5 . 


\subsubsection{Processamento em $S B_{j}$}

Cada servidor de busca $S B_{j}$ recebe das estações-base o conjunto TabCust Raizes descrevendo os custos dos melhores caminhos ligando todas as combinações possíveis de pontos presentes nos respectivos conjuntos Raizes para um dado estado $\mathbf{k}$.

Assim que todos conjuntos TabCustRaizes $\left(G_{i}\right)^{k}, 1 \leq i \leq N$ são recebidos $S B_{j}$ obtém/atualiza as árvores $M T_{r}^{k}$. O procedimento de atualização do estado global (k) do sistema será discutido em maiores detalhes na seção 4.9. Após as árvores $M T_{r}^{k}$ terem sido geradas/atualizadas, para cada conjunto TabCustRaizes $\left(G_{i}\right)^{k}$ recebido, $S B_{j}$ envia uma mensagem para $E B_{i}$ indicando que o conjunto TabCustRaizes $\left(G_{i}\right)^{k}$ foi recebido com êxito.

\subsection{Busca de caminhos}

Seja uma requisição de caminho de $X$ a $Y$ enviada à estação-base $E B_{X}$. O processamento da busca de caminhos é feito em dois níveis:

Intra-estação: busca no interior de $E B_{X}$ e/ou,

Inter-estação: nesse caso $E B_{X}$ consulta algum servidor de busca $S B_{i}$ para incluir no cálculo a informação do estado global do sistema.

Os clientes podem solicitar dois tipos de requisições de busca:

Global: um caminho completo de $X$ a $Y$. Neste caso, deseja-se encontrar todos os arcos que compõe o caminho.

Local: um subcaminho de $X$ a $Y$. Esse subcaminho é um caminho de $\mathrm{X}$ a $R$ tal que $R$ está em Raizes $\left(G_{X}\right)$. Nesse tipo de requisição o sistema escolhe, com base no estado global do sistema, o caminho de menor custo de $X$ a $Y$, mas retorna ao cliente apenas o subcaminho de $X$ a $R$.

As requisições locais podem ser particularmente interessantes para dispositivos móveis, uma vez que a unidade móvel poderia solicitar trechos de caminho antes de cada handoff [16] efetuado entre estações, mantendo informações mais atualizadas. Além disso, a resposta também poderia ser usada em algoritmos que fornecem suporte para agendamento de handoffs futuros.

A busca de um caminho de $X$ a $Y$ é realizada por 4 procedimentos principais:

- BuscaEB: executado em $E B_{X}$;

- BuscaInterEB: executado em $E B_{X}$; 
- ConsultaPorticEB: executado em $E B_{Y}$;

- BuscaSB: executado em $S B_{j}$.

Uma requisição (req) de caminho de um ponto $X$ a um destino $Y$ é enviada à estação-base $E B_{X}$, a qual executa o método BuscaEB. Este método calcula a árvore de caminhos com raiz $X$ $(T(X))$, como as informações de um dado estado, $(\mathrm{k})$, em geral, o estado mais recente. Caso o ponto $Y$ não esteja em $T(X)$ ou o caminho encontrado em $T(X)$ não seja satisfatório, o método BuscaInterEB é executado.

O procedimento BuscaInter $E B$ escolhe um servidor de busca $S B_{j}$ para solicitar que seja calculado um caminho entre os pontos $X$ e $Y$. Dessa forma, a partir de $T(X)$, esse procedimento constrói um conjunto (Custos $X_{-}$ate_Raizes) a ser enviado para $S B_{j}$, contendo os pesos dos melhores caminhos de $X$ até Raizes $\left(G_{X}\right)$.

$S B_{j}$ recebe como parâmetros o conjunto Custos $X_{-}$ate_Raizes, $X, Y$, a requisição req e o estado $k$ passado por $E B_{X}$ e executa o procedimento BuscaSB, que calcula um caminho de $X$ a $Y$, se existir. Para tanto, $S B_{j}$ pode invocar remotamente na estação-base $E B_{Y}$ o método ConsultaPorticEB para obter informações sobre os pesos dos melhores caminhos de Raizes $\left(G_{Y}\right)$ a $Y$, para o estado $k$.

Os procedimentos são descritos em maiores detalhes nas seções a seguir.

\subsubsection{Busca de caminhos em $E B_{i}$}

Conforme foi explicado anteriormente, toda requisição de caminho de um ponto $X$ a um destino $Y$ é enviada à estação-base $E B_{X}$, a qual executa os métodos BuscaEB e BuscaInterEB apresentados a seguir:

\section{Procedimentos BuscaEB e BuscaInterEB}

O procedimento de busca pode ser descrito pela função a seguir. $E B_{X}$ recebe uma requisição (req) para um caminho de $X$ a $Y$. Onde, req pode ser do tipo local ou global. Considere $k$ como sendo o identificador do estado mais recente calculado por $E B_{X}$.

\section{Procedure BuscaEB(X, Y, req)}

$E B_{X}$ calcula a árvore de caminhos mínimos $T^{k}(X)$ com informações do estado $\mathrm{k}$ (estado mais recente).

if $Y \in E B_{X}$ then

${ }^{*}$ Se há um caminho $P_{X Y}$ com custo inferior a constante $\delta$, retorna $P_{X Y} *$ / 
if $\exists$ um caminho $P_{X Y} \subseteq T^{k}(X) \mid \operatorname{Peso}\left(P_{X Y}\right) \leq \delta$ then return $P_{X Y}$

else

Seja $P_{\text {intra }}:=\left\{P_{X Y} \mid\right.$ Peso $\left(P_{X Y}\right)$ é mínimo $\}$

$P_{\text {inter }}:=\mathrm{BuscaInterEB}\left(\mathrm{X}, \mathrm{Y}\right.$, req, $\left.T^{k}(X), \mathrm{k}\right)$

Seja $P_{\text {min }}$ o caminho de peso mínimo entre $P_{\text {inter }}$ e $P_{\text {intra }}$

return $P_{\min }$.

else

return BuscaInterEB(X, Y, req, $\left.T^{k}(X), \mathrm{k}\right)$.

\section{End Procedure}

Quando $Y \in T^{k}(X)$, e existe um caminho $P_{X Y}$ de $X$ a $Y$ tal que $P e s o\left(P_{X Y}\right) \leq \delta, P_{X Y}$ é retornado ao cliente, independentemente da existência de um outro caminho ligando $X$ a $Y$ com custo menor passando por nós de outras estações-base. $\delta$ é definido de maneira arbitrária. Um exemplo de como $\delta$ pode ser definido, é sendo uma função da distância de $X$ a $Y$ ou baseado no histórico de cálculos de caminhos anteriores.

Procedure BuscaInterEB(X, Y, req, T, k)

CustosX_ate_Raizes $:=\emptyset$

${ }^{*}$ encontra os caminhos para as raizes */

for each $r \in$ Raizes $\left(G_{X}\right)^{k}$ do

if $r \in T^{k}(X)$ then

${ }^{*}$ guarda em CustosX_ate_Raizes o custo do caminho

de $X$ a r presente em $T^{k}(X)$, se existir*/

CustosX_ate_Raizes $:=$ CustosX_ate_Raizes $\cup\{r, \operatorname{Peso}(X, r)\}$

else

CustosX_ate_Raizes $:=$ Custos $X \_a t e \_R a i z e s \cup\{r, \infty\}$

Resp := RPC $\left(S B_{i}, \operatorname{BuscaSB}(\mathrm{X}, \mathrm{Y}\right.$, req, CustosX_ate_Raizes, k))

if req $=$ Global then

${ }^{*}$ Resp é um caminho: $R_{t} \rightarrow \mathrm{N1}->\ldots \rightarrow Y^{*} /$

Seja $R_{t}$ o nó inicial do caminho Resp. $R_{t} \in \operatorname{Raizes}\left(G_{X}\right)$

Seja $P_{t}^{\prime}$ o caminho de X a $R_{t}$, em $T^{k}(X)$. 
$I^{*}$ Retira-se o nó $R_{t}$ do conjunto */

Seja o conjunto $P_{t}=P_{t}^{\prime}-R_{t}$.

${ }^{*}$ Retorna o caminho $P_{t} \cup$ Resp */

return $P_{t} \cup$ Resp.

else

${ }^{*} \operatorname{Resp}=\left(R_{t}, C\right)$ retorna o nó $R_{t}$ em Raizes $\left(G_{X}\right)$

que gera o caminho de $X$ a $Y$ com custo mínimo $C$ */

Seja $C$ o peso mínimo calculado por $S B_{i}$ para chegar em Y. E, $R_{t} \in \operatorname{Raizes}\left(G_{X}\right)$

o nó que origina tal caminho. Seja $P_{t}$ o caminho de $\mathrm{X}$ a $R_{t}$, em $T^{k}(X)$.

$/^{*}$ Retorna o caminho $P_{t}$, com peso $C * /$

return $P_{t}$

\section{End Procedure}

\section{Procedimento ConsultaPorticEB}

Uma estação-base $E B_{Y}$ também pode executar o procedimento ConsultaPorticEB, invocado remotamente por algum servidor de busca do sistema. Esse procedimento devolve os custos dos melhores caminhos dos pontos $r \in \operatorname{Raizes}\left(G_{Y}\right)^{k}$ a $Y$ para o estado k. Maiores detalhes sobre onde este procedimento é chamado podem ser encontrados em 4.8.2.

Procedure ConsultaPorticEB $(\mathrm{Y}, \mathrm{k})$

CustosRaizes_ate_Y $:=\emptyset$

for each árvore $P T^{k}\left(R_{i}\right)$ do

if $Y \in P T^{k}\left(R_{i}\right)$ then

$I^{*}$ guarda em CustosRaizes_ate_Y o custo do melhor caminho $R_{i}$ a $Y$, presente em $P T^{k}\left(R_{i}\right) * /$

CustosRaizes_ate_Y $:=$ CustosRaizes_ate_Y $\cup\left\{R_{i}, \operatorname{Peso}\left(R_{i}, Y\right)\right\}$

else

CustosRaizes_ate_Y $:=$ CustosRaizes_ate_ $Y \cup\left\{R_{i}, \infty\right\}$

return $C$ ustosRaizes_ate_Y

\section{End Procedure}




\subsubsection{Busca de caminhos em $S B_{j}$}

Os servidores de busca $S B_{j}$ executam o procedimento $B u s c a S B(X, Y$, req, CustosX_ate_Raizes, $k$ ) que recebe os pontos $\mathrm{X}$ e $\mathrm{Y}$, o tipo de requisição, o conjunto CustosX_ate_Raizes e o estado (k), enviados pela estação $E B_{X}$.

Essa função obtém um caminho (se houver) com raiz em X e destino Y. Para tanto, $S B_{j}$ utiliza uma das árvores-modelo. Os detalhes de implementação de como as árvores-modelo são usadas num ambiente com acesso concorrente são discutidos no Capítulo 5.

O resultado retornado pela função $B u s c a S B$ depende do tipo de requisição: se a requisição for local, é retornado o nó $R_{t}$ em Raizes $\left(G_{X}\right)$ que origina o melhor caminho conhecido para chegar em $\mathrm{Y}$, bem como o custo $C$ calculado para o caminho de $\mathrm{X}$ a $\mathrm{Y}$.

No caso de uma requisição do tipo Global, é retornado o caminho completo $\mathrm{P}$ calculado de $\mathrm{X}$ até $\mathrm{Y}$. Nesse caso, após o servidor de busca obter a rota de X a Y, presente na árvore SPT, obtida com os dados de SG, o servidor de busca $S B_{j}$ necessita contactar cada uma das estações $E B_{i}$ que possuem um subcaminho $P_{i}$ de $\mathrm{P}$, visando obter a descrição completa dos nós que compõe $P_{i}$.

O procedimento BuscaSB está apresentado a seguir. Considere que a função DinamSPT obtém um caminho P' entre X e Y, recebendo-se os conjuntos CustosX_ate_Raizes, CustosRaizes_ate $Y$ e o estado k. Para tanto, DinamSPT utiliza a árvore-modelo $M T_{X}^{k}$, os conjuntos CustosX_ate_Raizes e CustosRaizes_ate_Y $Y$ e o algoritmo proposto por [18], conforme descrito na seção 4.5 .

Os detalhes de como o caminho é calculado, utilizando a estrutura de árvores modelo (apresentadas na seção 4.5) será descrito no Capítulo 5.

\section{Procedimento BuscaSB}

Procedure BuscaSB(X, Y, req, CustosX_ate_Raizes, k)

CustosRaizes_ate $Y:=\operatorname{RPC}\left(E B_{Y}, \operatorname{ConsultaPorticEB}(\mathrm{Y}, \mathrm{k})\right)$

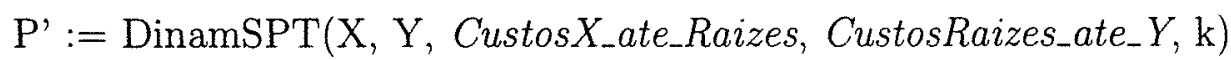

if req $=$ Local then

Seja $R_{t}$ o nó em Raizes $\left(G_{X}\right)$ de $E B_{X}$ que está no caminho P'

de $X$ até $Y$ e $C$ o custo associado.

return $\left\{R_{t}, C\right\}$

else

Seja $\mathrm{P}=\mathrm{P} 1->\mathrm{P} 2->\ldots .>\mathrm{Pn} \rightarrow \mathrm{Py}$ o caminho global, montado buscando-se 
os caminhos intermediários $\left(P_{i}\right)$ nas respectivas EBs envolvidas com o caminho $\mathrm{P}^{\prime}$. return $P$

\section{End Procedure}

\subsection{Atualização do sistema}

O processo de atualização do sistema segue um modelo parecido com a técnica de barreiras de sincronização [14], utilizada em sistemas paralelos e distribuídos. Para tanto, é escolhido um coordenador dentre as estações-base do sistema $\left(E B_{C}\right)$, o qual será o responsável por iniciar o processo de atualização global. O coordenador envia uma mensagem Update_Rset $(k+1)$ (supondo-se que o estado atual é $k, k+1$ identifica o novo estado) para cada uma das estações-base. Uma mensagem com a ação Update_Rwset $(k+1)$ e contendo o novo conjunto TabCustRaizes ${ }^{k+1}$ é enviada para os servidores de busca do sistema.

Assim que um servidor de busca $S B_{j}$ recebe a mensagem Update $R w s e t(k+1)$ com o novo estado TabCustRaizes $\left(G_{i}\right)^{k+1}$ de $E B_{i}$, com $1 \leq i \leq N$, é iniciado o procedimento para iniciar a atualização do seu grafo interno $S G j$, com os dados de TabCustRaizes $\left(G_{i}\right)^{k+1}$. Assim que todos os conjuntos TabCustRaizes $\left(G_{i}\right)^{k+1}$ para o estado $k+1$ são recebidos por $S B_{j}$, é realizada a atualização do conjunto de árvores-modelo de $S B(j)$ (apresentadas na seção 4.5). Esta etapa consiste em executar o algoritmo dinâmico ou o estático (caso o primeiro estado esteja sendo gerado), para que cada uma das árvores-modelo seja atualizada com os novos valores (estado $k+1$ ) recebidos das estações $E B_{i}$. Assim que as árvores tenham sido atualizadas, é enviada uma mensagem Received_Rwset $(k+1)$ para cada estação $E B_{i}$, confirmando o recebimento dos conjuntos TabCustRaizes $\left(G_{i}\right)^{k+1}$, do estado $k+1$.

Após todos os servidores de busca terem enviado a mensagem Received_Rwset $(k+1)$, para a estação $E B_{i}$, é enviada uma mensagem Received_Rset $(k+1)$ para o coordenador, $E B_{C}$ Depois que cada estação $E B_{i}$, com $1 \leq i \leq N$ tenha enviado a mensagem Received_Rset $(k+1)$ para $E B_{C}$, $E B_{C}$ envia uma mensagem (Commit_RSet $(k+1)$ ) para que cada estação $E B_{i}$ passe a utilizar efetivamente o seu novo estado. A mensagem Commit_RSet $(k+1)$ também é enviada para os servidores de busca, para que os mesmos utilizem os dados do novo estado nas próximas buscas.

A figura 4.6 apresenta o procedimento de atualização de 3 estações. $E B_{1}$ foi escolhida para ser a estação coordenadora $E B_{C}$. Supõe-se que o estado global do sistema é $k$ e $E B_{C}$ inicia a transação para atualizar o sistema para o estado $k+1$. Para isso, inicialmente $E B_{C}$ envia uma mensagem Update_RSet $(k+1)$ para $E B_{1}$ e $E B_{2}$. Após as duas estações receberem a mensagem de atualização, $E B_{1}, E B_{2}$ e $E B_{C}$ executam a etapa (I), a qual consiste em atualizar as suas árvores pórticos e enviar os novos conjuntos TabCustRaizes $\left(G_{i}\right)^{k+1}$ para os servidores de busca. Esta etapa não foi representada para não sobrecarregar a figura. Assim que todos os servidores de busca responderem que receberam os novos conjuntos TabCustRaizes ${ }_{i}^{k+1}$ para a estação $E B_{i}, E B_{i}$ envia a mensagem Received_RSet $(k+1)$ para $E B_{C}{ }^{2}$. Quando todas estações enviarem

\footnotetext{
${ }^{2}$ Deve-se ressaltar que os servidores de busca somente enviam as mensagens de recebimento dos conjuntos TabCustRaizes $\left(G_{i}\right)^{k+1}$ após terem atualizado as suas árvores-modelo.
} 


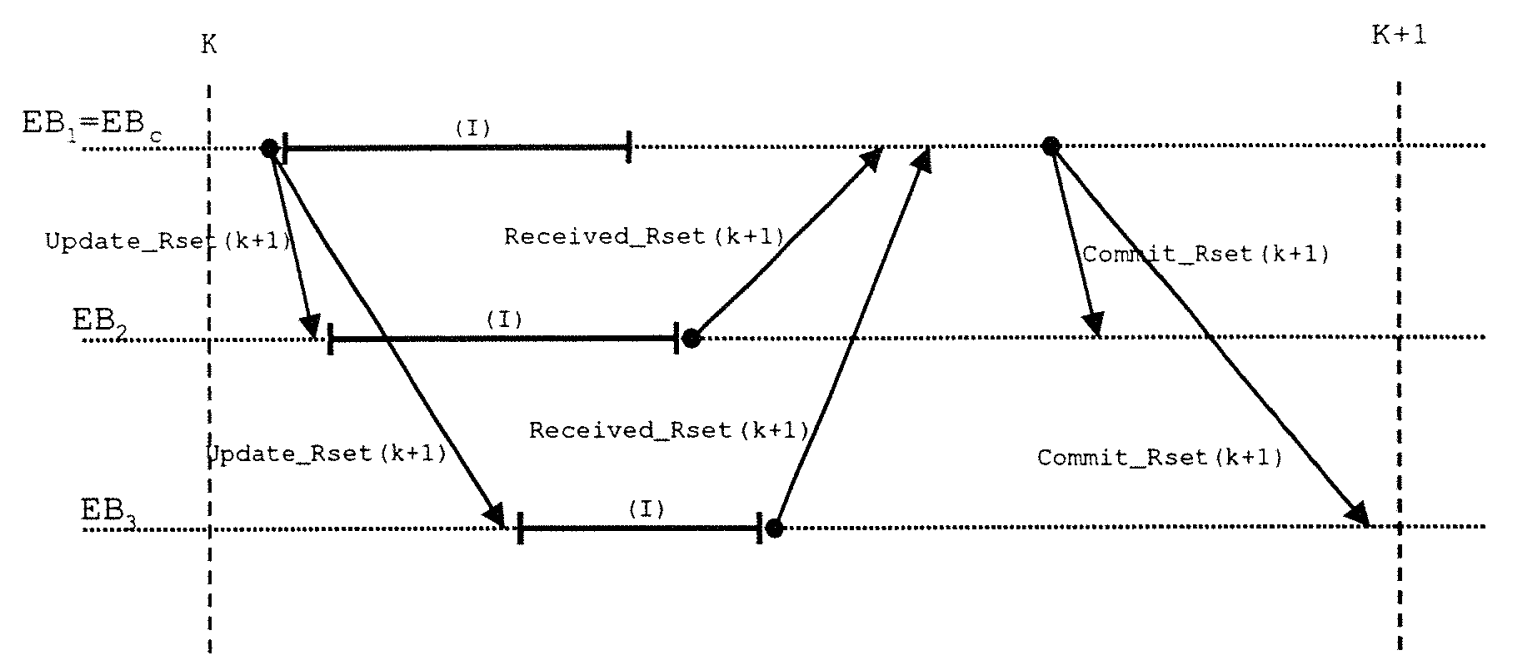

Figura 4.6: Processo de atualização do sistema para o estado $k+1$.

a mensagem Received_RSet $(k+1)$ para $E B_{C}$ (incluindo a própria estação $E B_{C}$ ), $E B_{C}$ envia a mensagem Commit_RSet $(k+1)$ para todas estações e servidores de busca, os quais fazem o estado $k+1$ tornar-se o estado atual.

\subsection{Complexidade estimada para trocas de mensagens}

É apresentada uma estimativa do tamanho da informação trafegada na rede durante a etapa de atualização. Devido à natureza dos tipos de mensagens que o modelo utiliza, acredita-se que a análise do tamanho das mensagens em conjunto com o número de mensagens trocada agrega mais informação do que a simples análise do número de mensagens trocadas sem uma definição mais precisa sobre qual o tipo das mensagens.

Dessa forma, considere um sistema contendo $P$ estações-base, $Q$ servidores de busca, cujos particionamentos de grafos geram Conjuntos Raízes de comprimento $N$. Para a análise aqui apresentada, considera-se que os servidores enviam 2 tipos de mensagens: mensagens contendo informações referentes ao novo conjunto TabCustRaizes e mensagens que apenas enviam informações menores, como a mensagem Update_Rset. Assume-se que as mensagens que não enviam conjuntos TabCustRaizes apresentam comprimento constante, $O(1)$. E as que contêm conjuntos TabCustRaizes tem complexidade $O\left(N^{2}\right)$.

Avaliando a etapa de atualização, verifica-se que inicialmente o coordenador precisa enviar $P$ mensagens Update_Rset às estações-base, de comprimento $O(1)$. Após as estações-base calcularem os novos conjuntos TabCustRaizes, estes devem ser enviados para todos servidores de busca, logo são enviadas P.Q mensagens Update_Rwset de comprimento $O\left(N^{2}\right)$. Assim que todos servidores de busca receberem todos conjuntos TabCustRaizes, são enviadas P.Q mensagens Received_Rwset de $O(1)$. A próxima etapa consiste no envio de $P$ mensagens Received_Rset das estações-base para o coordenador. Tendo recebido todas as notificações de mensagens Received_Rset, o coordenador 
envia $P+Q$ mensagens Commit_Rset para estações-base e servidores de busca de comprimento $O(1)$. Portanto, a complexidade do comprimento da informação trafegada na rede durante a atualização é $O\left(P \cdot Q \cdot N^{2}\right)$. Apenas para dar um exemplo prático, no caso de grafos distribuídos com Conjuntos Raízes com cerca de 100 nós, estimou-se que as mensagens de envio de conjuntos TabCustRaizes geram mensagens da ordem de $10^{2} \mathrm{~Kb}$.

\subsection{Análise do algoritmo distribuído}

Nesta seção é apresentada uma análise do algoritmo de busca apresentado. Em particular, serão apresentadas considerações para mostrar que o algoritmo calcula um caminho mínimo com os dados indexados pelo estado $k$. Além disso, é mostrado também que o tempo de execução do algoritmo de busca é polinomial, no pior caso.

Considere um grafo $\mathrm{G}$ particionado em $t$ estações-base e um servidor de busca $S B_{j}$. Para simplificar, admita que os conjuntos Raizes $\left(G_{t}\right)$ representam $100 \%$ das bordas de $E B_{t}$. Com os dados armazenados nas estações-base, o algoritmo de busca:

A. obtém um caminho mínimo para os dados indexados pelo estado $k$ nos servidores, se $\delta_{X Y}=$ 0

B. o tempo de execução da busca é polinomial, no pior caso.

Inicialmente, será mostrado o item A.

Considere inicialmente um cliente $C$ solicitando um caminho de $X$ a $Y$. Neste caso, $E B_{X}$ recebe a solicitação e obtém $T_{X}$.

i) Se $Y \in T_{X}$ e Peso $\left(P_{X Y}\right) \leq \delta_{X Y}, P_{X Y}$ é retornado para o cliente $\mathrm{C}$, para efeitos de otimização. Neste caso, pode ocorrer de $P_{X Y}$ não ser mínimo, pois pode existir um caminho $P_{X Y}^{\prime}$ passando por outras estações-base, tal que o $\operatorname{Peso}\left(P_{X Y}^{\prime}\right)<P e s o\left(P_{X Y}\right)$. Por isso, a otimização não é considerada se é desejado mostrar que o caminho calculado é mínimo, com os dados presentes nos servidores.

ii) Considere então $\delta_{X Y}=0$, logo se $Y \in T_{X}$ e $P e s o\left(P_{X Y}\right)>\delta_{X Y}, E B_{X}$ gera o con-

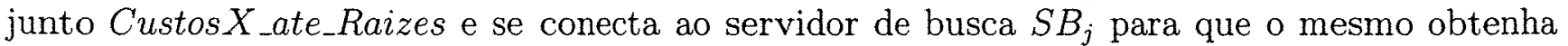
um caminho mínimo de $X$ a $Y$ com dados do estado global indexado por $k$. O conjunto CustosX_ate_Raizes é enviado para o servidor de busca $S B_{j}$, que inicia a execução do procedimento BuscaSB para obter um caminho.

Inicialmente, o procedimento BuscaSB solicita o conjunto CustosRaizes_ate_Y através da chamada do procedimento ConsultaPorticEB em $E B_{Y}$. Com os conjuntos Custos $X \_a t e \_R a-$ izes e CustosRaizes_ate_$Y, S B_{j}$ atualiza o grafo $S G$. O grafo $S G$ neste momento, apresenta arcos $(u, v)$ contendo os custos dos caminhos mínimos interligando os nós $u$ a $v$ com os dados do estado indexado por $k$. A partir de $S G$, um algoritmo para obtenção de caminho mínimo é executado para calcular um caminho de $\mathrm{X}$ a $\mathrm{Y}$. Esse algoritmo pode ser estático ou dinâmico. 
Dessa forma, $S B_{j}$ obtém um caminho mínimo de $X$ a $Y$ com os dados dos estados indexados por $k$ em cada estação-base.

Em particular, se a requisição cliente é global, $S B_{j}$ necessita requisitar os subcaminhos $P_{t}$ em $E B_{t}$.

A seguir é mostrado o item B, ou seja, o tempo de execução do algoritmo de busca é polinomial, no pior caso. Para a análise é assumido que o tempo de transferência de mensagens neste sistema tem tempo polinomial. Todas as mensagens do sistema tem comprimento polinomial.

Para mostrar que o algoritmo de busca roda em tempo polinomial, no pior caso, assuma que as piores implementações de algoritmos de busca conhecidos tem tempo polinomial. Neste caso, i) executa em tempo polinomial, pois essencialmente a construção de $T_{X}$ e o retorno do caminho $P_{X Y}$ consiste na execução de um algoritmo de busca de caminhos mínimos no grafo $G_{X}$.

Por outro lado, o tempo de execução de ii) é polinomial, no pior caso. Isso porque a geração de $T_{X}$, conforme discutido anteriormente, tem tempo polinomial. Durante a execução do procedimento BuscaSB, a geração do conjunto CustosRaizes_ate_Y custa $O(n)$. A etapa de atualização do grafo $S G$ de $S B_{j}$ é $O(n)$ e o cálculo de caminho mínimo de $X$ a $Y$ em $S G$ é dependente do tipo de algoritmo de busca sendo usado, que assume-se ter tempo de execução polinomial.

Finalmente, caso a requisição seja do tipo global, é necessário buscar em $E B_{t}$ os subcaminhos $P_{t}$. A etapa de busca de $P_{t}$ em $E B_{t}$ é $O(n)$ e a transferência de dados é assumida ter tempo polinomial, logo essa etapa adicional também tem tempo polinomial de execução.

\subsection{Considerações gerais}

Este Capítulo apresentou um modelo para realizar a busca de caminhos em grafos distribuídos em um conjunto de servidores. Em particular, ele permite que os dados armazenados nos arcos sofram alteração. A atualização do estado global pode ser feita utilizando algoritmos de busca dinâmicos. Conforme foi visto, o modelo assume a existência de 2 tipos de servidores especiais: estações-base e servidores de busca. As estações-base armazenam um subgrafo do domínio de aplicação. Todas as atualizações de arcos de um dado subgrafo $G_{i}$ são enviadas para estação-base $E B_{i}$. As estações-base conhecem apenas as informações dos subgrafos que elas armazenam. Os servidores de busca mantêm informação do estado global entre estações-base. Toda requisição de caminho de um ponto X a $\mathrm{Y}$ é encaminhada para a estação $E B_{X}$, a qual executa as funções de busca para prover uma estimativa (se existir) de caminho para o cliente. 


\section{Capítulo 5}

\section{Implementação}

Neste Capítulo, serão descritos detalhes da implementação do sistema proposto no Capítulo 4. A implementação está disponível em http://www.ime.usp.br/ mlv/distgraph/ index.html.

\subsection{Arquiteturas computacionais distribuídas}

Um dos principais objetivos deste trabalho é proporcionar que um grafo possa ser particionado em subgrafos disjuntos, os quais podem estar localizados em máquinas diferentes. Para isso, torna-se necessário adotar algum modelo de computação distribuída que permita a descentralização dos subgrafos de um grafo.

Assim, decidiu-se seguir um modelo para a criação de um grafo distribuído usando CORBA (Common Object Request Broker Architecture) ${ }^{1}$. CORBA é uma arquitetura para desenvolvimento em computação distribuída baseada no modelo RPC (Remote Procedure Call) [23]. Através do modelo RPC é possível que um cliente consiga executar um procedimento de um programa que está rodando em uma máquina remota e obter os dados de resposta, sendo que todo o processamento referente à chamada do procedimento é feito na remotamente. Para chamar o método remoto, o cliente dispõe de um interface (proxy), contendo as assinaturas dos métodos do programa, que está sendo executado na máquina remota. O CORBA funciona como uma camada intermediária (middleware) responsável pela comunicação cliente/servidor.

Uma das grandes vantagens de CORBA é sua característica multi-plataforma e multi-linguagem, ou seja, um cliente escrito em Delphi rodando em uma estação Windows pode perfeitamente se comunicar com um programa escrito em Java rodando em UNIX, por exemplo. Isso é possível, pois para o desenvolvimento de sistemas em CORBA é necessário que se especifique um arquivo de interface escrito em uma linguagem própria conhecida como Interface Definition Language (IDL). Esse arquivo de interface é posteriormente compilado por um compilador presente na biblioteca CORBA, que gera o código para a linguagem de programação para a qual ele foi projetado.

\footnotetext{
${ }^{1}$ http://www.omg.org/
} 
Por exemplo, um compilador para a linguagem Java gera as classes Java que representam os tipos descritos no arquivo de interface IDL. Outra característica de CORBA é que existe uma grande quantidade de serviços padronizados que permitem auxiliar o desenvolvimento. A seção 5.2 apresenta os principais serviços da arquitetura.

Existem outras arquiteturas de computação distribuída, dentre elas destacam-se a arquitetura Java Remote Method Invocation ${ }^{2}$ da Sun MicroSystems e DCOM ${ }^{3}$ da Microsoft que não apresentam características como multi-plataforma/multi-linguagem. Logo, decidiu-se usar CORBA para o suporte à computação distribuída. Existem várias implementações de CORBA. Para a implementação do trabalho aqui apresentado, o pacote CORBA usado é o JacORB 1.4.1 ${ }^{4}$, por ser uma implementação gratuita.

\subsection{Serviços da arquitetura CORBA}

Uma das vantagens de CORBA é a quantidade de serviços que a arquitetura oferece. Os CORBAservices são coleções de serviços em nível de sistema, empacotados com interfaces especificadas em IDL. A OMG ${ }^{5}$ (Object Management Group), órgão responsável pela arquitetura CORBA, publicou padrões para quinze serviços:

- Serviço de Ciclo de Vida: define operações para criar, copiar, mover e remover componentes;

- Serviço de Persistência: provê uma interface única para armazenar componentes persistentemente, sobre uma variedade de servidores para armazenamento, incluindo Bases de Dados Orientadas a Objetos (ODBMSs), Bases de Dados Relacionais (RDBMSs) e arquivos (flat files);

- Serviço de Nomes: permite que componentes localizem outros componentes por seu nome;

- Serviço de Eventos: permite que componentes se registrem para receber eventos específicos. Este serviço define um objeto bem-conhecido chamado event channel [23] que coleta e distribui eventos entre componentes independentes;

- Serviço de Controle de Concorrência: provê um gerenciador de bloqueios, que podem ser solicitados em transações ou por threads;

- Serviço de Transação de Objetos: provê uma coordenação de commit (realização de uma transação) em duas fases, entre componentes recuperáveis, usando transações flat (planas) ou transações aninhadas;

- Serviço de Relacionamento: provê um modo para criar associações dinâmicas (links) entre componentes independentes. Pode-se usar este serviço para qualquer tipo de ligação entre componentes;

\footnotetext{
${ }^{2} \mathrm{http}: / /$ java.sun.com/products/jdk/rmi/

${ }^{3}$ http://www.microsoft.com/com/tech/DCOM.asp

${ }^{4}$ http://www.jacorb.org

${ }^{5}$ http://www.omg.org
} 
- Serviço de Externalização: provê um padrão para obtenção de dados dentro e fora de um componente, usando um mecanismo de stream;

- Serviço de Consulta: provê operações de consultas para objetos. É um superconjunto de SQL e é baseado na especificação SQL3 e Object Query Language (OQL) do Object Database Management Group (ODMG);

- Serviço de Licenciamento: provê operações para medir o uso de componentes e garantir a compensação justa para seu uso. O serviço permite qualquer modelo de controle de uso, em qualquer ponto de um ciclo de vida do componente;

- Serviço de Propriedades: provê operações que permitem associar valores nomeados (propriedades) com qualquer componente. Usando este serviço, podemos dinamicamente associar propriedades com um estado do componente; por exemplo, um título ou uma data;

- Serviço de Tempo: provê interfaces para sincronizar tempo em um ambiente de objetos distribuídos;

- Serviço de Segurança: provê um arcabouço completo para segurança em ambiente de objetos distribuídos. Permite autenticação, listas de controle de acesso, confidencialidade e não-repudiação. Também gerencia a delegação de credenciais entre objetos;

- Serviço de Trader: provê um serviço como as páginas amarelas para objetos; permite que objetos publiquem seus serviços e ofereçam tarefas;

- Serviço de Coleção: provê interfaces CORBA para, genericamente, criarem-se objetos e agrupá-los dentro de coleções. Assim, múltiplos objetos podem ser manipulados como um grupo.

A implementação do trabalho aqui proposto utiliza alguns destes serviços, como o serviço de nomes, mas deseja-se utilizar os serviços de segurança, trader e de persistência em versões futuras.

\section{$5.3 \quad$ IDL}

A seguir é mostrada a IDL (Interface Description Language) do sistema apresentado neste trabalho. A IDL foi desenvolvida visando-se atender os requisitos principais da arquitetura apresentada neste trabalho.

Para tanto, há dois módulos encapsulando a parte central da IDL: dgraph e orb. No interior do módulo orb, há elementos de uso geral, por exemplo a exceção DgServerException, a seqüência VertexIdSet, a estrutura de dados DgAbstractData, a seqüência DataSet e a estrutura DgAbstractRequest.

A seqüência VertexIdSet permite a criação de uma lista de identificadores de vértices de grafos do sistema. A estrutura DgAbstractData representa o custo de um caminho formado por 
uma seqüência de vértices. Para isso, DgAbstractData mantém uma seqüência VertexIdSet e um campo para armazenar o custo (value). A sequência DataSet representa uma coleção de objetos DgAbstractData.

A estrutura DgAbstractRequest encapsula as informações gerais representando uma mensagem a ser trafegada entre os servidores do sistema. A seguir, é apresentada uma lista dos campos atualmente utilizados pelo sistema:

id: identificador global único do processo que está tratando a mensagem no servidor corrente;

remoteId: identificador do processo que está tratando a mensagem no servidor remoto. Pode ocorrer de um processo $A_{1}$ necessitar executar uma ação de outro processo $A_{2}$ (remoto ou não) e receber a resposta. Nesse caso, este campo permite que $A_{1}$, ao enviar a mensagem para $A_{2}$, especifique o seu identificador, para poder receber o resultado da computação efetuada por $A_{2}$;

remoteServer: da mesma forma que um processo $A_{1}$ pode precisar usar o seu identificador remoteId, é vital que ele também possa identificar o seu o endereço, para que possa receber a resposta da computação em outro agente, por exemplo $A_{2}$. O campo utilizado para isso é remoteServer;

type: identifica o tipo de agente que deve tratar a mensagem;

status: identifica o resultado da computação de uma mensagem por um dado agente, normalmente indicando a causa do problema. Para tanto, foi definida uma coleção de respostas possíveis do sistema;

data: Os dados pertinentes à mensagem sendo enviada, por exemplo, o valor de um caminho entre dois pontos quaisquer de um determinado grafo;

stateId: identificador do estado global do sistema sendo usado nas ações a serem desempenhadas para tratar a mensagem;

position: normalmente, o sistema gera mensagens relativamente grandes. Dessa forma, em muitas situações, é necessário particionar a mensagem em várias partes, a serem transmitidas. O campo position permite identificar qual a posição da sub mensagem recebida. Assim que todas as partes tenham sido recebidas, será possivel remontar a mensagem original no servidor de destino, para ser usada pelo sistema. O sistema implementado apresenta métodos especiais que tornam transparente para os agentes o fato de a mensagem ter sido enviada em partes ou não, uma vez que eles sempre recebem a mensagem completa;

total: Esse campo permite identificar o número de partes que compõem uma mensagem previamente particionada em um conjunto de sub mensagens.

Verificou-se que o sistema apresenta dois tipos possiveis de mensagens: mensagens de atualização e de busca. Para tanto, foram criadas duas estruturas especiais DgSearchRequest 
e DgUpdateRequest implementando mensagens de busca e mensagens de atualização da arquitetura, respectivamente. Essas estruturas estendem DgAbstractRequest. A idéia inicial da diferenciação foi de se poder ter atributos específicos para cada tipo de mensagem.

A seguir são apresentados os campos específicos para mensagens para realização de buscas:

sourceVertex: identifica o nó inicial do caminho solicitado para ser calculado;

destVertex: identifica o nó final do caminho solicitado para ser calculado;

searchType: o tipo de função de busca: Local ou Global.

Em princípio, alguém poderia pensar que os campos sourceVertex e destVertex são desnecessários, haja vista que já existe o campo data, herdado de DgAbstractData. Isso não é verdade, pois se forem observadas mensagens como as enviadas durante a execução do agente FindRset2YAgent, descrito na seção 5.6.3, observa-se que o campo data é o responsável por armazenar o resultado dos melhores caminhos do conjunto Raizes $\left(G_{Y}\right)$ a $Y$, enquanto os campos sourceVertex e destVertex representam as informações específicas dos pontos origem e destino do caminho solicitado por um cliente.

Por outro lado, a estrutura DgUpdateRequest utiliza apenas um campo específico description, que serve para enviar descrições sobre ações de atualização.

No interior do módulo orb há o módulo server o qual encapsula as interfaces descrevendo os servidores do sistema. Para tanto há uma interface genérica, DgAbstractServer à qual mantém o método processRequest. Esse método recebe um argumento DgAbstractRequest e lança a exceção DgServerException.

Dada à existência de dois tipos de servidores no sistema, o módulo server possui ainda as interfaces DgBaseServer e DgSearchServer as quais estendem a interface DgAbstractServer. A intenção do uso dessas interfaces adicionais também foi a de se adicionar possíveis futuros métodos específicos a um dado tipo de servidor.

O código a seguir apresenta a IDL do sistema em detalhes:

Listing 5.1: Interface Description Language desenvolvida

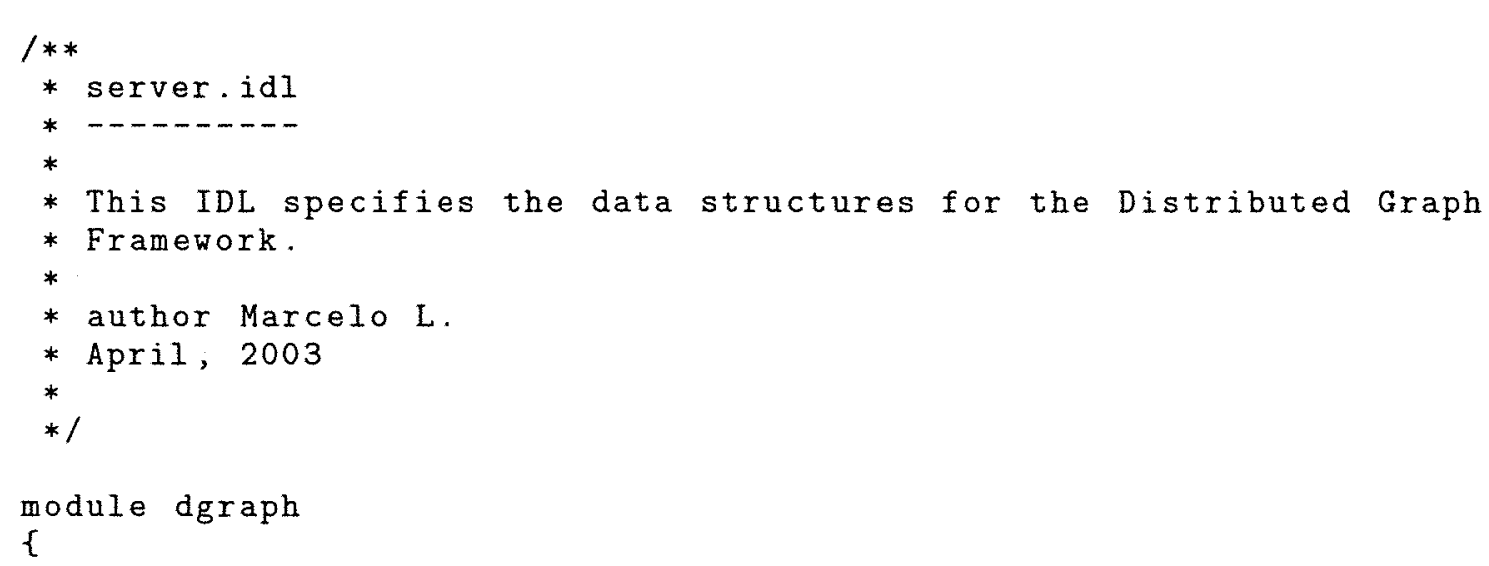




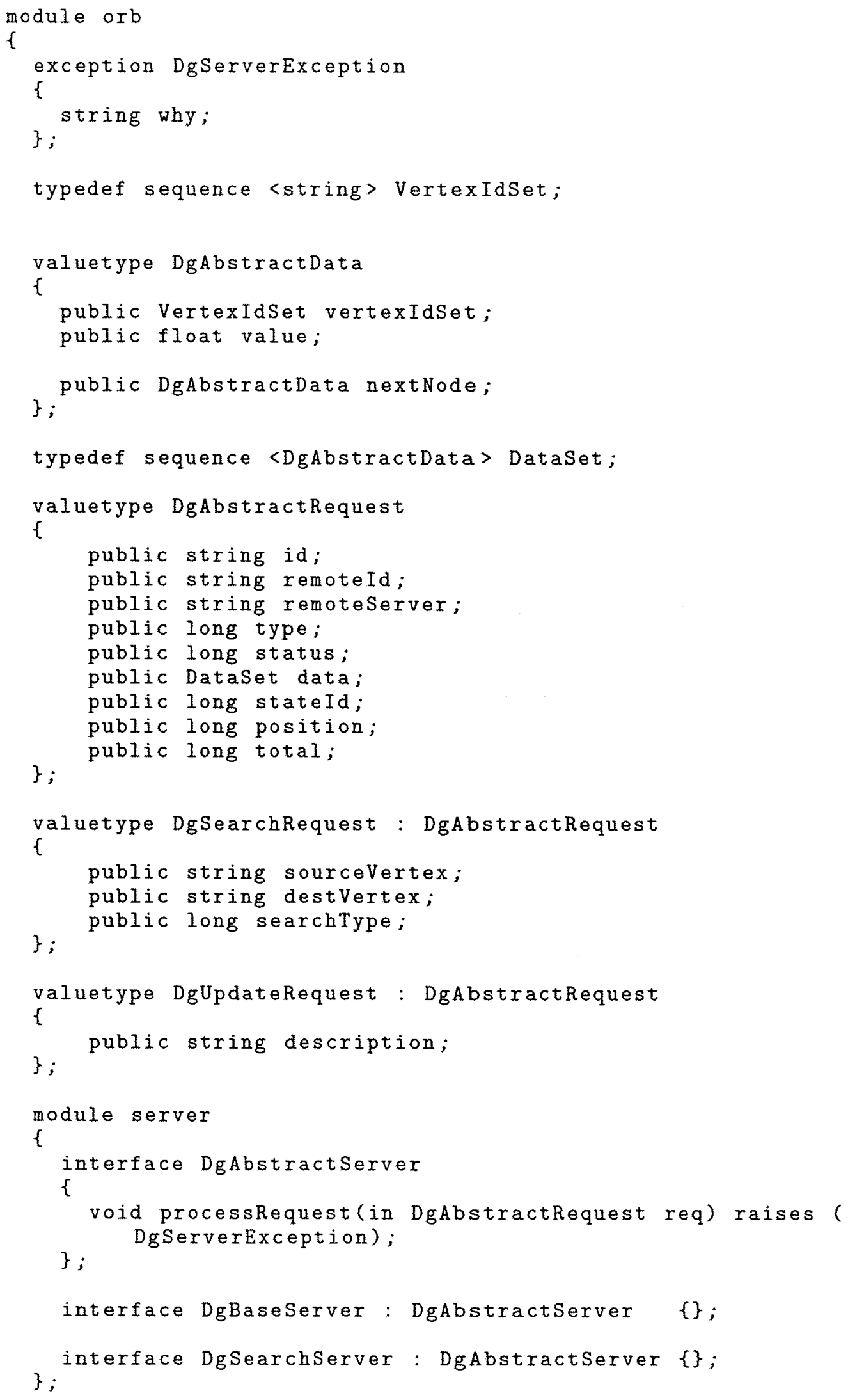


$72 \quad\}$;

73 \};

Um detalhe importante a ser observado é que a IDL desenvolvida procura utilizar os conceitos genéricos para mensagens e interfaces servidoras justamente para permitir que novas ações sejam adicionadas ao sistema sem que sejam feitas alterações no conteúdo do arquivo descritor da IDL.

\subsection{Hierarquia de classes}

Nesta seção se apresenta a hierarquia de pacotes criada para as principais classes do projeto desenvolvido. A seguir são apresentados os 12 pacotes principais do projeto desenvolvido.

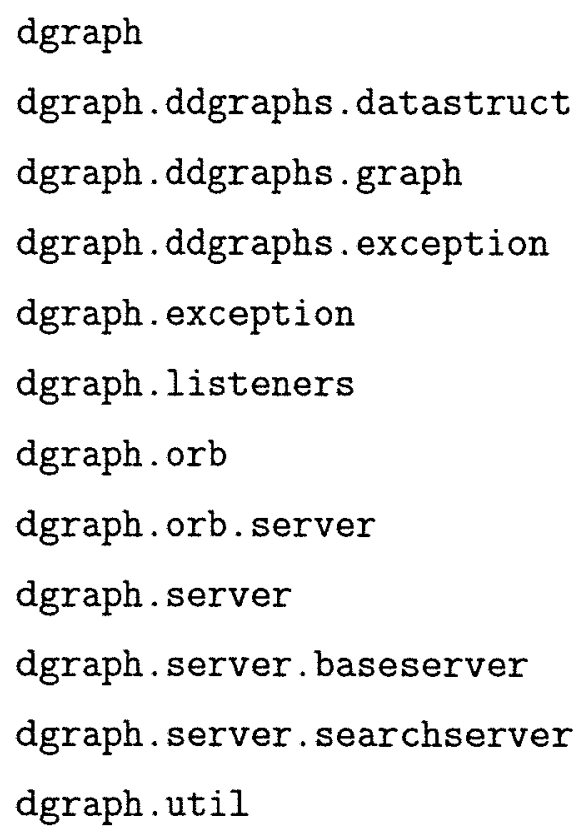

Nos próximos itens serão apresentados os pacotes em maiores detalhes, inclusive mostrando as principais classes que os compõem.

\subsection{1 dgraph}

Este pacote apresenta as classes que implementam os servidores do sistema. Essas classes permitem instanciar servidores de busca, estações-base e clientes do sistema.

As principais classes deste pacote são:

BaseServerImpl

SearchServerImpl 
DGraphClient

A classe BaseServerImpl permite que seja instanciada uma estação-base do sistema. Para tanto, é necessário indicar o caminho de um arquivo de configuração de propriedades, conforme será visto na seção A.2. Analogamente, a classe SearchServer Impl permite que seja instanciado um servidor de busca do sistema, também lendo um arquivo de configurações.

A classe DGraphClient permite a instanciação de um cliente do sistema. Um cliente pode solicitar informações de buscas locais ou globais de caminhos, enviar dados para atualizações, etc, conforme será descrito na seção A.4.

\title{
5.4.2 dgraph.ddgraphs.datastruct
}

Esse pacote foi desenhado para manter estruturas de dados especiais que vão sendo incorporadas ao sistema. Atualmente, há 5 classes e interfaces que merecem destaque especial:

\author{
Linkable \\ LinkableList \\ PriorityQueue \\ PriorityQueueElem \\ PriorityVector
}

A classe LinkableList implementa a estrutura de lista duplamente ligada. Os objetos a serem inseridos nas listas devem obrigatoriamente implementar a interface Linkable.

A interface PriorityQueue apresenta métodos descrevendo o protótipo de uma implementação de fila de prioridades. Em particular, a classe PriorityVector é uma implementação de Priorityqueue. Os itens a serem inseridos nas filas de prioridades devem obrigatoriamente ser instâncias da classe PriorityQueueElem, o qual mantém um objeto do tipo ComparableItem. Conforme será visto adiante, dois objetos que implementam a interface ComparableItem podem ser comparados entre si.

\subsection{3 dgraph.ddgraphs.graph}

Esse pacote apresenta as classes responsáveis pela implementação de uma biblioteca para permitir acessos concorrentes a um grafo. As classes principais desse pacote são:

AbstractData

AbstractGraph

AbstractVisitor 
AlgorithmNST

Algorithms

ComparableItem

Data

DDException

DuplicateElementException

DynamicUpdateListener

DynamicUpdateRegister

Edge

Graph

InAnotherGraphException

NSTTest

Vertex

VertexNotFoundException

Uma descrição mais detalhada da biblioteca implementada pode ser encontrada no item 5.5. Os algoritmos até agora utilizados pela arquitetura estão neste pacote. Como já foi explicado anteriormente, os algoritmos de busca podem ter uma natureza estática ou dinâmica. Os algoritmos de busca estática estão na classe Algorithms. Dentre eles, destaca-se o algoritmo de Dijkstra implementado com fila de prioridades (classe PriorityVector presente no pacote dgraph.ddgraph.datastruct).

Com relação aos algoritmos dinâmicos, a arquitetura disponibiliza uma implementação do algoritmo proposto por Narváez et al., apresentado no Capítulo 3. A classe que implementa o algoritmo dinâmico se chama AlgorithmNST. Ela implementa os passos descritos pelo algoritmo dinâmico proposto por Narváez et al., apresentando a possibilidade de ser executado como uma implementação do primeiro método ou segundo método incrementais.

Maiores detalhes de implementação sobre as classes com o algoritmo de busca dinâmica podem ser vistas na seção A.1.

\subsection{4 dgraph.ddgraphs.exception}

Este pacote mantém as classes de exceções gerais do sistema.

A seguir são listadas as classes do pacote:

DgraphException

ServerException 
A classe DgraphException serve para captura de exceções inter-módulos que estão relacionadas às estruturas de dados e grafos do sistema. A classe ServerException, por sua vez, possibilita o tratamento de exceções inter-módulos relacionadas com problemas em servidores do sistema.

\title{
5.4.5 dgraph.listeners
}

Este pacote apresenta interfaces especiais para implementação de listeners. A seguir são apresentados as principais classes deste pacote:

MTAgentListener

PTAgentListener

Os objetos que implementam a interface MTAgentListener recebem eventos sobre o término da execução de um dado objeto MTAgent. Conforme será visto, a classe MTAgent trata da criação/atualização de uma determinada árvore-modelo. Analogamente, os objetos que implementam a interface PTAgentListener recebem eventos indicando o término da execução de um dado objeto PTAgent, que trata da criação/atualização de uma dada árvore pórtico.

\subsection{6 dgraph.orb / dgraph.orb.server}

Estes pacotes apresentam as classes geradas pelo compilador de IDL, quando executado com a IDL mostrada na seção 5.3. No caso específico do compilador de IDL do JacORB, são geradas aproximadamente 40 classes que mapeiam a IDL do sistema em linguagem Java.

\subsection{7 dgraph.server}

Este pacote apresenta classes genéricas de uso tanto com servidores de busca (SearchServers) quanto estações-base (BaseServers). As classes principais são:

\author{
AbstractAgent \\ AbstractRequest \\ AbstractServer \\ RootSet \\ SearchAgent \\ SearchRequest \\ UpdateAgent \\ UpdateRequest
}


Maiores detalhes da funcionalidade destas classes serão dados na seção 5.6.8.

\title{
5.4.8 dgraph.server.baseserver
}

Este pacote apresenta as classes que se relacionam com as ações de estações-base do sistema, como por exemplo, os BSAgents. Dentre as principais classes e interfaces deste pacote, destacamse:

\author{
BaseServer \\ BaseServerAdapter \\ BaseServerRequestAgent \\ FindRset2YAgent \\ PTAgent \\ RequestSubPathAgent \\ UpdateDataLinkAgent \\ UpdateLinkState \\ UpdateRSetAgent \\ UpdateTransactionAgent \\ UpdateTransactionTimer
}

Maiores detalhes sobre as classes apresentadas serão dadas na seção 5.6 .8 e na seção 5.6.2.

\subsection{9 dgraph.server.searchserver}

Este pacote apresenta as classes que se relacionam com as ações de servidores de busca do sistema, como por exemplo, os SSAgents. Dentre as principais classes e interfaces deste pacote, destacam-se:

CommitRSetAgent

MTAgent

PerformShortestPath

SearchServer

SearchServerAdapter

UpdateRWSetAgent

Maiores detalhes sobre as classes apresentadas serão dadas na seção 5.6.8. 


\title{
5.4.10 dgraph.util
}

Este pacote apresenta classes gerais ao sistema implementado. Dentre elas, destacam-se:

\author{
Constants \\ DefaultComparable \\ DefaultComparableItem \\ Props \\ ThreadTask \\ ThreadTaskManager \\ Util
}

A classe Constants armazena valores de constantes. A interface DefaultComparable permite estabelecer padrões de comparação entre os objetos que a implementam. Por exemplo, as classes Edge e Vertex implementam essa interface, para possibilitar comparações entre os objetos. A classe DefaultComparableItem é uma implementação da interface DefaultComparable para possibilitar a comparação de um objeto do String com qualquer outro que implemente a interface DefaultComparable.

A classe Props é um singleton [8] para armazenamento de propriedades. A classe ThreadTaskManager permite o controle do número mínimo e máximo de processos sendo executados concorrentemente. Por exemplo, se o número máximo de processos concorrentes é 5 , essa classe somente dispara o processo número 6 depois que algum dos 5 processos, que estão sendo executados, terminar. Os processos a serem inseridos no gerenciador necessitam estender a classe abstrata ThreadTask. O gerenciador de processos (ThreadManager) é utilizado principalmente na atualização das árvores pórticos e árvores-modelo, para limitar o número máximo de processos concorrentes.

A classe Util apresentam métodos genéricos utilitários, como métodos para formatação de saída de impressão.

\subsection{Uma biblioteca para grafos com acessos concorrentes}

Devido à natureza concorrente e distribuída do sistema, as bibliotecas utilizadas que dão suporte à criação de estruturas de dados baseadas em grafos, precisam ser bem definidas. Em geral, as bibliotecas atualmente disponíveis em Java, como por exemplo a apresentada em http: //www.cs.rpi.edu/projects/pb/jgb/ não se adequam ao modelo proposto.

Em geral, vários processos podem estar executando algoritmos de busca sobre um mesmo grafo, sendo que as implementações conhecidas não possibilitam, de imediato, tal funcionalidade. Por isso, foi implementada uma biblioteca especial para permitir o processamento concorrente de algoritmos de busca em um mesmo grafo alocado na memória do servidor. Esta seção destina-se 


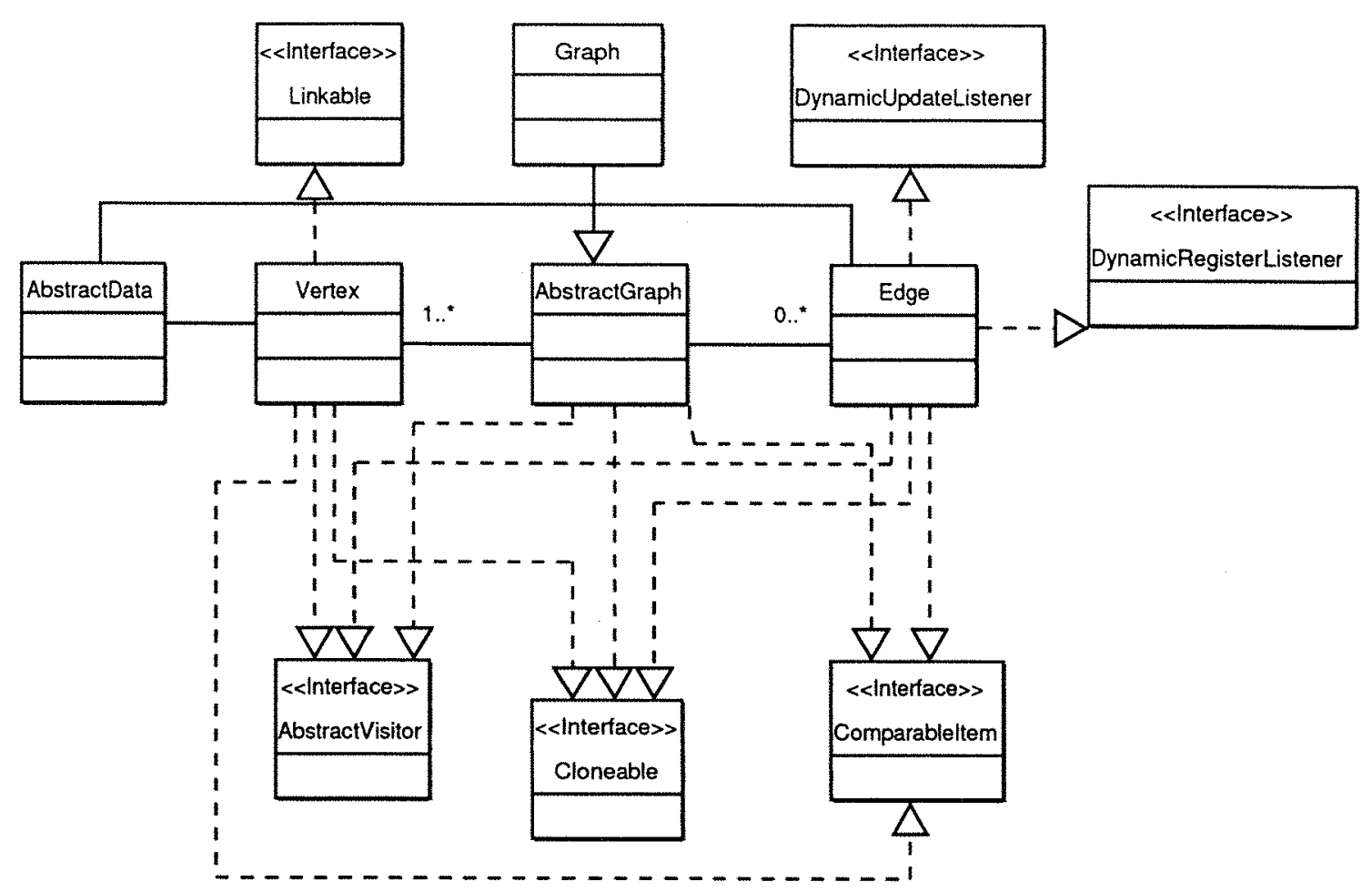

Figura 5.1: Diagrama de classes da biblioteca de grafos da arquitetura.

a apresentar a biblioteca desenvolvida.

A figura 5.1 descreve de maneira geral as principais classes que compõem a biblioteca.

Em princípio, há a classe abstrata AbstractGraph. Essa classe representa a estrutura genérica de um grafo. Na biblioteca, a classe Graph é um exemplo de classe concreta que estende AbstractGraph. As classes Edge e Vertex implementam as estruturas de arcos e vértices, respectivamente. A classe AbstractGraph apresenta tabelas mapeando o seus conjuntos de arcos e vértices. Ela também possui os métodos necessários para inserção, remoção e atualização dos seus componentes internos.

A classe Vertex mantém uma lista de arcos chegando ao objeto Vertex corrente (incomingEdges) bem como a lista de arcos saindo do objeto Vertex corrente (outgoingEdges). Devido à necessidade de que vários processos possam executar algoritmos ao mesmo tempo, a classe Vertex mantém tabelas especiais para indexar informações como a distância atual do vértice corrente à raiz da árvore de caminhos sendo calculada por um determinado processo. Para que um agente designado para realizar um algoritmo de caminhos consiga armazenar e consultar dados referentes ao seu processo, ele precisa passar o seu identificador (threadId). Por exemplo, um agente que deseje saber qual é o nó pai do vértice $\mathrm{v}$ pode usar o método getParent (String threadId), passando o seu identificador (threadId).

A classe Edge apresenta métodos e campos apropriados para as funções especiais de arcos. A biblioteca não apresenta especializações de arcos, como por exemplo, o conceito de arestas. A implementação de arestas pode ser feita com dois arcos com pesos idênticos, mas em sentidos 
inversos, ligados ao mesmo par de vértices.

Conforme descrito anteriormente, uma das principais características da arquitetura proposta é que os arcos podem sofrer atualizações periódicas. Dessa forma, a classe Edge implementada pela biblioteca permite que sejam armazenados vários valores para custos, indexados pelo estado (k) ao qual eles estão associados. Como apresentando anteriormente, a cada atualização de estados, os arcos podem passar a possuir novos valores de custos.

De acordo com a especificação da biblioteca, um arco pode ser de dois tipos: Edge_Single_Value ou Edge_Multi_Value. Nos arcos Edge_Multi_Value vários valores de custos podem ser associados ao arco, para um determinado estado (k). Entretanto, cada valor associado ao arco em um determinado $\mathrm{k}$ precisa possuir um identificador único, normalmente o identificador global único (threadId) do agente executando algum algoritmo no grafo. Os arcos do tipo Edge..Single_Value permitem apenas um único valor para o custo, para cada estado.

Normalmente, os arcos em um grafo são do tipo Edge_Single_Value, isto é, aceitam apenas um único valor a eles associados, para cada estado. Entretanto, no caso dos grafos $S G_{j}$, que armazenam os conjuntos TabCustRaizes $\left(G_{i}\right)$ em $S S_{j}$, existem arcos que são do tipo Edge_Multi_Value. Os arcos desse tipo são justamente aqueles que se ligam aos nós especiais Origem e Sorvedouro. Isso ocorre pois esses arcos apresentam valores particulares para cada processo de busca sendo executado por agentes no servidor de busca, possivelmente para o mesmo estado ( $\mathrm{k}$ ). Assim sendo, assim que um agente, por exemplo, o agente PerformShortestPathAgent é executado no servidor de busca, ele atualiza os custos dos arcos contendo os nós Origem $\left(G_{X}\right)$ ou Sorvedouro $\left(G_{Y}\right)$, com os valores enviados pelas estações $E B_{X}$ e $E B_{Y}$, respectivamente.

A utilização de arcos Edge_Multi_Value permite que a mesma estrutura de dados seja utilizada por inúmeros agentes do tipo PerformShortestPathAgent, economizando espaço de memória alocada. Uma implementação alternativa sem a utilização de arcos Edge_Multi_Value poderia ser muito custosa, pois para cada agente PerformShortestPathAgent sendo executado, uma réplica do grafo $S G$ deveria ser criada. Isso é necessário, pois para cada prcesso sendo executado, os pesos de arcos que possuem conexões com os pontos $\mathrm{X}$ ou $\mathrm{Y}$ apresentam valores diferentes para cada requisição sendo atendida.

Devido à característica dinâmica do sistema, a classe Edge implementa as interfaces DynamicUpdateListener e DynamicRegisterListener. A interface DynamicRegisterListener disponibiliza métodos para registrar e remover objetos que implementem a interface DynamicUpdateListener. A interface DynamicUpdateListener apresenta o protótipo de um método genérico dynamicUpdateAction. A idéia é que qualquer classe que implemente DynamicRegisterListener permita cadastrar objetos (que implementem DynamicupdateListener) que serão informados assim que houver uma alteração de custo no arco (classe Edge).

De uma forma geral, as classes que descrevem a estrutura de grafos implementam as interfaces Cloneable, AbstractVisitor e ComparableItem.

A interface Cloneable permite que sejam criadas cópias (clones) dos objetos bem como dos componentes internos que também implementam a interface Cloneable. A interface AbstractVisitor permite que os elementos que constituem um grafo possam ser visitados de forma recursiva para algum fim, por exemplo, a impressão dos itens que compõem o grafo. 
A interface ComparableItem apresenta métodos gerais que permitem a personalização de funções de comparação entre os objetos do sistema. Essa interface disponibiliza dois métodos a serem implementados: comparableItem e getComparableID. O método comparableItem recebe um objeto que implementa ComparableItem como parâmetro e devolve, se houver, o objeto que apresenta o mesmo valor retornado pelo método getComparableID.

\subsection{Arquitetura das classes servidoras}

A partir deste momento será dada uma descrição da arquitetura das principais classes que compõem a estrutura de servidores do sistema. Para tanto, a figura 5.2 descreve em um diagrama de classes UML as principais associações e estrutura de hierarquia das classes.

Os itens a seguir irão apresentar com maiores detalhes as classes apresentadas no diagrama da figura 5.2. A ordem de apresentação das classes foi formulada visando um melhor entendimento. Para isso, as classes foram divididas nos seguintes grupos, de acordo com a funcionalidade: classes de solicitação (request), classes agentes (agents), classes de representação de domínios, classes de implementação de servidores e classes adaptadoras.

\subsubsection{Classes de solicitação}

As classes de solicitação (request) são responsáveis por armazenar dados referentes a uma solicitação de ação a ser transmitida ou trocada entre servidores e clientes. Dentro da arquitetura proposta neste trabalho, previu-se a existência de dois tipos especiais de requisições: de atualização (update) ou de busca (search).

Todas as classes de solicitação da arquitetura servidora estendem a classe AbstractRequest. Essa classe apresenta os campos genéricos de uma solicitação. Dependendo do tipo de solicitação, podem existir campos específicos. Neste caso, há duas classes as quais estendem AbstractRequest: SearchRequest e UpdateRequest. A classe SearchRequest apresenta campos específicos para uma solicitação de busca de caminhos, por exemplo, os vértices inicial e final da requisição. Analogamente, a classe UpdateRequest apresenta campos específicos para solicitações de atualização.

Há uma estreita relação entre as classes para solicitação geradas pela IDL descrita na seção 5.3 e as classes de solicitação da arquitetura servidora. Mais especificamente, AbstractRequest apresenta os mesmo campos apresentados em DgAbstractRequest, SearchRequest possui os mesmos campos de DGSearchRequest e UpdateRequest mantém os mesmos campos de DgUpdateRequest.

A opção de se utilizar outro conjunto de classes de solicitação na arquitetura servidora e não aproveitar as classes de solicitação geradas pelo compilador IDL foi devida à intenção de manter as classes da arquitetura servidora o mais separadas possível das classes mapeadas pela IDL, permitindo que a arquitetura independesse da IDL utilizada. O principal motivo dessa abordagem é permitir que as classes que implementam as camadas superiores do modelo não 


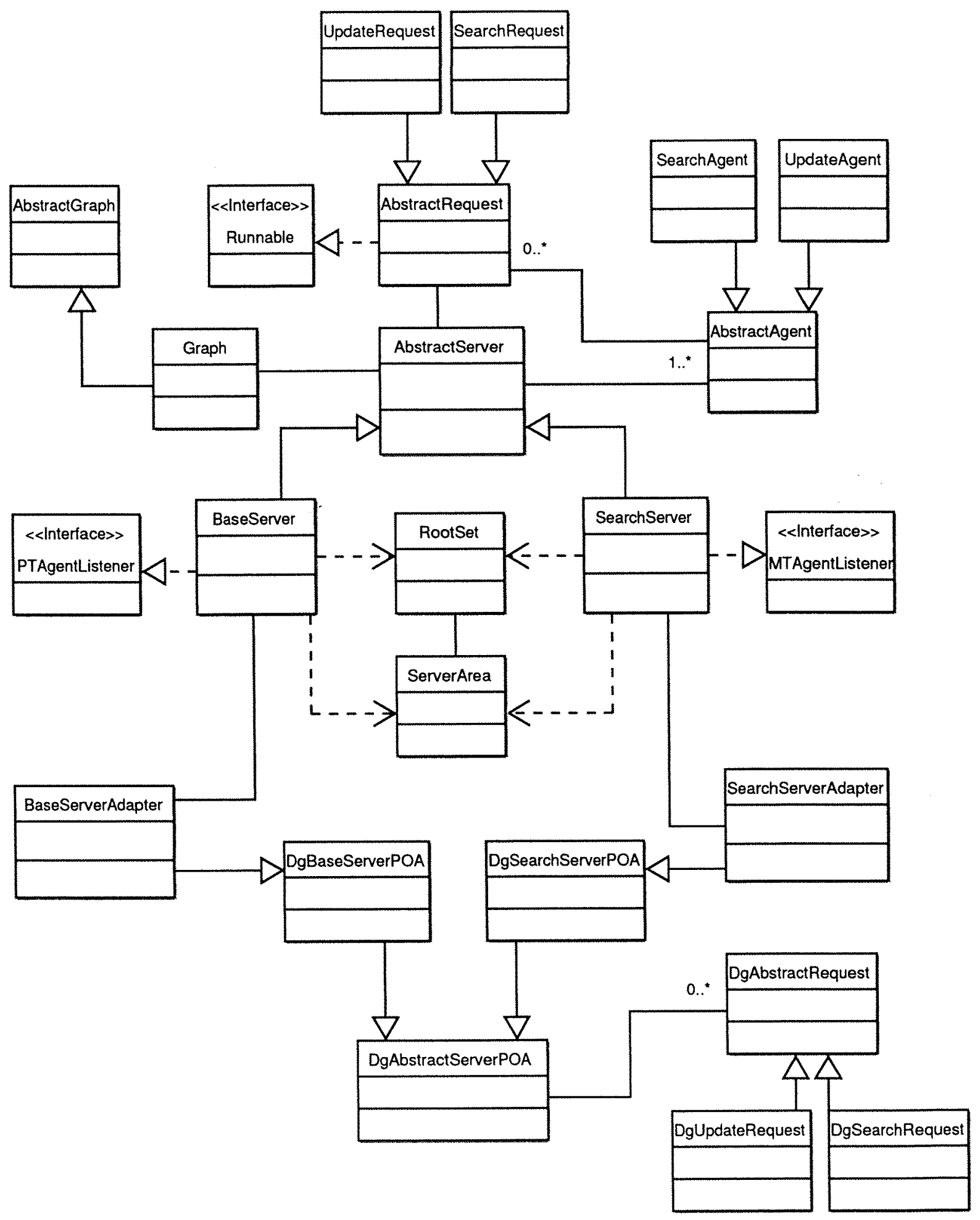

Figura 5.2: Diagrama de classes dos servidores da arquitetura. 
utilizem classes que são destinadas à implementar as camadas de comunicação. Dessa forma, uma mudança futura da arquitetura usada na camada de comunicação (por exemplo, de CORBA para RMI) seria transparente para as camadas superiores.

Para tanto, foram desenvolvidas algumas classes adaptadoras que realizam a ponte entre as classes da arquitetura servidora e as classes geradas pelo compilador IDL. No caso específico das classes de solicitação, há 3 classes adaptadoras, que realizam as associações entre classes servidoras e classes mapeadas pelo compilador IDL: DgAbstractRequestImpl, DgSearchRequestImpl e DgUpdateRequest Impl. Essas três classes possuem métodos que permitem as conversões entre classes mapeadas e classes servidoras e vice-versa.

\subsubsection{Classes agentes}

De acordo com o tipo de funcionalidade à qual o servidor se destina, ele terá um conjunto definido de ações pertinentes, a serem desempenhadas. Uma ação comum a um dado servidor do sistema é sempre desempenhada por um agente. Os agentes são processos especiais que são iniciados pelos servidores a fim de realizar uma tarefa específica. Em geral, os agentes são processos leves (lightweight processes), tais como threads em Java.

Todos os agentes da arquitetura servidora implementam a classe abstrata AbstractAgent. Essa classe apresenta 2 métodos: run e execute. O método run é devido ao fato de que AbstractAgent implementa a interface Runnable. Assim que o agente é criado, é executado o código no interior do método run. O método execute recebe um objeto AbstractRequest, contendo os valores de uma requisição previamente solicitada pelo agente. Isso ocorre porque esse método serve para que o agente continue um processamento previamente paralisado, devido à necessidade de se realizar uma solicitação de alguma tarefa de outro agente, por exemplo. Assim que a solicitação é devolvida (um objeto AbstractRequest), o agente pode continuar o seu processamento previamente paralisado.

Nas figuras 5.3 e 5.4, são apresentadas as ações desempenhadas por estações-base e servidores de busca, bem como os seus respectivos agentes invocados por clientes e/ou servidores. As ações apresentadas acima das linhas tracejadas se relacionam com os processos de busca de caminhos enquanto aquelas nas partes inferiores são usadas para executar a atualização de estados do sistema. Para uma melhor compreensão do texto, decidiu-se classificar os agentes do sistema em dois grupos, de acordo com o tipo de servidor ao qual eles estão associados. Assim, de acordo com o local onde um agente é executado, ele pode ser chamado de BSagent (executado em estações-base) ou SSagent (executado em servidores de busca).

\subsubsection{BSAgents para busca de caminhos}

Os itens a seguir apresentarão os principais agentes da arquitetura implementada. 


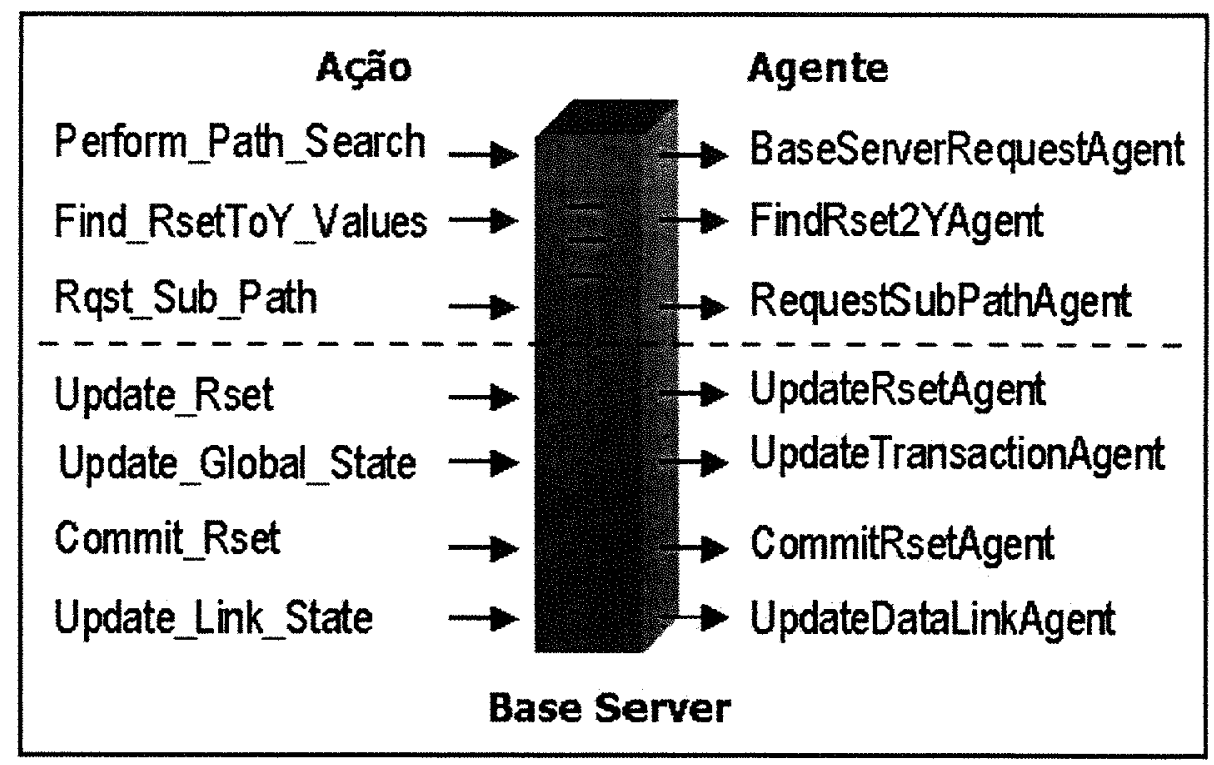

Figura 5.3: Relação de ações e agentes em estações-base.

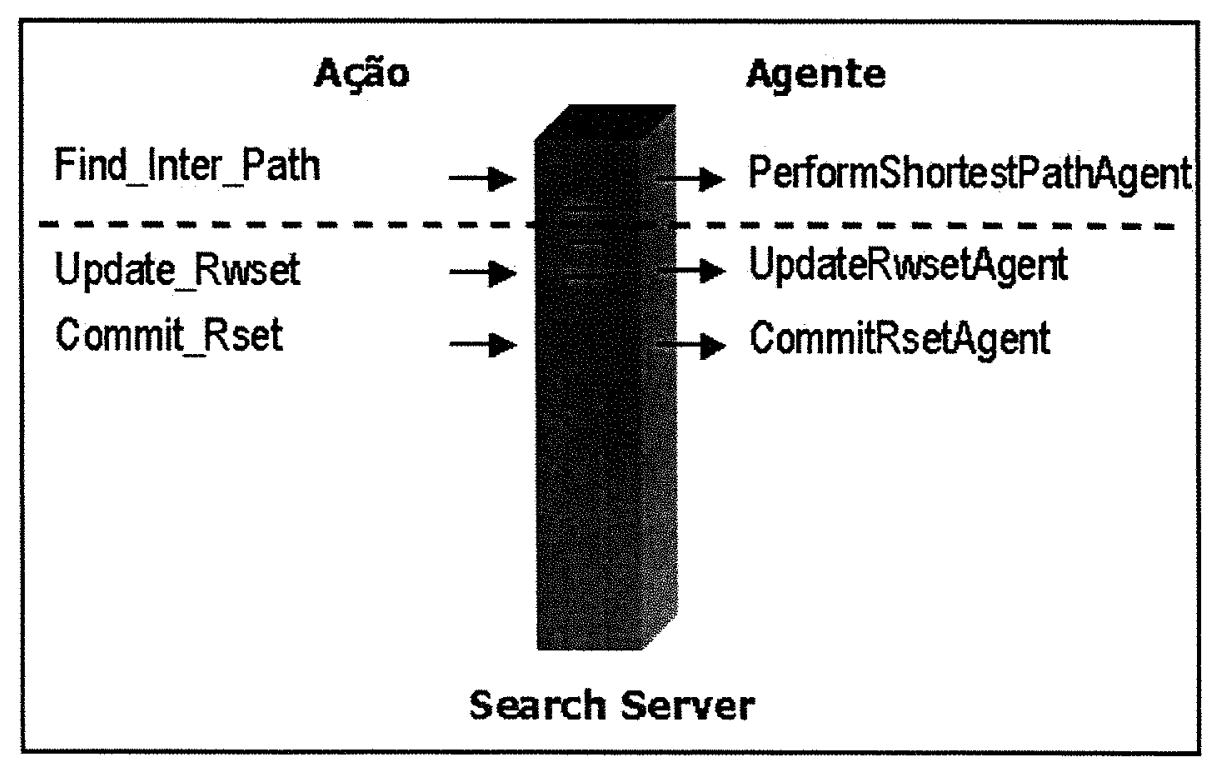

Figura 5.4: Relação de ações e agentes em servidores de busca. 


\section{$\mathrm{O}$ agente BaseServerRequestAgent}

O agente BaseServerRequestAgent é responsável por tratar a requisição cliente de um caminho de $\mathrm{X}$ a $\mathrm{Y}$. Para isso, é calculada a árvore de caminhos com raiz em $X$, com os dados do estado corrente do servidor $E B_{X}(\mathrm{k})$, Este agente implementa as funcionalidades do procedimento BuscaEB, conforme apresentado na seção 4.8.1.

Quando não há um caminho entre os pontos X e Y ou o caminho encontrado não apresenta um peso aceitável, o procedimento BuscaInterEB é executado. Esse procedimento escolhe um dos servidores de busca para realizar o processamento considerando-se as informações globais.

\section{O agente FindRset2YAgent}

Uma estação-base $E B_{Y}$ também pode executar o agente FindRset2YAgent, invocado remotamente por algum servidor de busca do sistema. Esse agente retorna os custos dos melhores caminhos dos pontos $r \in \operatorname{Raizes}\left(G_{Y}\right)$ a $Y$, a partir dos dados de $G_{Y}$, com estado igual ao valor passado na variável k. É utilizado o procedimento ConsultaPorticEB, anteriormente apresentado na seção 4.8 .1 .

\section{O agente RequestSubPathAgent}

Esse agente é requisitado por servidores de busca (durante a execução do procedimento BuscaSB, descrito no item 4.8.2), quando a solicitação cliente é por uma requisição de caminho global. Nesse caso, após o servidor de busca ter calculado o caminho inter-estações, é necessário solicitar a cada estação-base participante do caminho calculado o fornecimento de todos os pontos que compõem o subcaminho dentro de seu grafo. Essa ação é executada pelo agente RequestSubPathAgent.

\subsubsection{SSAgents para busca de caminhos}

\section{O agente PerformShortestPathAgent}

Um servidor de busca $S B_{j}$ executa o agente PerformShortestPathAgent para obter caminhos com os dados globais do sistema. Este agente implementa as funcionalidades do procedimento BuscaSB, executado pelos servidores de busca. Maiores detalhes desse procedimento podem ser encontrados na seção 4.8.2.

Para tanto, os servidores de busca $S B_{j}$ recebem uma mensagem da estação-base $E B_{X}$, com os pontos $\mathrm{X}$ e $\mathrm{Y}$, o tipo de requisição, o conjunto CustosX_ate_Raizes e o estado ( $\mathrm{k}$ ) que se deseja usar para o cálculo.

É calculado um caminho de X a Y, se existir, a partir do grafo $S G_{j}$, utilizando-se para tanto uma réplica temporária dos dados presentes na árvore-modelo com raiz $\operatorname{Origem}\left(G_{X}\right)$ e estado k, $M T_{X}^{k}$. Conforme foi explicado anteriormente, o grafo $S G_{j}$ é mantido por $S B_{j}$, com os dados 
dos conjuntos TabCustRaizes $\left(G_{i}\right)$, enviados pelas estações-base $B S_{i}$, durante os processos de atualização de estados.

Para realizar a busca de um caminho de $X$ a $Y$ em $S G_{j}$, são utilizados nós especiais de $S G_{j}$ para representar X e Y. O nó $\operatorname{Origem}\left(G_{X}\right)$ faz conexão com os vértices que descrevem o conjunto Raizes $\left(G_{X}\right)$. Os arcos que saem de $\operatorname{Origem}\left(G_{X}\right)$ e se ligam aos nós do conjunto Raizes $\left(G_{X}\right)$, têm seus pesos definidos de acordo com o conjunto CustosX_ate_Raizes enviado pela estação-base que solicitou o caminho, $E B_{X}$.

Analogamente, o nó Sorvedouro $\left(G_{Y}\right)$ se conecta aos vértices que descrevem o conjunto Raizes $\left(G_{Y}\right)$, cujos pesos dos arcos são definidos no conjunto CustosRaizes_ate_Y. O conjunto CustosRaizes_ate_Y é obtido pela chamada do agente FindRset2YAgent (descrito anteriormente) na estação que contém o nó $\mathrm{Y}\left(E B_{Y}\right)$.

As definições dos pesos dos arcos de Origem $\left(G_{X}\right)$ e Sorvedouro $\left(G_{Y}\right)$ são executadas pelo método updateGraphWithRWSet e podem ser descritas como segue: $S G_{j}$ mantém apenas 2 nós, Origem $\left(G_{i}\right)$ e Sorvedouro $\left(G_{i}\right)$, para cada conjunto Raizes $\left(G_{i}\right)$. Assim, caso $S B_{j}$ receba 2 solicitações de busca, de $X_{1}$ a $Y_{1}$ e de $X_{2}$ a $Y_{2}$, tais que $\left\{X_{1}, X_{2}\right\} \in E B_{w}$ e $\left\{Y_{1}, Y_{2}\right\} \in E B_{z}, S G_{j}$ se utiliza do mesmo nó $\operatorname{Origem}\left(G_{w}\right)$ para representar $X_{1}$ e $X_{2}$ e, analogamente, o mesmo nó Sorvedouro $\left(G_{z}\right)$ para representar $Y_{1}$ e $Y_{2}$, para realizar as buscas.

Dessa forma, o procedimento DynamSPT descrito em 4.8.2 permite obter um caminho de $\mathrm{X}$ a Y a partir da réplica da árvore-modelo $M T_{X}^{k}$, atualizando-se os arcos especiais com os pesos enviados nas mensagens CustosX_ate_Raizes e CustosRaizes_ate_Y e utilizando-se o algoritmo dinâmico descrito no Capítulo 3. Maiores detalhes podem ser encontrados no item 4.5.

$O$ resultado devolvido pelo agente PerformShortestPathAgent depende do tipo de requisição: se a requisição for local, é retornado o nó $R_{t}$ em Raizes $\left(G_{X}\right)$ que origina o melhor caminho conhecido para chegar em $\mathrm{Y}$ bem como o custo $C$ calculado para o caminho de $\mathrm{X}$ a $\mathrm{Y}$.

No caso de uma requisição do tipo Global, é devolvido o caminho completo P calculado de X até $\mathrm{Y}$. Nesse caso, após o servidor de busca obter a rota de X a Y, presente na árvore SPT, obtida com os dados de $S G_{j}$, o servidor de busca $S B_{j}$ necessita contactar cada uma das estações $E B_{i}$ que possuem um subcaminho $P_{i}$ de $\mathrm{P}$, visando obter a descrição completa dos nós que compõem $P_{i}$.

\subsubsection{BSAgents para atualização de estados}

\section{$\mathrm{O}$ agente UpdateTransactionAgent}

Conforme apresentado na seção 4.9, a atualização global do sistema é feita por uma estaçãobase coordenadora. Para tanto, após um intervalo de tempo ${ }^{6}$ a partir da última atualização do estado global, é disparado o agente UpdateTransactionAgent no coordenador, que é responsável por coordenar as tarefas de atualização do estado. Basicamente, este agente envia mensagens às estações-base e servidores de busca para que sejam calculados novos estados, envia mensagens para que os servidores realizem a ação de sedimentação do novo estado (commit), etc. Para o

\footnotetext{
${ }^{6}$ Esse intervalo é configurado no arquivo de propriedades da estação-base coordenadora
} 
cálculo de novos estados, atualização de árvores pórtico e árvores-modelo, os servidores executam agentes específicos, como por exemplo, o agente UpdateRsetAgent, descrito a seguir.

\section{O agente UpdateRsetAgent}

O agente UpdateRsetAgent é criado por uma estação-base, para tratar as mensagens $U p$ dateRset, enviadas pelo coordenador. Dentre as principais funcionalidades desse agente, destacase a atualização das árvores pórtico ou a criação delas (caso esteja sendo gerado o primeiro estado), bem como o envio do conjunto TabCustRaizes, gerado pela atualização das árvores pórtico, para a lista de servidores de busca do sistema. Assim que todos os servidores de busca devolvem a mensagem Received_Rwset, UpdateRsetAgent envia para o coordenador a mensagem Received_Rset. Para a atualização das árvores pórtico, os servidores de busca instanciam os agentes PTAgent que são processos (ThreadTask) a serem inseridos no gerenciador de processos ThreadTaskManager. Os agentes PTagent executam os algoritmos de busca estática para criação das árvores ou algoritmos dinâmicos para atualização. Maiores informações sobre as classe ThreadTask e ThreadTaskManager podem ser obtidas na seção 5.6 .8

\section{O agente CommitRsetAgent}

O agente CommitRsetAgent é instanciado por uma estação-base para tratar uma mensagem Commit_Rset $(k+1)$, enviada pelo coordenador. Dessa forma, a estação-base passará a utilizar as informações do estado $(k+1)$. Também este agente atualiza informações para que o agente UpdateDataLinkAgent (apresentado na próxima seção) passe a receber mensagens para atualizações de arcos e armazenar os novos valores para os arcos, indexados pelo estado $k+2$.

\section{O agente UpdateDataLinkAgent}

Conforme foi explicado anteriormente, o agente permite receber mensagens contendo listas de novos pesos para os arcos do subgrafo armazenado na estação-base $E B_{i}$. Os dados recebidos são sempre armazenados no próximo valor de $k$ (estado), para que na próxima atualização de estados, eles sejam efetivamente utilizados.

\subsubsection{SSAgents para atualização de estados}

\section{O agente UpdateRwsetAgent}

O agente UpdateRwsetAgent é criado por um servidor de busca, para tratar as mensagens UpdateRwset, enviadas pelo coordenador. Dentre as principais funcionalidades desse agente, destaca-se a atualização das árvores-modelo ou a criação delas (caso esteja sendo gerado o primeiro estado). Para a atualização das árvores-modelo, os servidores de busca instanciam os agentes MTAgent, que são processos (ThreadTask) a serem inseridos no gerenciador de processos ThreadTaskManager. Os agentes MTagent executam os algoritmos de busca estática para 
criação das árvores ou algoritmos dinâmicos para atualização. Maiores informações sobre as classe ThreadTask e ThreadTaskManager podem ser obtidas na seção 5.6.8 Assim que todas árvoresmodelo tenham sido atualizadas, UpdateRwsetAgent envia uma mensagem Received_Rwset para todas estações-base participantes da etapa de atualização.

\section{O agente CommitRwsetAgent}

O agente CommitRwsetAgent é instanciado por um servidor de busca para tratar uma mensagem Commit_Rwset $(k+1)$, enviada pelo coordenador. Dessa forma, o servidor de busca passará a utilizar as informações do estado $(k+1)$, enviada junto a mensagem Commit_Rwset, para realizar os processamentos de busca de caminhos.

\subsubsection{Classes de representação de domínios}

As classes de representação de domínios permitem que sejam identificados, por exemplo, quais os vértices que compõem o Conjunto Raízes de um dado servidor ou quais os vértices que constituem a área de cobertura da estação-base. Dentre as principais classes representantes de domínios, destacam-se as classes RootSet e ServerArea.

A classe RootSet permite que seja armazenada a descrição dos vértices que formam o Conjunto Raízes de uma dada estação-base. A classe ServerArea, por sua vez, possibilita o encapsulamento dos detalhes sobre quais os vértices que compõem a partição do domínio a ser controlada por uma dada estação.

\subsubsection{Classes de implementação de servidores}

As principais classes da arquitetura servidora são aquelas que implementam os servidores.

Todos os servidores da arquitetura proposta implementam a classe abstrata AbstractServer. Essa classe apresenta a lógica e estruturas de dados genéricas para os dois tipos de servidores propostos neste trabalho: estações-base e servidores de busca. Por exemplo, os servidores apresentam uma estrutura de dados descrevendo um grafo (classes AbstractGraph e Graph).

A classe AbstractServer apresenta o método abstrato processRequest, o qual precisa ser implementado por suas subclasses. Esse método recebe como parâmetro um objeto AbstractRequest, contendo a requisição a ser atendida pelo servidor. Essa classe apresenta métodos genéricos, como por exemplo, para realizar a conexão remota com outros servidores, realizar a remoção de estados antigos que não estão sendo mais utilizados ou particionar a mensagem enviada em várias partes.

As estações-base são implementadas pela classe BaseServer e os servidores de busca são implementados pela classe SearchServer. As classes BaseServer e SearchServer estendem a classe AbstractServer e, portanto, precisam possuir uma implementação concreta do método processRequest. Esse método realiza a associação entre solicitação e agente, ou seja, identifica para qual agente a solicitação deve ser encaminhada. 
A trecho de código mostrado a seguir exemplifica o método processRequest da classe BaseServer:

Listing 5.2: Exemplo do método processRequest

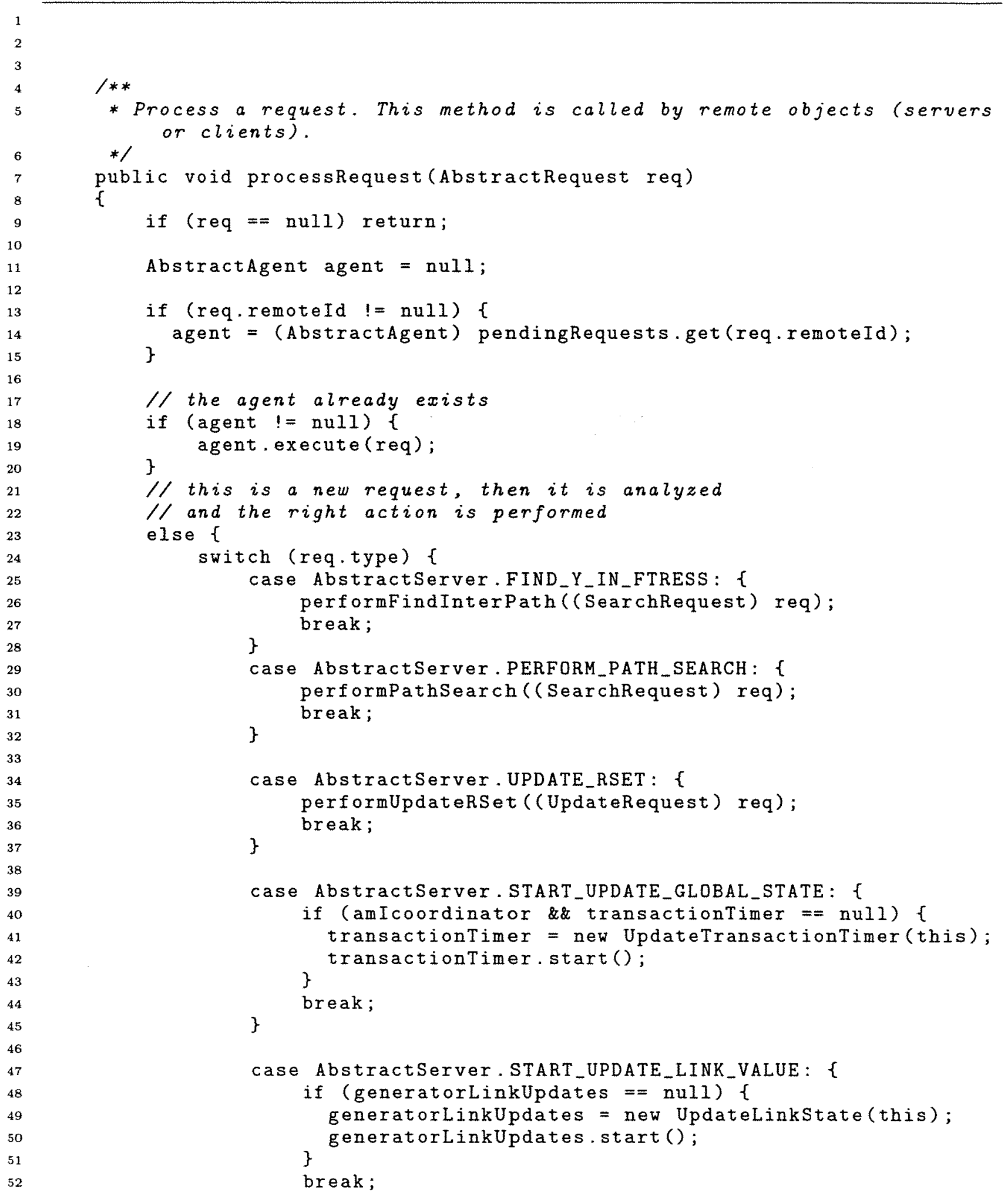




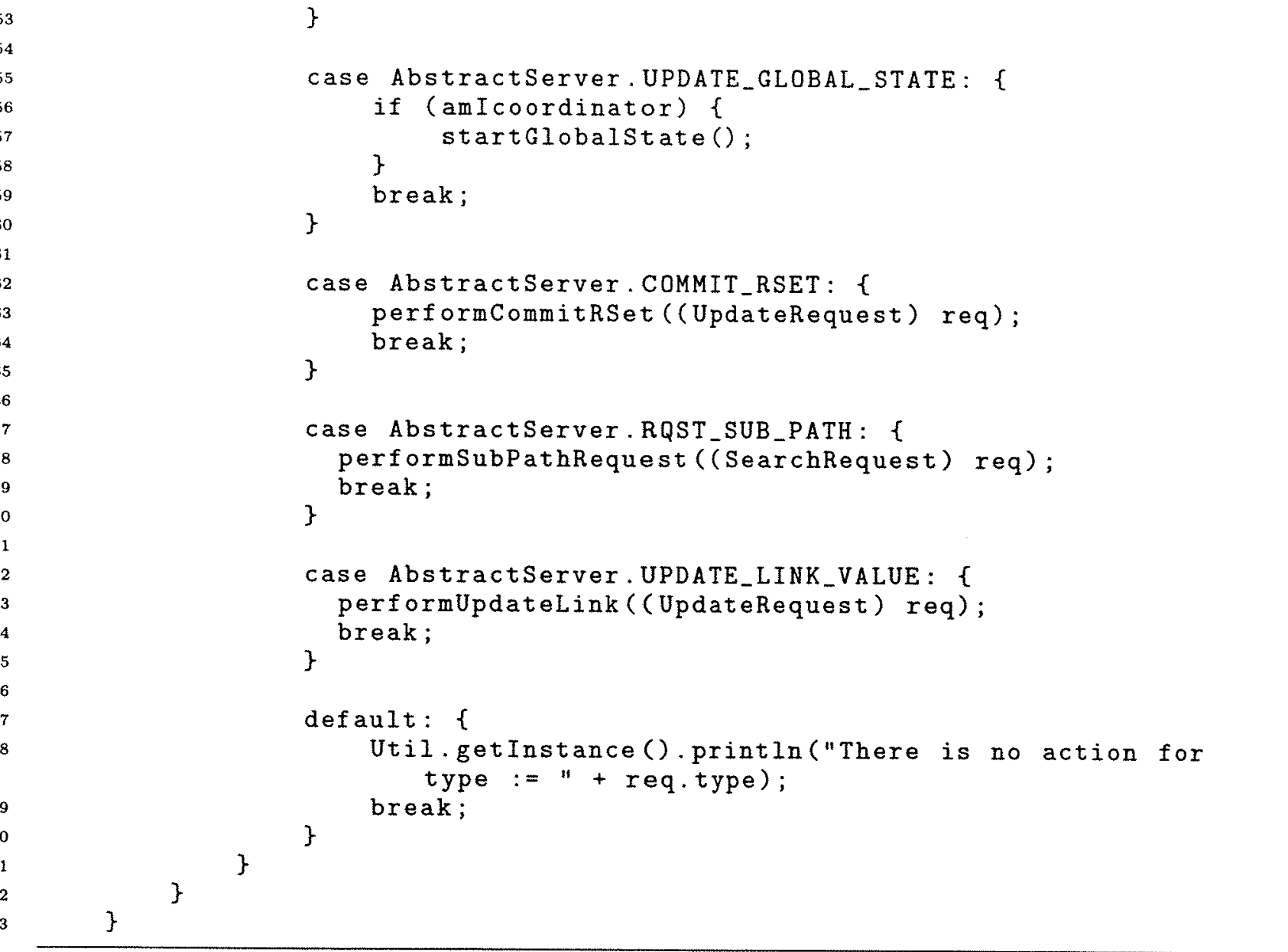

Assim que uma requisição chega à classe BaseServer, é verificado o identificador descrito no campo remoteId da solicitação. Este é procurado na lista de solicitações pendentes para verificar se a solicitação é o resultado de um pedido de algum agente previamente acionado. Se esse for o caso, a requisição é passada ao agente, para que o mesmo consiga continuar seu processamento. Para isso, é chamado o método execute do agente, passando-se a solicitação (objeto AbstractRequest), conforme descrito anteriormente. Assim que o agente finaliza sua execução, ele automaticamente solicita a sua retirada da lista de requisições pendentes do servidor.

Caso a solicitação não esteja na lista de requisições pendentes, é avaliado o campo type da requisição para que seja instanciado o agente (processo) correto para tratar a requisição.

Dentre uma das principais tarefas de atualização de estações-base, destaca-se a atualização das árvores pórtico. Para tanto, a classe BaseServer instancia um agente especial, PTAgent, que é um processo leve (thread). Dessa forma, BaseServer implementa a interface PTAgentListener a qual permite que um agente PTAgent informe ao servidor quando ele terminou o seu processamento.

Para evitar que muitos processos sejam executados simultaneamente, os objetos BaseServer apresentam uma instância da classe ThreadTaskManager, para permitir o controle fino do número mínimo e máximo de processos (classes ThreadTask) sendo executados ao mesmo tempo.

Analogamente para os servidores de busca, uma das principais tarefas da etapa de atualização 
é a atualização das árvores-modelo. Para tanto, a classe SearchServer instancia um agente especial, MTAgent, que é um processo (thread) responsável para realizar a atualização de uma árvore-modelo. SearchServer implementa a interface MTAgentListener e também utiliza uma instância da classe ThreadTaskManager.

\subsubsection{Classes adaptadoras}

As classes adaptadoras foram desenvolvidas para realizar a integração entre as classes principais da arquitetura servidora proposta e as classes geradas pelo compilador IDL. Conforme foi explicado anteriormente, o principal objetivo dessa ação é manter um certo grau de isolamento da arquitetura proposta e uma particular IDL, possibilitando assim que uma mudança na organização na IDL, não acarrete mudanças drásticas nas classes que descrevem a arquitetura servidora, mas apenas nas classes adaptadoras.

Conforme apresentado no item 5.6.1, as classes de solicitação apresentam classes que permitem a transformação de dados entre classes de solicitação servidoras e classes de solicitação da IDL.

Analogamente para os servidores de busca e estações-base, foram desenvolvidas as classes BaseServerAdapter e SearchServerAdapter que realizam a associação entre as classes que descrevem os servidores geradas pelo compilador IDL e as classes servidoras da arquitetura proposta.

As classes geradas pelo compilador IDL para mapear servidores de busca ou estações-base estendem a classe DgAbstractServerPOA. Dessa forma, as classes DgBaseServerPOA e DgSearchServerPOA estendem DgAbstractServerPOA e são as classes geradas pelo compilador IDL para mapear estações-base e servidores de busca, respectivamente.

A classe BaseServerAdapter estende DgBaseServerPOA e SearchServerAdapter estende DgSearchServerPOA.

\subsection{Remoção de estados}

Uma das tarefas de estações-base e servidores de busca é realizar a remoção de estados antigos, que não são mais utilizados. Os servidores da arquitetura utilizam uma política simples que, pode ser melhorada, de acordo com as necessidades. Basicamente, são removidas as informações de estados $\mathrm{E}$ tais que $E \leq k-x$, onde $\mathrm{k}$ indica o valor do estado atual e $\mathrm{x}$ é o valor indicado na propriedade dgraph. numpreservedstates, presente nos arquivos de configuração dos servidores. Maiores detalhes sobre os arquivos de configuração podem ser encontrados em A.2.

Assim que uma solicitação de busca de caminhos é devolvida ao cliente, o resultado do processamento para encontrar o caminho é removido pelos servidores. Na prática, a regra geral para remoção dos dados calculados durante uma busca de caminhos é a seguinte: assim que um agente é removido do seu servidor hospedeiro, o processamento gerado pela sua execução é removido, especialmente valores de distâncias de caminhos, que são mantidos nos grafos. Para realizar a remoção dos dados gerados por uma busca, é utilizado o identificador threadId da 
mesma.

Maiores detalhes podem ser encontrados no apêndice A ou na documentação do código implementado.

\subsection{Considerações gerais}

Este Capítulo apresentou detalhes de implementação do modelo proposto no Capítulo 4 . Conforme foi visto, CORBA foi a arquitetura para computação distribuída utilizada na implementação do modelo. A IDL definida na seção 5.3 foi especificada visando limitar a necessidade de grandes alterações, caso novas funcionalidades venham a ser incorporadas.

Para permitir vários processos executando algoritmos (por exemplo, de busca) na mesma estrutura de um grafo, foi desenvolvida uma biblioteca especial que permite acessos concorrentes, conforme descrito na seção 5.5. As classes servidoras apresentadas na seção 5.6 apresenta a arquitetura definida para a implementação de servidores do sistema. As classes que compõem a arquitetura servidoras foram classificadas em 5 grupos, de acordo com a funcionalidade: classes de solicitação (request), classes agentes (agents), classes de representação de domínios, classes de implementação de servidores e classes adaptadoras.

Em particular, conforme foi visto na seção 5.6.9, foram utilizadas classes adaptadoras [8] na implementação para possibilitar que as classes que compõem as camadas superiores da arquitetura não tenham interferência das classes que definem as camadas mais baixas. Essa abordagem é particularmente interessante, caso se deseje alterar, por exemplo, a arquitetura de computação distribuída usada, pois permite que a alteração seja transparente para as camadas superiores da arquitetura.

Toda ação que é desempenhada por um servidor do sistema é tratada por um agente 5.6.2. Os agentes são processos especiais (lightweight processes) que estendem a classe AbstractAgent. São exemplos de agentes, os agentes relacionados com ações de estações-base (BSAgents) e os agentes relacionados com ações desempenhadas em servidores de busca (SearchServers). 


\section{Capítulo 6}

\section{Testes}

Nesta seção são mostrados alguns resultados coletados em testes efetuados com a arquitetura implementada. Veremos comparações relativas à qualidade da solução, assim como testes de desempenho do sistema.

\subsection{Ambiente computacional}

Os testes foram realizados com os equipamentos disponíveis no Laboratório de Computação Paralela e Distribuída ${ }^{1}$, em máquinas Pentium II com $400 \mathrm{MHz}$ e $128 \mathrm{MB}$ de memória RAM, em sistema operacional Linux. A versão da linguagem Java utilizada foi o pacote JDK $1.3 .1^{2} \mathrm{e}$ o pacote CORBA usado foi o JacORB $1.4 .1^{3}$.

\subsection{Visão geral}

Os testes efetuados permitiram realizar comparações de desempenho com a arquitetura implementada, comparando-se os principais parâmetros envolvidos. Para tanto, foram realizados testes variando-se o Conjunto Raízes considerado, o grau, o número de nós, entre outros. Além disso, foi verificada a influência da porcentagem de arcos afetados, escalabilidade, bem como comparações entre algoritmos de busca dinâmicos e estáticos e testes de qualidade da solução encontrada. Também foram efetuadas execuções para observar o comportamento do sistema variando-se o número de clientes ativos. Os testes foram efetuados para vários conjuntos de servidores. As seções a seguir apresentarão os resultados das execuções realizadas com a arquitetura implementada.

Para os testes realizados, foi considerada a utilização do algoritmo estático de Dijkstra utilizando filas de prioridades e a versão dinâmica do algoritmo de Dijkstra com fila de prioridades

\footnotetext{
${ }^{1}$ http://www.lcpd.ime.usp.br/

${ }^{2}$ http://www.javasoft.com/

${ }^{3}$ http://www.jacorb.org
} 
usando o primeiro método incremental, conforme apresentado no Capítulo 3.

Deve-se ressaltar que os testes comparativos foram realizados com os mesmos conjuntos de dados. Esse é um aspecto importante, principalmente para os testes de qualidade de solução (descritos na seção 6.6), onde a principal preocupação foi a de comparar os valores de custos de caminhos obtidos variando-se os Conjuntos Raízes. Os valores médios apresentados neste capítulo foram obtidos considerando-se 5 repetições. Nesse caso, foi necessário calcular valores obtidos para caminhos considerando-se Conjuntos Raízes de tamanhos variáveis. Dessa forma, para realizar as comparações e cálculos de erros médios, foi imprescindível que as buscas fossem feitas em grafos idênticos (em estrutura e nos valores de pesos de arcos).

\subsection{Influência do Conjunto Raízes}

Um dos parâmetros mais importantes da arquitetura apresentada neste trabalho é o Conjunto Raízes. Dependendo do conjunto sendo considerado, o sistema pode ter um desempenho melhor ou pior. Por isso, foram realizados diversos testes em grafos particionados de diversas maneiras. Foram realizados testes para conjuntos variáveis de servidores, visando-se analisar o desempenho de ações de busca e atualização no sistema implementado.

Para os testes de verificação da influência do Conjunto Raízes no sistema, foram considerados grafos contendo aproximadamente 10000 nós, com grau 4. Os grafos foram particionados de diversas formas e armazenados em 1, 2, 3, 4 ou 5 estações-base, utilizando-se 1 servidor de busca. O motivo da escolha de grafos contendo 10000 nós é devido ao fato de que grafos com muito mais nós não poderem ser alocados em um único servidor com a infra-estutura disponível. Além disso, os testes para busca de caminhos desta etapa precisam também ser realizados em grafos alocados em uma única estação-base, para comparar o desempenho do algoritmo centralizado com o do distribuído.

Em geral, o comprimento atribuído às bordas das partições geradas nas execuções variaram entre 250 a 500 nós. Assume-se então que o número médio de nós nas bordas das partições é de aproximadamente 350 nós. Para as bordas fixadas, realizaram-se testes variando-se os Conjuntos Raízes entre $25 \%$ até $100 \%$ da borda considerada. Além disso, as execuções efetuadas consideraram que, em média, $50 \%$ dos arcos sofreram alterações de seus pesos, para serem processadas na próxima etapa de atualização. As variações de pesos de arcos são aleatórias, dentro de uma faixa definida.

As seções a seguir mostram os resultados dos testes avaliando a influência do Conjunto Raízes nas funções de atualização e busca.

\subsubsection{Atualização}

Os gráficos 6.1, 6.2, 6.3 e 6.4 apresentam os tempos para a atualização de estados para servidores de busca utilizando o algoritmo estático (SB-E), servidores de busca utilizando o algoritmo dinâmico (SB-D), estações-base utilizando o algoritmo estático (EB-E), estações-base utilizando 


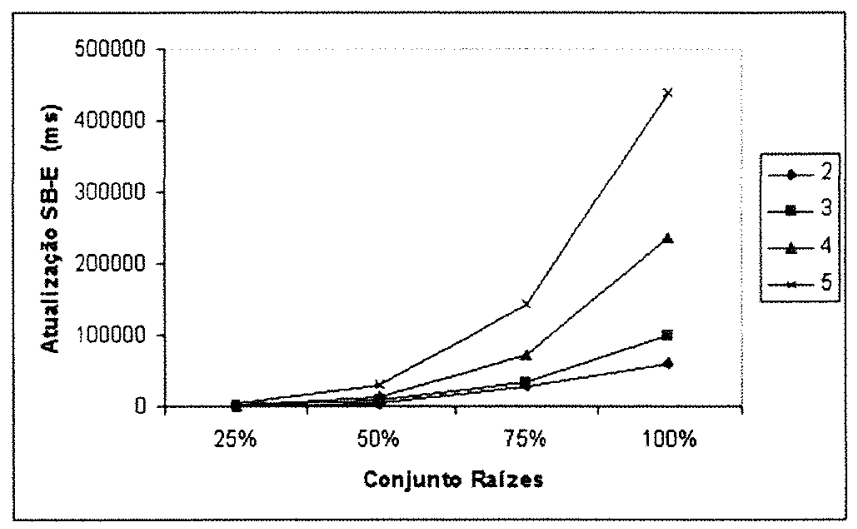

Figura 6.1: Atualização em servidores de busca utilizando o algoritmo estático

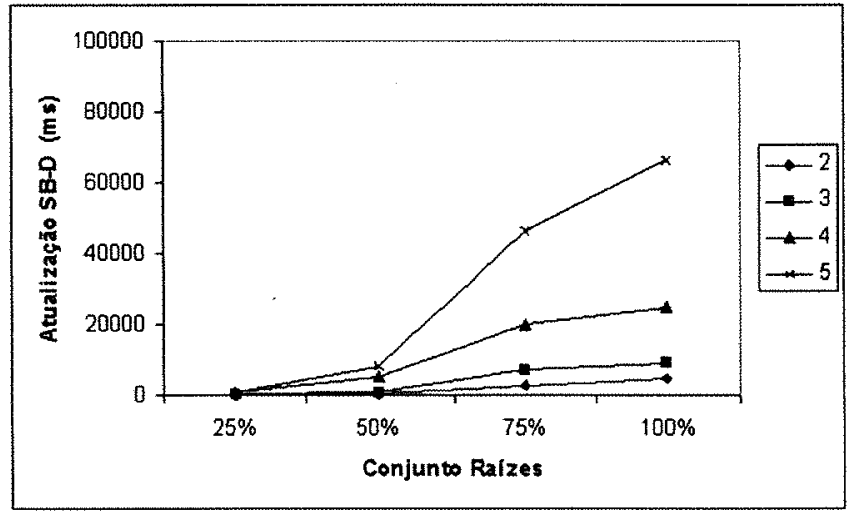

Figura 6.2: Atualização em servidores de busca utilizando o algoritmo dinâmico

o algoritmo dinâmico (EB-D), respectivamente, para grafos de tamanho 10000 particionados em $2,3,4$ e 5 estações-base. É interessante observar que os gráficos 6.1 e 6.2 não estão na mesma escala.

Os gráficos 6.5 e 6.6 apresentam comparações entre os tempos de atualização de estados usando o algoritmo estático e o dinâmico variando-se os tamanhos de Conjuntos Raízes, para grafos particionados em 2, 3, 4 e 5 estações. O gráfico 6.5 apresenta os resultados comparativos para a atualização de estados de estações-base e o gráfico 6.6 apresenta as comparações para os tempos de atualização de servidores de busca.

Os gráficos 6.1, 6.2, 6.3 e 6.4 permitem verificar que para Conjuntos Raízes de tamanhos pequenos, a variação do número de estações-base apresenta uma influência menor quando comparada a Conjuntos Raízes maiores. O gráfico 6.2 permite verificar que o uso do algoritmo dinâmico, em geral, melhora o desempenho comparativo para grafos particionados em 2, 3, $4 \mathrm{e}$ 5 estações-base. Em particular, para Conjuntos Raízes de tamanhos a partir de $50 \%$ da borda, observa-se que os tempos de atualização em servidores de busca para sistemas contendo um número maior de estações-base são significativamente maiores do que para sistemas com um número menor de estações-base. Isso ocorre pois, com o aumento de estações-base, há uma au- 


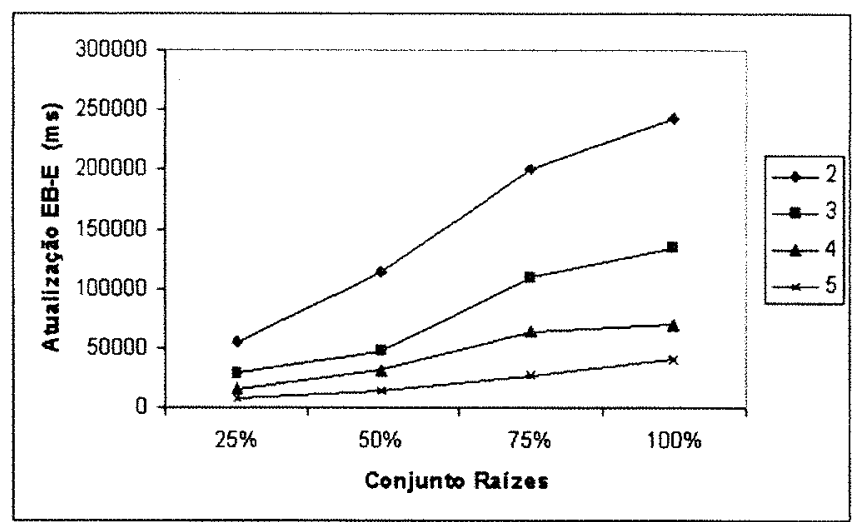

Figura 6.3: Atualização em estações-base utilizando o algoritmo estático

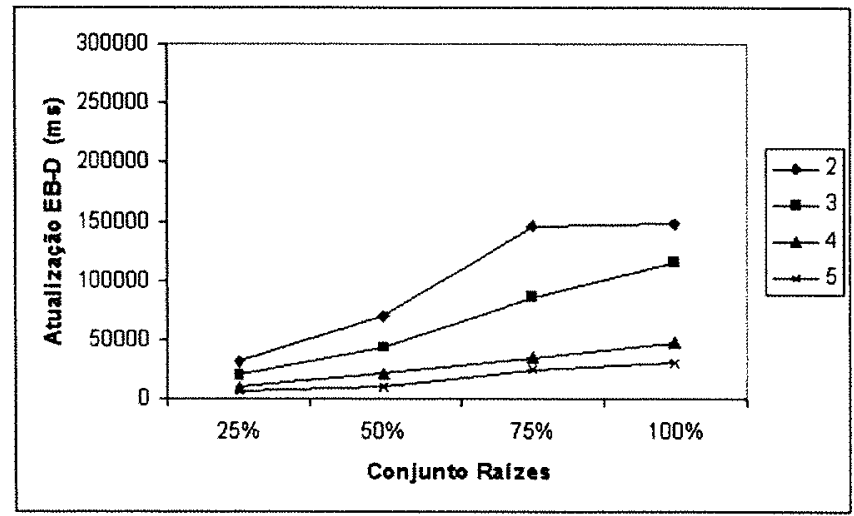

Figura 6.4: Atualização em estações-base utilizando o algoritmo dinâmico

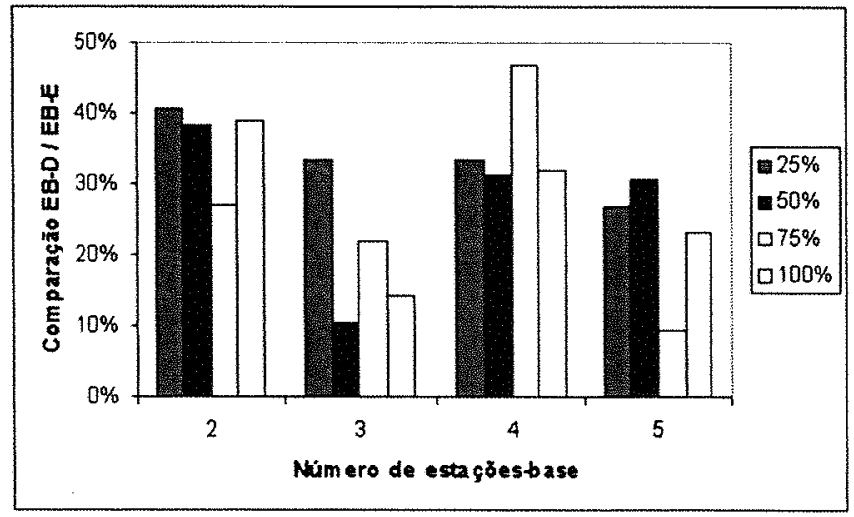

Figura 6.5: Comparação entre algoritmos durante a atualização de estações-base 


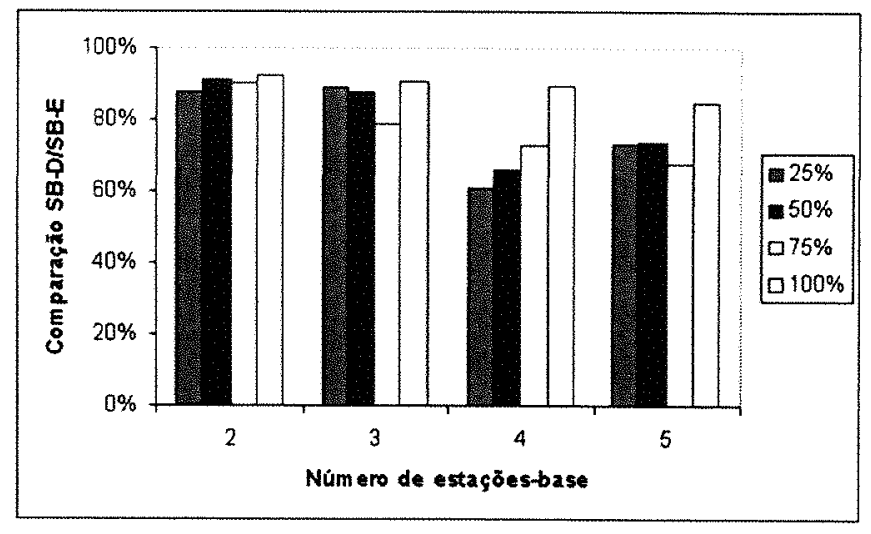

Figura 6.6: Comparação entre algoritmos durante a atualização de servidores de busca

mento no número de partições, gerando grafos SG (presentes nos servidores de busca) maiores. O gráfico 6.3 apresenta os tempos de atualização em estações-base usando o algoritmo estático. Por esse gráfico, é possivel verificar que os tempos de atualização são maiores para sistemas usando um número menor de partições do grafo representante do domínio de aplicação. Isso ocorre, pois o número menor de partições acarreta subgrafos maiores, o que ocasiona um tempo de processamento de atualização superior. O gráfico 6.4 apresenta os tempos de atualização em estações-base usando o algoritmo dinâmico. Por ele, é possível perceber que também para estações-base, o emprego desses algoritmos, em geral, apresenta resultados melhores quando comparados aos algoritmos estáticos.

É possível verificar também que o tamanho dos Conjuntos Raízes sendo usados influencia fortemente o desempenho do sistema. Em particular, é possível observar que os servidores de busca são mais sensíveis a mudanças no Conjunto Raízes, pois percebe-se que seus tempos de atualização sofrem um crescimento mais acentuado do que os tempos de atualização de estaçõesbase. Isso ocorre porque, com Conjuntos Raízes maiores, há um maior número de combinações possíveis entre nós, indicando um crescimento de tempo de ordem quadrática. Além disso, os gráficos 6.5 e 6.6 apresentam a vantagem da utilização do algoritmo dinâmico nas etapas de atualização do sistema. $O$ uso do algoritmo dinâmico em servidores de busca apresenta um desempenho comparativo (gráfico 6.6) superior ao desempenho comparativo mostrado para as estações-base (gráfico 6.5). Isso ocorre pois os grafos armazenados em servidores de busca são, em geral, menores em número de nós e com grau elevado. Esse corportamento foi descrito pelos autores do arcabouço proposto por Narváez et al. [18], onde são apresentadas execuções que mostram que à medida que o grau aumenta, a complexidade dos algoritmos diminui. Maiores detalhes estão na seção 9.5 de [18]. Deve-se ressaltar que a computação do estado inicial (0), necessita utilizar algoritmos estáticos, uma vez que os algoritmos dinâmicos assumem a préexistência de uma árvore de caminhos previamente calculada.

Os resultados apresentados indicam que o número de vértices nos Conjuntos Raízes tem grande importância e por isso, deve-se dar preferências a particionamentos que minimizem o número de vértices nas bordas.

Uma análise mais detalhada sobre a influência da distribuição no desempenho de atualizações 


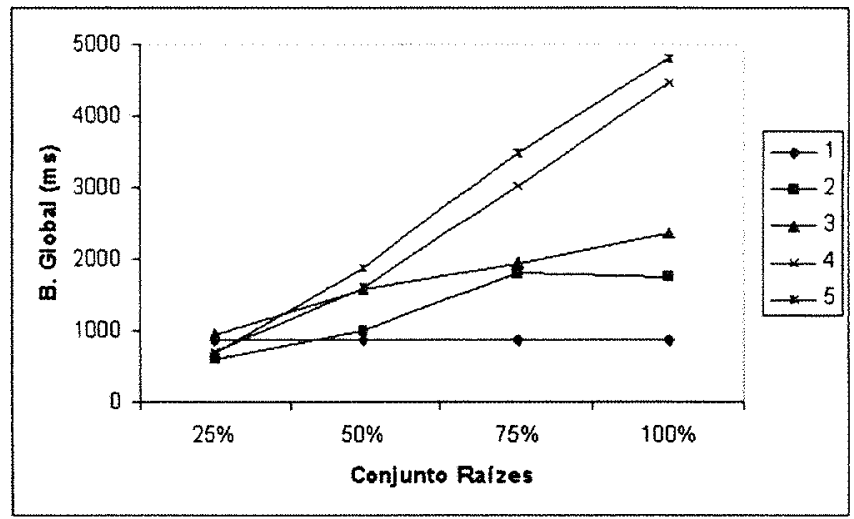

Figura 6.7: Busca globais em função dos Conjuntos Raízes

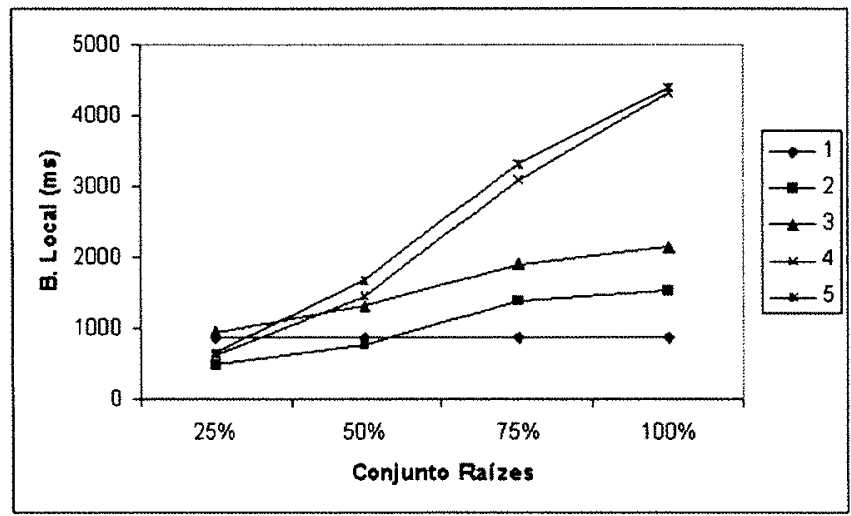

Figura 6.8: Buscas locais em função dos Conjuntos Raízes

de estados globais e buscas de caminhos serão dados na seção 6.9.

\subsubsection{Buscas de caminhos}

Os gráficos 6.7 e 6.8 apresentam resultados para a busca de caminhos globais e locais, respectivamente, para pares de vértices aleatórios (em geral, exigindo consulta ao servidor de busca), em função do Conjunto Raízes. O gráfico 6.9 apresenta uma comparação entre buscas locais e globais, apresentando a diferença média em porcentagem entre os dois tipos de buscas, para grafos particionados em 1, 2, 3, 4 e 5 estações-base, variando-se o Conjunto Raízes.

A análise dos dados apresentados mostra que para grafos particionados em 4 ou 5 estaçõesbase, apresentam-se tempos de busca razoavelmente maiores do que para partições usando 1, 2 ou 3 estações. Isso ocorre pois à medida que se aumenta o número de partições do domínio, imediatamente torna-se necessário aumentar o número de Conjuntos Raízes (um para cada partição), o que acaba aumentando o número de vértices e de arcos nos grafos $\mathrm{SG}$, presentes nos servidores de busca. Para os testes realizados, observou-se que a busca global leva, aproximadamente, $10 \%$ a mais de tempo, para ser realizada, quando comparada aos tempos médios de buscas locais. 


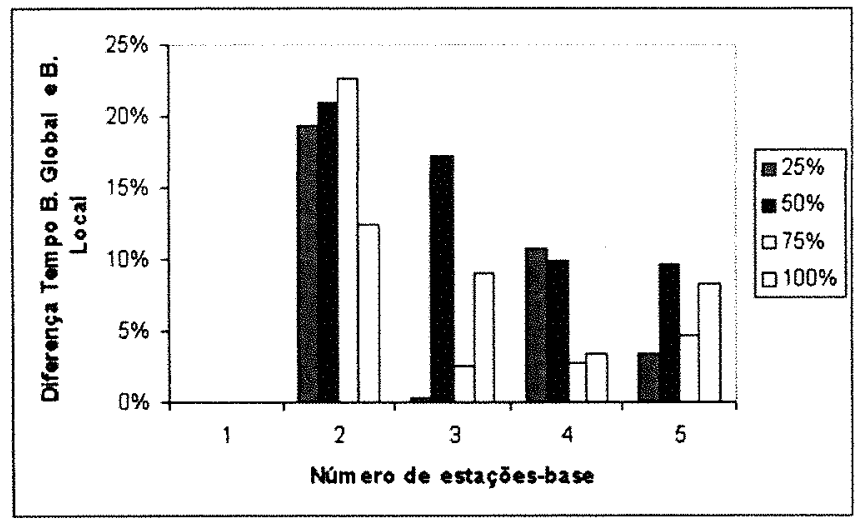

Figura 6.9: Comparações entre buscas locais e buscas globais

Conforme pode ser visto através dos gráficos, o tamanho dos Conjuntos Raízes usados é um importante fator no desempenho das funções de busca do sistema. Por exemplo, com os dados apresentados, buscas distribuídas com Conjuntos Raízes contendo cerca de 500 nós (100\%), as buscas distribuídas levam entre 2 e 5 vezes o tempo de buscas centralizadas.

\subsection{Arcos afetados}

Foram realizadas execuções para avaliar a influência do número de arcos afetados durante as etapas de atualização do sistema. Para tanto, foram feitos diversos testes com grafos particionados em 2, 3, 4 e 5 estações-base. Para estes testes, o Conjunto Raízes foi fixado em $50 \%$ e realizaram-se testes com grafos contendo aproximadamente 10000 nós, com grau 4. Em geral, o comprimento atribuído às bordas das partições geradas nas execuções foi de 500 nós.

Com essa infra-estrutura, foram realizadas execuções considerando-se que $25 \%, 50 \%, 75 \%$ e $100 \%$ dos arcos tiveram seus pesos alterados, desde a última atualização. Os valores dos pesos foram modificados aleatoriamente, dentro de um intervalo estabelecido. Os resultados dos testes podem ser vistos nos gráficos $6.10,6.11,6.12$ e 6.13. Eles apresentam os resultados das médias de tempos para testes de atualização de estados para servidores de busca usando o algoritmo estático (SB-E), para servidores de busca usando algoritmo dinâmico (SB-D), para estaçõesbase usando algoritmo estático (EB-E) e para estações-base usando algoritmo dinâmico (EB-D), respectivamente.

Conforme pode ser visto, aparentemente para os dados testados, o número de arcos afetados não apresenta uma influência significativa no modelo. Um destaque especial deve ser dado para os resultados das execuções envolvendo algoritmos dinâmicos, uma vez que elas utilizam os algoritmos descritos em A.1, os quais foram desenvolvidos com o cuidado especial para que, independente do número de arcos afetados (incrementos ou decrementos), eles executem um número fixo de instruções, dependendo apenas da natureza do grafo. 


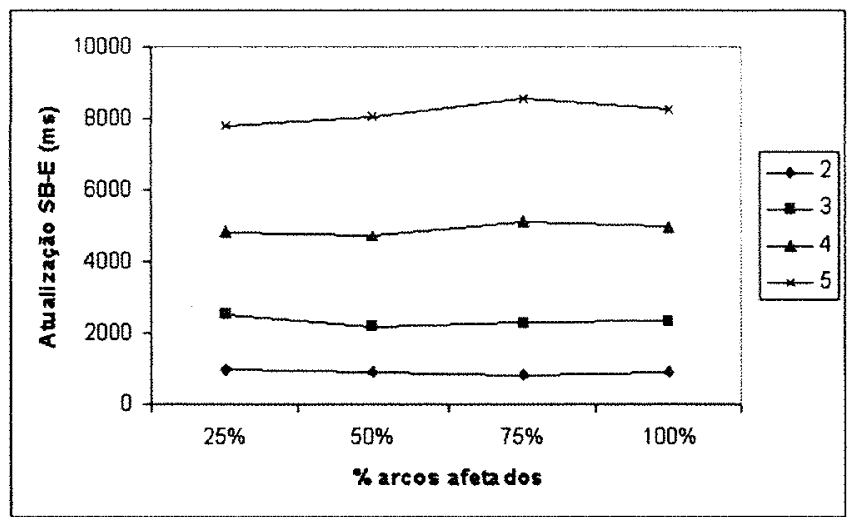

Figura 6.10: Variação de arcos afetados para servidores de busca usando o algoritmo estático

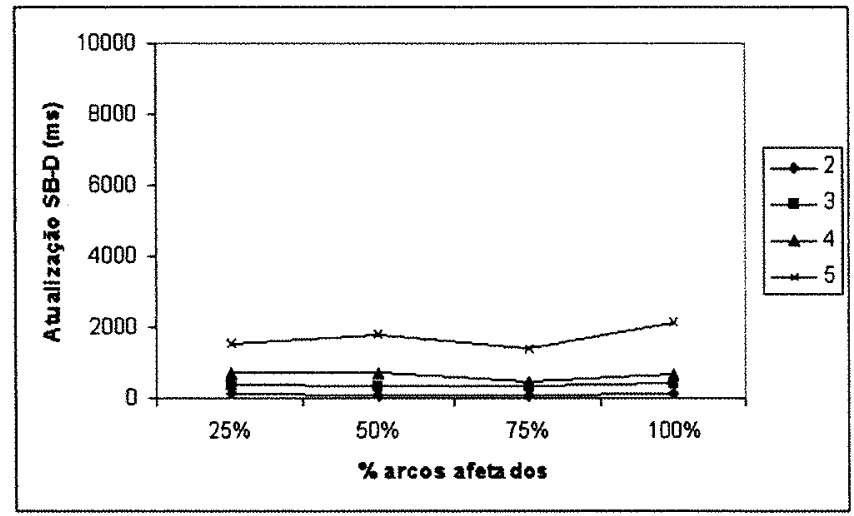

Figura 6.11: Variação de arcos afetados para servidores de busca usando o algoritmo dinâmico

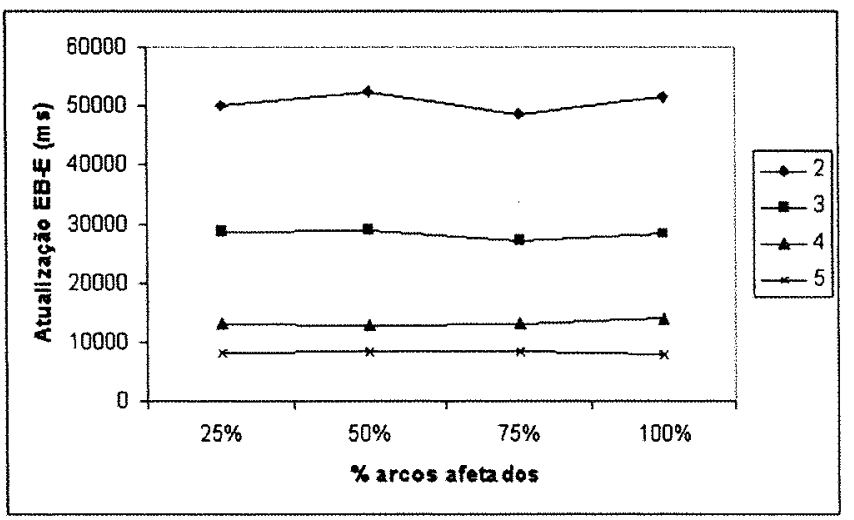

Figura 6.12: Variação de arcos afetados para estações-base usando o algoritmo estático 


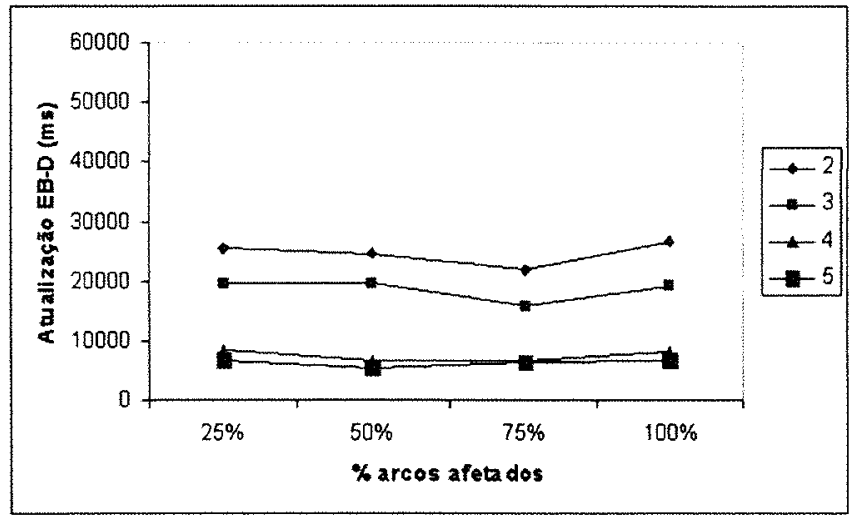

Figura 6.13: Variação de arcos afetados para estações-base usando o algoritmo dinâmico

\subsection{Influência do grau}

Foram realizados testes para avaliar a influência do grau dos grafos na atualização do sistema e buscas de caminhos.

Foram feitos testes com grafos particionados em 1, 3 e 5 estações-base. Para estes testes, os Conjuntos Raízes foram fixados em $30 \%$ e realizaram-se testes com grafos contendo aproximadamente 10000 nós. Em geral, o comprimento atribuído às bordas das partições geradas nas execuções foi de 500 nós. A taxa de arcos afetados foi fixada em $50 \%$.

Com essa infra-estrutura, foram realizadas execuções com grafos possuindo arcos com graus variando no intervalo de 2 a 8 . Os resultados das execuções podem ser vistos nos gráficos 6.14 , 6.15 e 6.16 .

O gráfico 6.14 apresenta valores médios de 50 buscas locais (conforme explicado anteriormente, uma busca local pode invocar uma chamada a um servidor de busca) de caminhos aleatórios, variando-se o grau dos grafos, particionados em 1, 3 e 5 estações-base.

O gráfico 6.15 apresenta as médias de tempos para testes de atualização de estados para servidores de busca usando algoritmo estático (SB-E) e para servidores de busca usando algoritmo dinâmico (SB-D). Os grafos usados foram particionados em 3 ou 5 estações. Neste caso, SB-3$\mathrm{D}$ representa os valores obtidos para a atualização de servidores de busca (SB) utilizando o algoritmo dinâmico, com grafos particionados em 3 estações-base, SB-3-E representa os valores obtidos para a atualização de servidores de busca (SB) utilizando o algoritmo estático, com grafos particionados em 3 estações-base. O mesmo raciocínio pode ser seguido para 5 estações

O gráfico 6.16 apresenta as médias de tempos para testes de atualização de estados para estações-base usando algoritmo estático (EB-E) e para estações-base usando algoritmo dinâmico (EB-D). Os grafos usados foram particionados em 3 ou 5 estações. Neste caso, EB-3-D representa os valores obtidos para a atualização de estações-base (EB) utilizando o algoritmo dinâmico, com grafos particionados em 3 estações-base, EB-3-E representa os valores obtidos para a atualização de estações-base (EB) utilizando o algoritmo estático, com grafos particionados em 3 estaçõesbase. Um raciocínio análogo pode ser seguido para 5 estações. 
Conforme pode ser visto pelo gráfico 6.14, para os dados testados, verificou-se que a variação crescente do grau ocasiona um aumento nos tempos de atualização mais nítido em sistemas com 1 estação-base (centralizados). Para sistemas contendo 3 ou 5 estações-base, pode ser observado que o crescimento é bem menos acentuado. Isso pode ser explicado pois para sistemas com 3 ou 5 estações-base, em geral, as buscas exigiam consultas aos servidores de busca, os quais utilizam o algoritmo dinâmico para atualizar a árvore-modelo necessária para calcular o caminho solicitado. Conforme descrito em [18], o arcabouço dinâmico proposto por Narváez et al. apresenta uma diminuição de complexidade em função do aumento do grau do grafo. Entretanto, essa tendência de diminuição não fica nítida para os dados mostrados no gráfico 6.14: apenas é verificado que o crescimento é menor para sistemas usando 3 ou 5 estações-base. Isso ocorre pois possivelmente os graus testados não são muito altos e também porque os procedimentos de busca representam dois tipos de algoritmos: nas estações-base que recebem a solicitação, é executado o algoritmo estático e as requisições de caminhos em servidores de busca usam o algoritmo dinâmico. Deve ser observado que nesses tipos de sistemas, a busca é realizada essencialmente por algoritmos estáticos.

Em relação ao gráfico 6.15, verifica-se comparativamente que os tempos de atualização em servidores de busca usando algoritmos estáticos são superiores aos tempos de atualização usando o algoritmo dinâmico. Em particular, o gráfico apresenta que para servidores de busca de sistemas com 5 estações-base com o algoritmo estático, houve a maior taxa de crescimento, em função do aumento de grau. O gráfico 6.16 também apresenta o fato de que o aumento de grau ocasiona um aumento nos tempos de atualização de estações-base maior para testes usando o algoritmo estático. Conforme explicado anteriormente, segundo [18], o aumento do grau acarreta. a diminuição da complexidade do algoritmo dinâmico. Essa tendência não ficou muito nítida para os testes realizados, possivelmente porque os graus usados nos testes não foram muito altos. Entretanto, para os testes realizados com servidores de buscas e estações-base (6.15 e 6.16, respectivamente) usando sistemas com 5 subgrafos e o algoritmo dinâmico, percebe-se que, com o crescimento do grau, há uma diminuição sutil nos tempos de atualização.

\subsection{Qualidade da solução}

Foram realizadas execuções para avaliar a qualidade da solução para buscas de caminhos, em função dos Conjuntos Raízes considerados.

Foram feitos testes com grafos particionados em 3, 4 e 5 estações-base. Para estes testes, os tamanhos dos Conjuntos Raízes foram fixados em 50\% dos tamanhos totais e realizaram-se execuções com grafos contendo aproximadamente 10000 nós. Em geral, o tamanho atribuído às bordas das partições geradas nos testes variou entre 300 e 500 nós. O grau dos grafos testados foi fixado em 4.

Com essa infra-estrutura, foram realizados testes com Conjuntos Raízes variando entre $25 \%$ até $75 \%$. Os resultados dos testes podem ser vistos no gráfico 6.17.

Os valores obtidos são os resultados das médias de erros calculadas para 500 buscas de diversos caminhos nos grafos testados, comparando-se sempre com o valor correto. Assume-se que o valor 


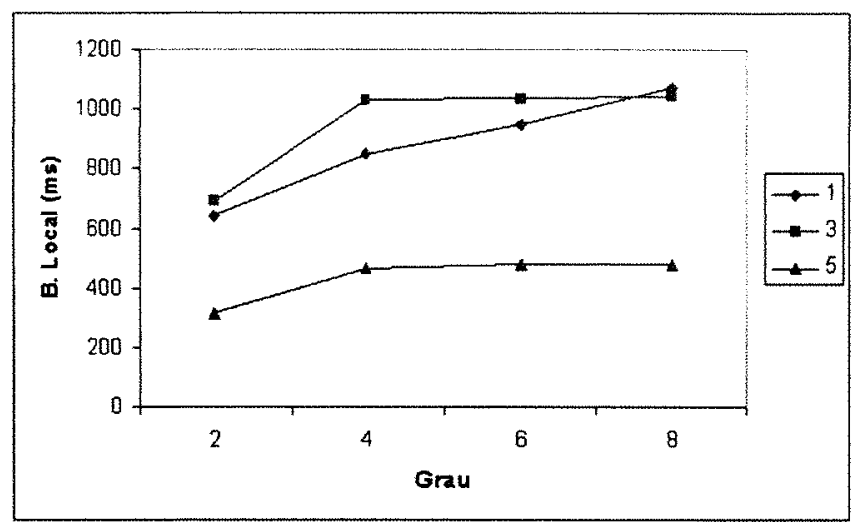

Figura 6.14: Buscas locais de caminhos em sistemas em função do grau

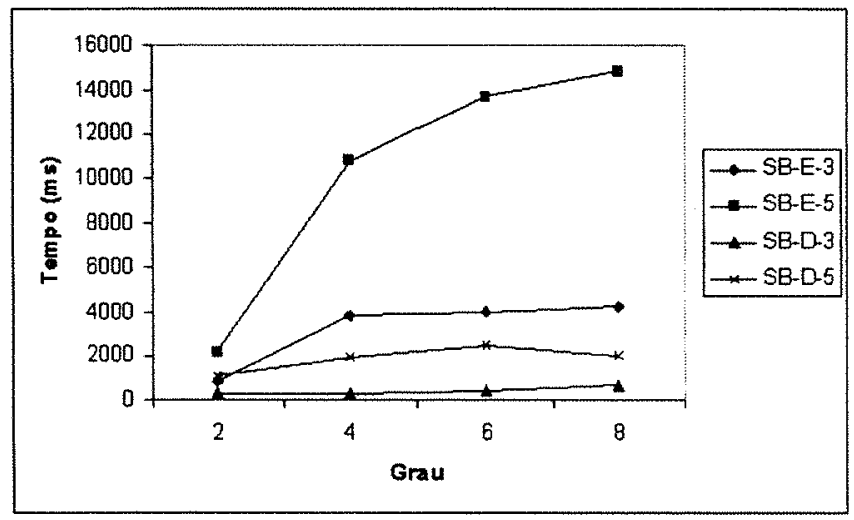

Figura 6.15: Atualização de servidores de busca em função do grau

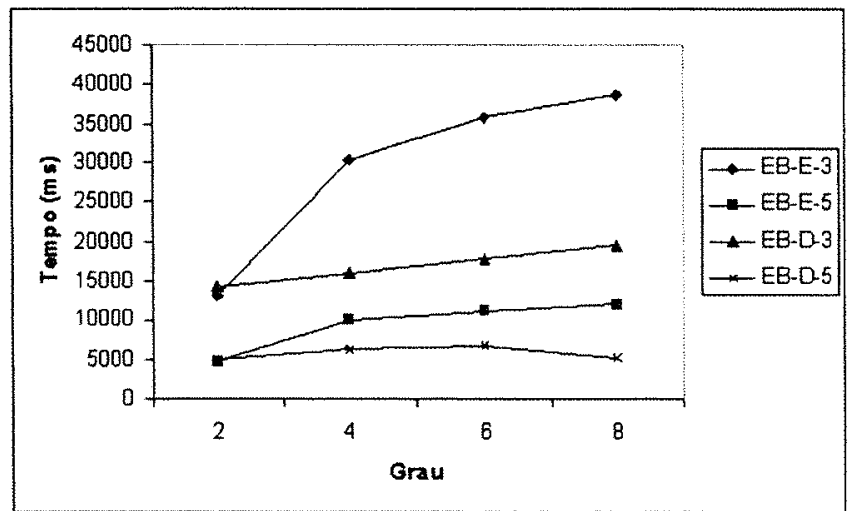

Figura 6.16: Atualização de estações-base em função do grau 


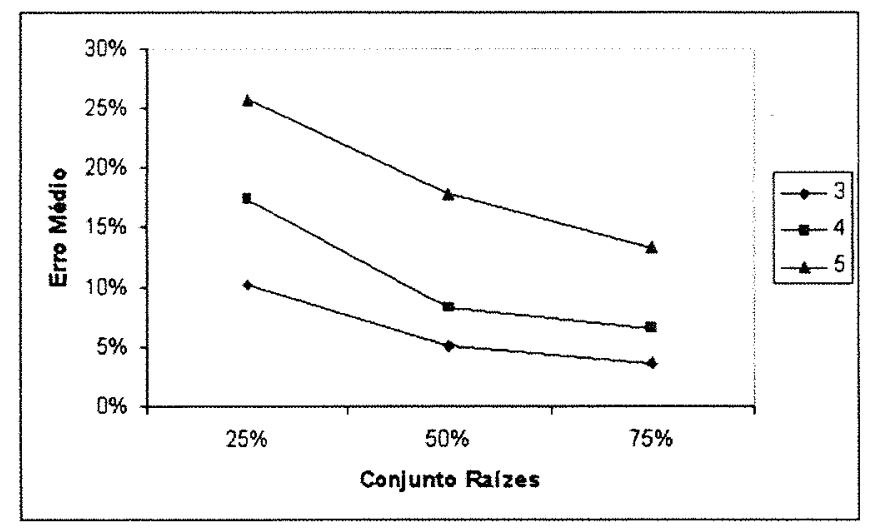

Figura 6.17: Qualidade da solução variando-se os Conjuntos Raízes

correto é aquele calculado para cenários utilizando Conjuntos Raízes iguais a 100\%. Na realidade, primeiramente as buscas por caminhos foram testadas utilizando Conjuntos Raízes iguais a $100 \%$. Depois, os mesmos grafos e valores de pesos de arcos foram utilizados para realizar as mesmas buscas, considerando-se Conjuntos Raízes variando entre $25 \%$ e $75 \%$. Deve-se ressaltar que os testes procuraram utilizar uma distribuição uniforme de nós na borda para formar os Conjuntos Raízes, evitando uma concentração grande de nós para poucas partes da borda e uma carência de nós em outras, o que poderia ocasionar grandes contrastes nas soluções encontradas.

Conforme pode ser visto no gráfico apresentado, à medida que são considerados valores maiores para os Conjuntos Raízes, o erro médio associado às soluções encontradas diminui. $\mathrm{O}$ assunto de controle de qualidade de solução é bastante importante e abre possibilidades para inúmeras políticas para tentar melhorar o resultado obtido, por exemplo, obter interpolações entre nós vizinhos, manter uma distribuição equilibrada de nós da borda, para os Conjuntos Raízes considerados, entre outras.

\subsection{Desempenho em função do tamanho do grafo de domínio}

Foram realizadas execuções para avaliar a escalabilidade e desempenho do sistema em função do tamanho do grafo sendo utilizado.

Foram feitos testes com grafos particionados em 1,2, 3, 4 e 5 estações-base. Cada estaçãobase armazenou os maiores gráficos que podiam ser alocados em memória sem problemas de falta de memória, considerando a infra-estrutura computacional utilizada. Definiu-se que cada estação-base armazenaria um grafo com 10000 nós e grau aproximadamente 4, isto é, contendo aproximadamente 40000 arcos. Dessa forma, os testes abrangeram grafos de 10000 a 50000 nós e, de 40000 a 200000 arcos, aproximadamente. Para estes testes, os Conjuntos Raízes foram fixados em 50\%. Em geral, o comprimento atribuído às bordas das partições geradas nas execuções foi entre 400 e 500 nós.

Os resultados dos testes podem ser vistos nos gráficos $6.18,6.19$ e 6.20. O objetivo destas execuções foi justamente ver o comportamento do sistema considerando-se grafos de dimensões 


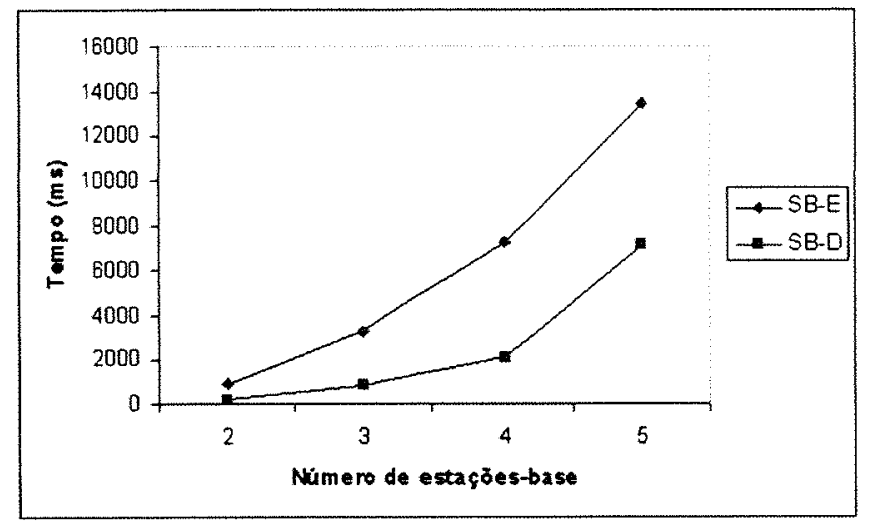

Figura 6.18: Atualização em servidores de busca em função do tipo de algoritmo

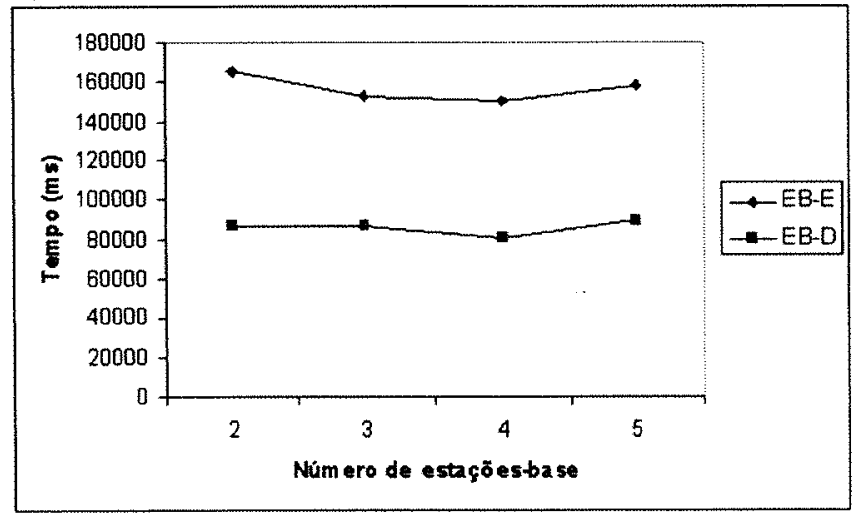

Figura 6.19: Atualização em estações-base em função do tipo de algoritmo

maiores.

Os gráficos 6.18 e 6.19 apresentam os tempos médios de atualização em servidores de busca e estações-base, respectivamente. Percebe-se que o crescimento de tempos de atualização em servidores de busca é mais acentuado, justamente pelo fato de que com o crescimento do número de estações-base, há um maior número de Conjuntos Raízes. Os tempos de atualização em estações-base permanecem aproximadamente constantes. Isso ocorre pois os tamanhos de seus subgrafos e Conjuntos Raízes não foram alterados.

Por outro lado, pode ser visto pelos gráficos que os tempos de atualização em estações-base são maiores do que em servidores de busca. Isso pode ser explicado porque, em geral, as estações-base apresentam um número muito maior de árvores para atualizar (cujas raízes estão nos respectivos Conjuntos Raízes) do que em servidores de busca, os quais precisam atualizar apenas as árvoresmodelo. Em geral, o número de árvores-modelo é igual ao número de partições, o qual é muito menor do que os tamanhos de Conjuntos Raízes. Além disso, conforme explicado na seção 6.3, é apresentado em [18] que à medida que o grau aumenta, a complexidade do algoritmo diminui: em geral, os grafos armazenados em servidores de busca apresentam um grau muito superior ao grau de nós presentes em estações-base. Um outro motivo para o fato observado é que os 


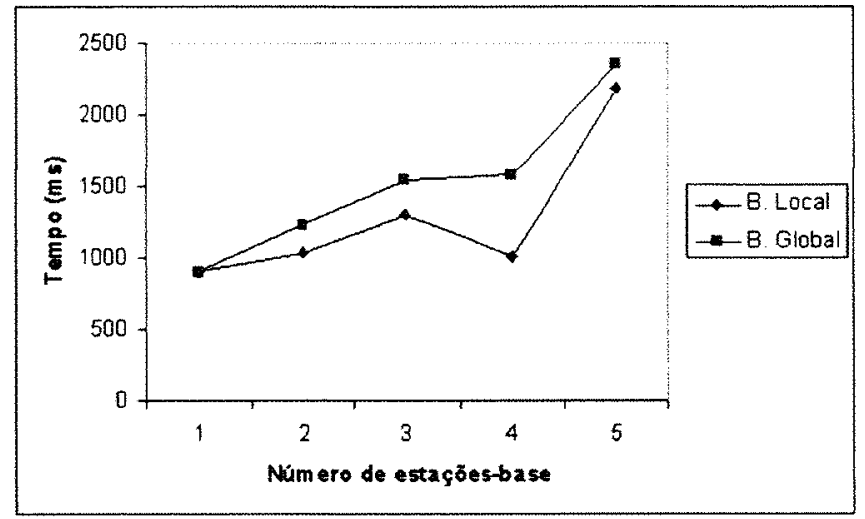

Figura 6.20: Desempenho de buscas de caminhos globais e locais

próprios grafos armazenados em servidores de busca apresentam um número inferior de nós quando comparados com os subgrafos armazenados em estações-base.

O gráfico 6.20 apresenta os resultados de busca de caminhos locais e globais para vários pares de vértices dos grafos considerados, em geral, escolheu-se caminhos inter-domínios, ou seja, que exigiam consulta aos servidores de busca. Como pode ser observado, os tempos de busca ficaram entre $1000 \mathrm{~ms}$ e $2500 \mathrm{~ms}$ para os dados testados.

\subsection{Número de acessos de clientes}

Foram efetuados testes para avaliar o desempenho das funções de busca em função do número de clientes ativos. Para tanto, os comportamentos de sistemas variando-se o número de estaçõesbase e também o número de servidores de busca foram observados.

Os testes efetuados utilizaram grafos contendo aproximadamente 10000 nós com grau 4, em média. A taxa de arcos que tiveram os pesos alterados (desde a última atualização realizada) foi de $50 \%$ em média e foram geradas partições de forma que os subgrafos apresentassem bordas de 100 a 300 nós, considerando-se Conjuntos Raízes de 70\%. Com esses ambientes foram realizadas buscas locais aleatórias. Em geral, os caminhos solicitados exigiam o uso de servidores de busca.

O gráfico 6.21 apresenta os resultados de tempos médios de buscas em sistemas utilizando-se um servidor de busca e 1, 2 ou 3 estações-base. O gráfico 6.22 apresenta os resultados de tempos médios de busca em sistemas contendo 2 estações-base e variando-se o número de servidores de busca entre 1 e 2. Para os testes efetuados, os números de acessos de clientes ativos variaram de 100 a 1400. Para os testes, definiu-se que 5000 ms seria o máximo tempo de resposta médio aceitável.

O gráfico 6.21 mostra que sistemas centralizados apresentam um limite não muito alto para o número de clientes ativos no sistema. Conforme pode ser visto no gráfico 6.21, um sistema contendo o grafo de domínio totalmente inserido em um servidor (centralizado) apresenta um limite de clientes ativos: para os testes realizados, o número máximo de clientes em sistemas 


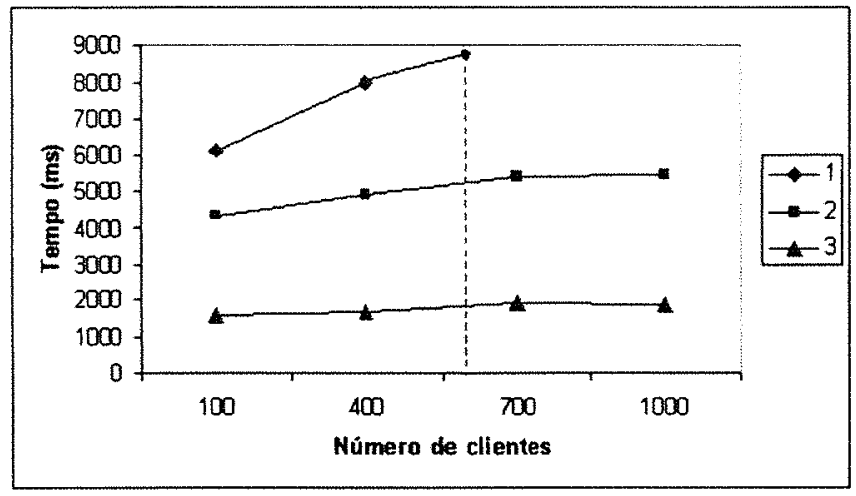

Figura 6.21: Tempos de buscas em função do número de clientes variando-se o número de estações-base

centralizados foi de 573 clientes, em média. Considerando-se que o tempo médio de resposta aceitável para o cálculo de caminhos é de até 5000 ms, o número máximo de clientes em sistemas centralizados foi de aproximadamente 50 clientes. Pelo gráfico 6.21 observa-se que, as mesmas buscas, ao serem efetuadas em sistemas distribuídos, (com 2 ou 3 estações-base) apresentaram um número superior de clientes ativos, considerando-se o máximo tempo de resposta aceitável. Em particular, sistemas contendo 3 estações-base apresentaram o melhor desempenho.

Apesar do fato de o gráfico 6.21 apresentar as vantagens de sistemas distribuídos para o número de acesso de clientes ativos, os testes foram realizados usando apenas 1 servidor de busca. Entretanto o modelo proposto no Capítulo 4 permite o uso de múltiplos servidores de busca. Dessa forma, o gráfico 6.22 apresenta dados para sistemas contendo 1 ou 2 servidores de busca, mantendo-se fixo o número de estações-base em 2 . Os testes usando 2 servidores de busca foram definidos de forma que cada estação-base acessasse exclusivamente um dado servidor de busca para solicitar os caminhos, ou seja, a estação-base $E B_{i}$ usa o servidor de busca $S B_{i}$, $i=1,2$. Os dados apresentados no gráfico 6.22 mostram os tempos médios obtidos para buscas do tipo local, cujos caminhos solicitados exigiam acesso aos servidores de busca. Com os dados apresentados, verifica-se que os sistemas contendo mais servidores de busca apresentam um limite de acessos maior, considerando-se um tempo médio de resposta de no máximo $5000 \mathrm{~ms}$.

\subsection{Considerações gerais}

Analisando os diversos resultados obtidos, observa-se que a variação dos Conjuntos Raízes tem uma grande influência no desempenho dos tempos de atualização e busca do sistema, conforme mostrado na seção 6.3.

Além disso, a seção 6.6 apresentou que existe um compromisso claro entre a variação de tamanho dos Conjuntos Raízes usados e a qualidade da solução obtida. Para melhorar a qualidade das soluções para Conjuntos Raízes com tamanhos inferiores aos tamanhos das bordas, poderiam ser utilizadas técnicas auxiliares, como por exemplo, realizar a interpolação de dados ou melhorar a distribuição de nós nos Conjuntos Raízes selecionados. 


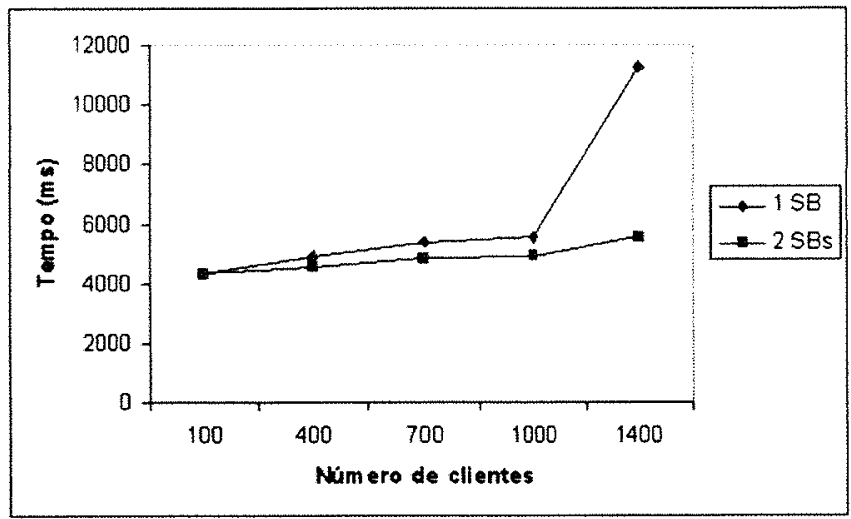

Figura 6.22: Tempos de buscas em função do número de clientes variando-se o número de servidores de busca

A figura 6.23 apresenta os resultados observados de testes efetuados para obter o tempo total de atualização de estados em função do número de estações-base. O objetivo desses testes foi de observar se a distribuição do grafo de domínio de aplicação em um número maior de estaçõesbase permite melhorar o desempenho das etapas de atualização. Para os testes executados, foram utilizados grafos contendo aproximadamente 10000 nós, com grau variando de 2 a 8 . A taxa de atualização de arcos contendo pesos alterados a cada atualização foi de $50 \%$ em média. Com esse cenário, foram executados testes para calcular o tempo total de atualização do estado global de sistemas variando-se o número de estações-base de 2 a 5 . O gráfico 6.23 mostra os resultados obtidos para testes com Conjuntos Raízes de $25 \%, 50 \%, 75 \%$ e $100 \%$. Com os dados testados, pode-se observar que à medida que o número de estações-base aumenta, os tempos totais de atualização de estados diminui. Em contrapartida, com foi observado na figura 6.7, à medida que o número de partições aumenta (maior número de estações-base), os tempos de busca de caminhos tendem a crescer.

Pôde ser observado pelos gráficos mostrados na seção 6.8 , que existe um limite não muito alto para o número de clientes ativos em sistemas centralizados. Os resultados apresentados mostram que, em geral, os sistemas com mais de 1 estação-base, possuem um limite maior para o número de clientes ativos. Também foi apresentado que o uso de um número maior de servidores de busca melhora o desempenho de buscas do sistema além de permitir uma quantidade maior de clientes utilizando o sistema.

A análise dos resultados mostra que a distribuição de um grafo em um conjunto de servidores não necessariamente melhora o desempenho das buscas de caminhos, mas permite o aumento de escalabilidade, tanto no tamanho do grafo quanto no número de acessos de clientes. Além disso, conforme foi afirmado anteriormente, os particionamentos deveriam privilegiar comprimentos mínimos de bordas, pois Conjuntos Raízes de tamanhos maiores mostraram ter um desempenho pior. 


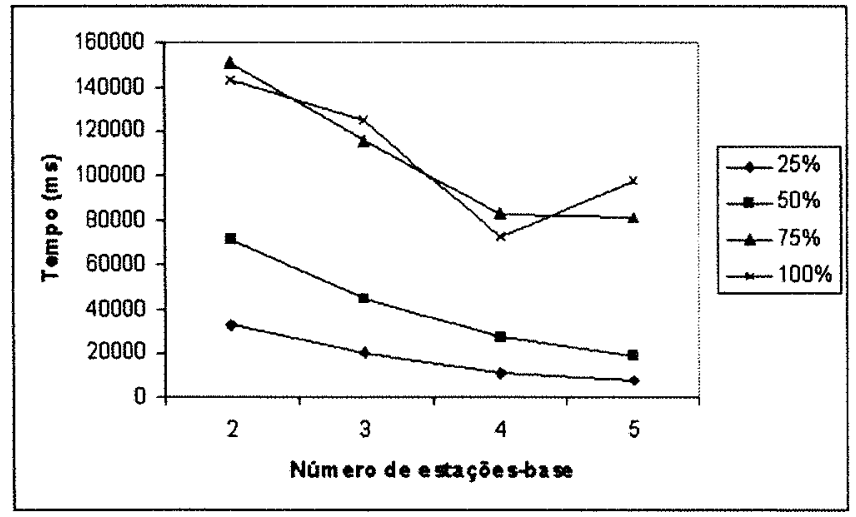

Figura 6.23: Tempos totais de atualização de estados em função do número de estações-base 


\section{Capítulo 7}

\section{Considerações Finais}

Este trabalho apresentou um modelo que permite o cálculo de estimativas de caminhos em um grafo particionado em um conjunto de servidores conectados através de uma rede de interconexão, sendo que o grafo sofre atualizações nos pesos dos arcos em determinados intervalos de tempo. Para isso, são considerados algoritmos de busca em grafos dinâmicos, tal como o proposto por Narváez et al. [18]. O arcabouço proposto por Narváez et al. foi discutido no Capítulo 3. O modelo apresentado neste trabalho foi denominado de "Roteamento adaptativo através de árvores dinâmicas".

Conforme foi apresentado no Capítulo 4, o modelo apresenta dois tipos especiais de servidores: estaçōes-base e servidores de busca. As estações-base são responsáveis por manter informações do subgrafo representante da partição do domínio que está sob sua responsabilidade. Todas as atualizações de arcos e requisições de caminhos cujos nós iniciais estão no interior do subgrafo armazenado na estação-base $E B_{X}$ são encaminhados para essa estação. Os servidores de busca são elementos responsáveis por manter a informação dos melhores caminhos conhecidos entre as estações-base. De tempos em tempos, uma estação-base do sistema (coordenador) realiza a atualização do estado global do sistema.

Conforme foi apresentado no Capítulo 5, o modelo apresentado foi implementado usando CORBA e a linguagem Java. Os resultados apresentados no Capítulo 6 indicam que o tamanho das bordas consideradas em cada partição tem um papel preponderante no desempenho do sistema. Em geral, verificou-se que o sistema apresenta um desempenho muito superior quando as partições têm Conjuntos Raízes menores. Existe um compromisso claro entre a qualidade da solução e o tempo necessário para calculá-la.

Os resultados apresentados na seção 6.6 indicam que a escolha de Conjuntos Raízes de dimensões muito menores que o comprimento total da borda considerada pode gerar diferenças nos valores de custos de caminhos calculados. Uma possível técnica para melhorar as estimativas é decidir por se usar técnicas de interpolação.

Um outro aspecto que pôde ser observado através dos resultados apresentados na seção 6.3 é que os algoritmos de busca em grafos dinâmicos se adequaram bem ao modelo proposto neste trabalho. 
Os testes apresentados na seção 6.8 mostram que sistemas distribuídos de busca permitem um número maior de clientes ativos no sistema, quando comparados com as respectivas versões centralizadas. Também pôde ser visto que o uso de um número maior de servidores de busca melhoram o desempenho e diminuem os tempos médios de busca de caminhos.

Deve-se ressaltar que, ao melhor de nosso conhecimento, a arquitetura aqui apresentada é o primeiro trabalho que aborda aspectos de distribuição para algoritmos de busca de caminhos em grafos dinâmicos.

\subsection{Trabalhos futuros}

Um modelo como o proposto neste trabalho é bastante extenso. Existe uma série de melhorias que podem ser incorporadas ao protótipo implementado. A seguir são listadas algumas idéias de possíveis trabalhos futuros no modelo implementado:

- Desenvolvimento de padrões para interpolações a fim de se minimizar erros utilizando-se Conjuntos Raízes de comprimentos menores;

- Criação de uma interface gráfica para visualização de gráficos e caminhos;

- Desenvolvimento de API cliente para acesso ao sistema através de dispositivos móveis, como handhelds;

- Criação de heurísticas para realizar previsões do estado da rede: como a atualização do estado global é realizada em determinados períodos de tempo, alguns sistemas de tempo real utilizam algoritmos especiais para estimar o estado da rede em um determinado momento futuro, baseando-se nos estados anteriores previamente calculados;

- Expandir a API atual para realizar buscas e atualizações usando outros algoritmos de busca (estáticos e/ou dinâmicos);

- Utilização de serviços de persistência de dados para, por exemplo, armazenar estados antigos em bancos de dados persistentes;

- Utilização de serviços de segurança e trader de CORBA: o protótipo atual não tem nenhuma preocupação com controles de segurança dos dados. Além disso, poderia ser usado o serviço de páginas amarelas (trader) para publicação dos serviços de localização para outros objetos Corba. 


\section{Apêndice A}

\section{Alguns detalhes da implementação}

Este Apêndice destina-se a apresentar detalhes extras da arquitetura implementada.

\section{A.1 Classes para implementação de algoritmos de busca}

Os algoritmos até agora utilizados pela arquitetura estão no pacote dgraph.ddgraph.graph. Como já foi explicado anteriormente, os algoritmos de busca podem ter uma natureza estática ou dinâmica. Os algoritmos de busca estática estão na classe Algorithms. Dentre eles, destaca-se o algoritmo de Dijkstra implementado com fila de prioridades (classe PriorityVector presente no pacote dgraph.ddgraph.datastruct).

Com relação aos algoritmos dinâmicos, a arquitetura disponibiliza uma implementação do algoritmo proposto por Narváez et al. [18], apresentado no Capítulo 3. A classe que implementa o algoritmo dinâmico se chama AlgorithmNST. Ela implementa os passos descritos pelo algoritmo dinâmico proposto por Narváez et al., apresentando a possibilidade de ser executado como uma. implementação do primeiro ou segundo método incrementais.

Devido ao fato de que o algoritmo precisa operar em um grafo contendo múltiplas atualizações simultâneas, a implementação presente na classe AlgorithmNST contempla a possibilidade de que o grafo possua essas características. Detalhes de como o algoritmo de Narváez et al. pode ser adaptado para múltiplas atualizações podem ser encontrados em [18] ou no Capítulo 3.

O trecho de código demonstra um exemplo de uso da classe AlgorithmNST:

Listing A.1: Exemplo de uso da classe AlgorithmNST

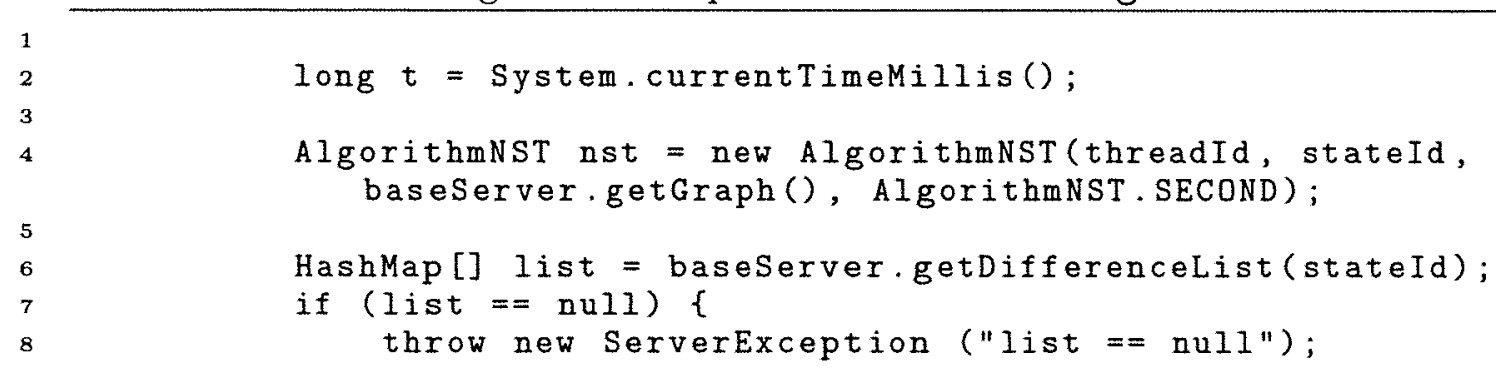




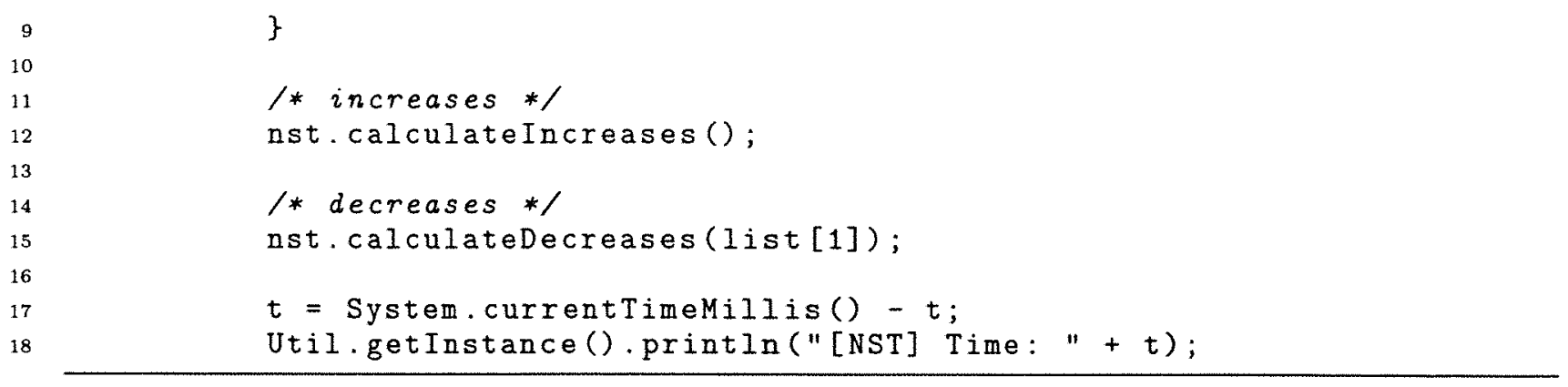

O trecho de código anterior foi extraído da classe PTAgent (responsável pela atualização de uma dada árvore pórtico) e demonstra como a classe AlgorithmNST é utilizada para realizar a atualização de uma árvore de caminhos com identificador threadId e estado stateId.

Conforme descrito no Capítulo 3 , as adaptações no algoritmo para realizar múltiplas atualizações de pesos são feitas na etapa de inicialização. Basicamente, são realizadas 2 inicializações, uma considerando todos os arcos que tiveram pesos incrementados e a outra para todos arcos com pesos decrementados. Após ser efetuada a etapa de inicialização específica, o restante da execução do algoritmo segue os passos descritos no Capítulo 3: Seleção de nós, Atualização de Distâncias e Busca de nós. Por isso, o algoritmo é executado 2 vezes, uma para cada tipo de inicialização: com arcos incrementados e com arcos decrementados.

Na primeira execução do algoritmo, são considerados todos os arcos que tiveram seus pesos incrementados, para que seja verificada a lista de nós presentes na árvore de caminhos previamente obtida e que foram afetados pelos aumentos de pesos. $\mathrm{O}$ trecho de código a seguir apresenta o método increase, que realiza a etapa de inicialização considerando todos os arcos que tiveram os pesos incrementados.

No código apresentado, o método updateDistAndCalcMaxDescendents realiza a atualização das distâncias de caminhos na árvore previamente obtida com as novas diferenças (incrementos) de pesos dos arcos do grafo. Além disso, este método obtém uma lista dos vértices afetados (nodesMap) pelas alterações. Para os nós contidos em nodesMap, é verificado se as novas distâncias de caminhos são melhores que as previamente obtidas na árvore e, se esse for o caso, o nó é inserido através do método enqueue na lista queue, para ser posteriormente processado pelos passos 2,3 e 4 descritos no algoritmo apresentado no Capítulo 3.

Listing A.2: Método increase

1
2
3
4
5
6
7
8
9
0
1
2
3
4

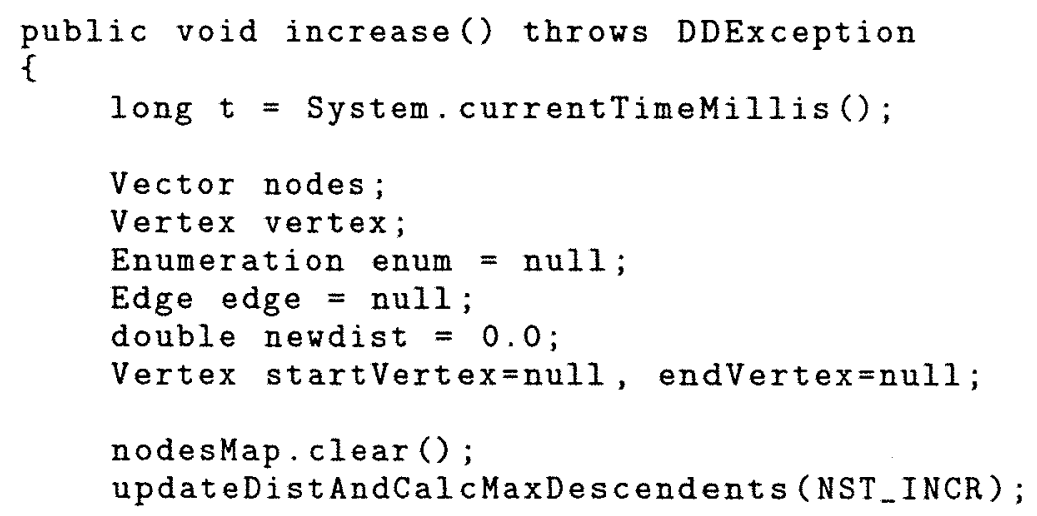




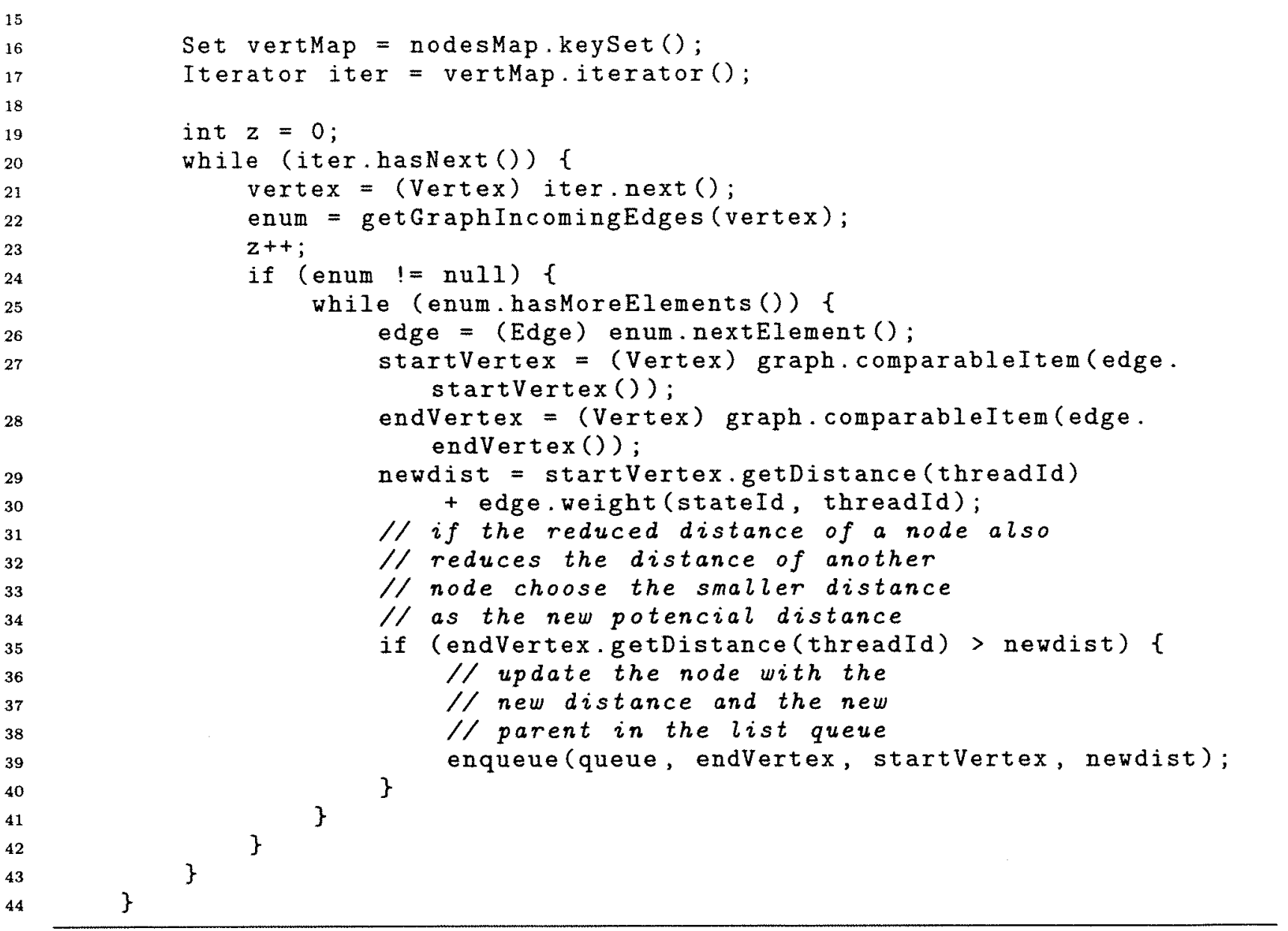

Após a primeira execução do algoritmo com os arcos incrementados, são considerados todos os arcos que sofreram decremento. Para tanto, o método decrease da classe AlgorithmNST recebe uma lista dos arcos (iedges) que sofreram decremento de peso, bem como as respectivas diferenças entre os novos e antigos valores para cada arco decrementado. Com estas informações, a árvore previamente calculada é atualizada, corrigindo-se as informações de relação entre nós pai e filho, observando-se os nós conectados aos arcos que tiveram os pesos decrementados. Se existir um arco $E$ cujo decremento de peso acarreta uma diminuição do custo de algum caminho na árvore previamente calculada, então um par de nós do caminho terá sua relação pai-filho alterada, utilizando-se o arco $E$.

Em seguida, o método updateDistAndCalcMaxDescendents é chamado para realizar a atualização das distâncias de caminhos na árvore previamente obtida com as novas diferenças (decrementos) de pesos dos arcos do grafo. Além disso, este método obtém uma lista dos vértices afetados (nodesMap) pelas alterações. Com os nós contidos em nodesMap, é verificado se as novas distâncias de caminhos são melhores que as previamente obtidas na árvore e, se esse for o caso, o nó é inserido através do método enqueue na lista queue, para ser posteriormente processado pelos passos 2, 3 e 4 descritos no algoritmo apresentado no Capítulo 3 .

Listing A.3: Método decrease 


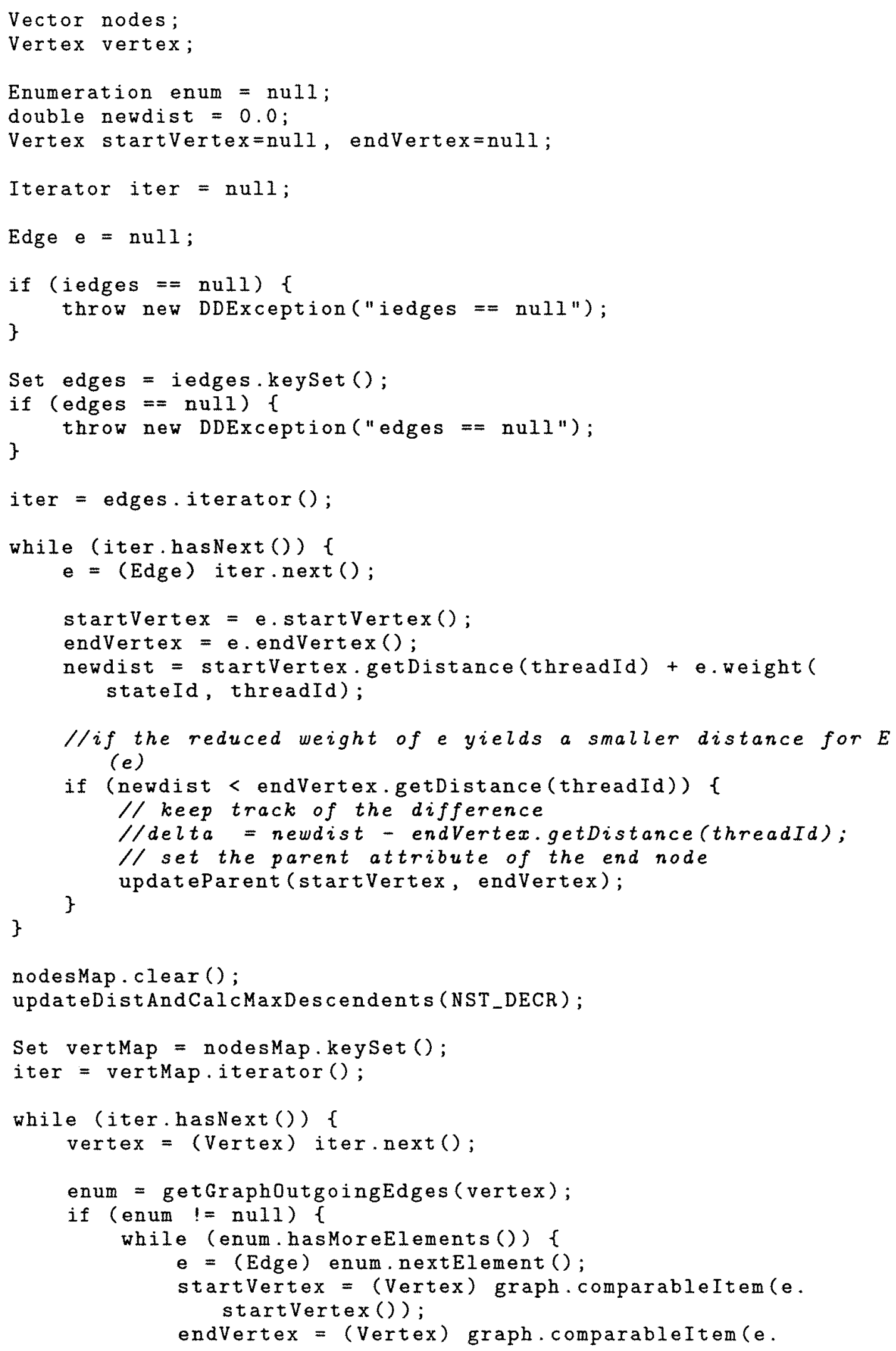




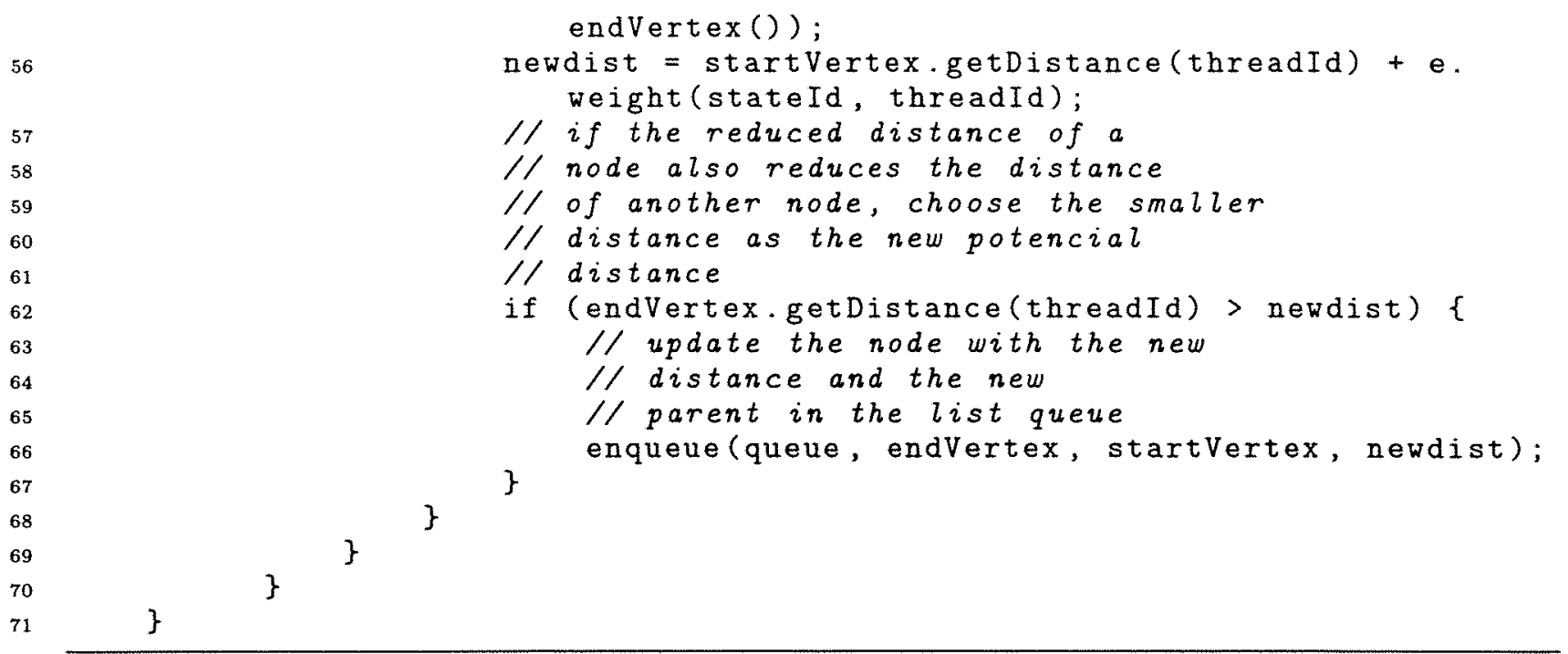

Conforme foi explicado anteriormente, o método updateDistAndCalcMaxDescendents permite que as distâncias de caminhos previamente obtidos na árvore sejam atualizados com os novos pesos de arcos incrementados (parâmetro NST_INCR) ou decrementados (parâmetro NST_DECR) bem como gerar uma lista de nós afetados pela alteração de pesos dos arcos. A implementação corrente deste método foi feita de forma que o grafo fosse visitado apenas uma vez independente do número de arcos afetados.

\section{A.2 Arquivos de configuração de servidores}

O exemplo a seguir apresenta o conteúdo básico do arquivo de configuração de servidores de busca e estações-base.

Listing A.4: Exemplo de arquivo de configuração

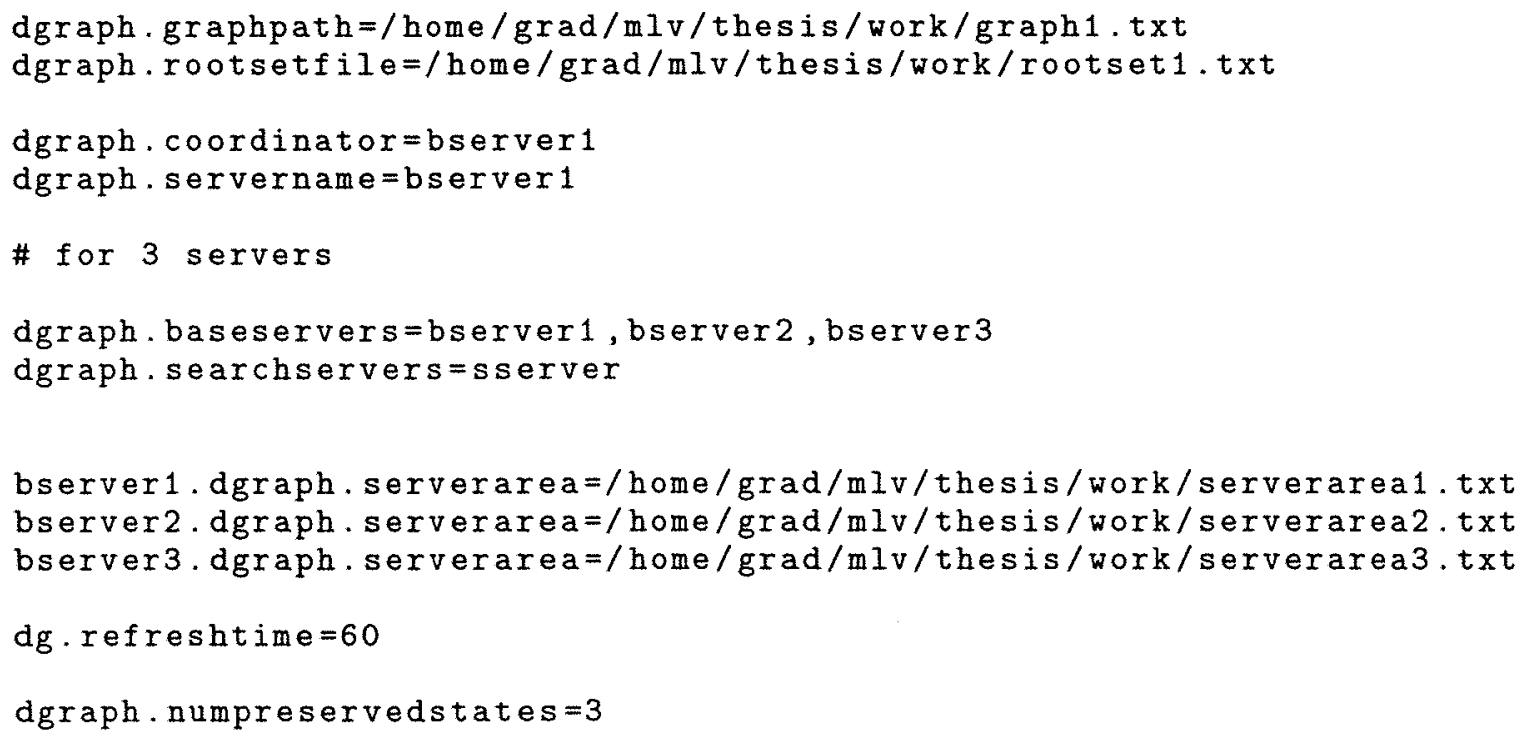


Será dada a descrição das propriedades apresentadas:

- dgraph.graphpath: descreve o caminho de um arquivo contendo o grafo descrevendo o domínio a ser monitorado pela estação-base. Trata-se de uma propriedade específica às estações-base. O formato do arquivo será dado na Seção A.3;

- dgraph.rootset: descreve o caminho de um arquivo contendo a lista de nós no Conjunto Raízes do domínio a ser monitorado pela estação-base. Trata-se de uma propriedade específica às estações-base. O formato do arquivo será dado na Seção A.3;

- dgraph.coordinator: identificador do coordenador. De uso geral (estações-base e servidores de busca);

- dgraph. servername: identificador do servidor. Pode ser qualquer valor, desde que identifique unicamente o servidor. De uso geral;

- dgraph.baseservers: lista de estações-base do sistema. De uso geral;

- dgraph.searchservers: lista de servidores do sistema. De uso geral;

- identificador.dgraph.serverarea: para cada estação-base, é necessário especificar a lista de nós que compõem o seu domínio. Para tanto, existe a propriedade dgraph.serverarea, que recebe um arquivo descrevendo a lista de nós compondo o domínio de uma estação-base. O formato do arquivo será dado na Seção A.3. Para cada estação-base, existe uma propriedade dgraph. serverarea. No exemplo anterior, há 3 estações-base com identificadores bserver1, bserver2 e bserver3. Dessa forma, são necessárias 3 propriedades: bserver1. dgraph. serverarea, bserver2. dgraph. serverarea e bserver3. dgraph. serverarea. De uso geral;

- dgraph.refreshtime: Identifica o intervalo de tempo (em minutos) que o coordenador deverá esperar para iniciar um novo processo de atualização, tendo o atual estado sido estabelecido;

- dgraph.numpreservedstates: Indica o número máximo de estados a serem armazenados no servidor. Maiores detalhes podem ser encontrados na Seção 5.7.

Existem outras propriedades utilizadas para agilizar os processos de testes. Essas propriedades bem como breves descrições podem ser vistas nos arquivos de configuração presentes no pacote contendo a implementação da arquitetura, conforme apresentado no início deste Capítulo.

\section{A.3 Formatos de entrada para criação de grafos}

Esta seção se destina a apresentar o formato de entrada dos arquivos mencionados na seção A.2. 


\section{A.3.1 Formato do arquivo usado na propriedade dgraph.graphpath}

Este arquivo apresenta a descrição do grafo que representa o domínio monitorado pela estaçãobase. O formato de entrada do arquivo é muito simples.

A seguir é mostrado um exemplo para criação do grafo para a estação-base bserverX.

Listing A.5: Exemplo de arquivo de construção do grafo de domínio

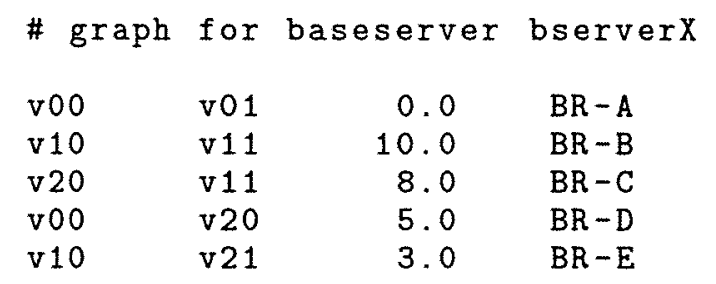

Cada linha do arquivo deve apresentar um arco, contendo o identificador dos nós, o peso inicial e um apelido ou descrição do arco. Por exemplo, para o arquivo mostrado acima, foi atribuído um peso de 0.0 ao arco ligando os vértices v00 a v01, com uma descrição adicional de "BR-A".

\section{A.3.2 Formato do arquivo usado na propriedade dgraph.serverarea}

Este arquivo apresenta a descrição dos nós do domínio monitorado por uma estação-base.

A seguir é mostrado um exemplo da descrição dos nós no domínio da estação-base bserverX.

Listing A.6: Exemplo de arquivo de construção de áreas

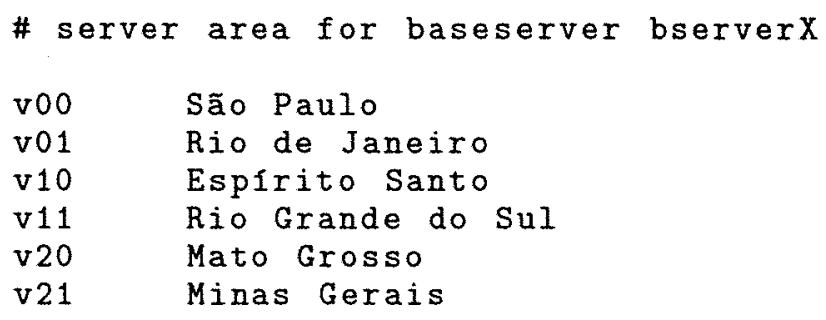

Cada linha do arquivo deve apresentar um nó do domínio e um apelido ou descrição do mesmo. Por exemplo, para o arquivo mostrado acima, foi adicionado à primeira linha o nó v00 com descrição "São Paulo".

\section{A.4 Classes clientes}

A versão atual da arquitetura implementada disponibiliza a classe dgraph.DGraphClient para proporcionar acesso às estações-base, a fim de solicitar informações sobre caminhos. 
A sintaxe utilizada é a seguinte:

jaco dgraph.DGraphClient -bserver bservername -action actiontype params

Onde, bservername é o identificador da estação-base a ser requisitada, actiontype é o tipo da ação a ser desempenhada. Para buscas, há dois tipos de ações: localsearch, para no caso de buscas locais e globalsearch, para buscas globais. params indica a lista de parâmetros especifica ao tipo de ação, por exemplo, no caso de buscas locais ou globais, deve-se indicar os nós inicial e final para os quais se deseja encontrar um caminho. No exemplo a seguir apresentado, é solicitada a busca local de caminho do vértice v0,0 ao vértice v99,99 à estação-base bserverX, que é a estação que possui o vértice vo, 0 em seu domínio.

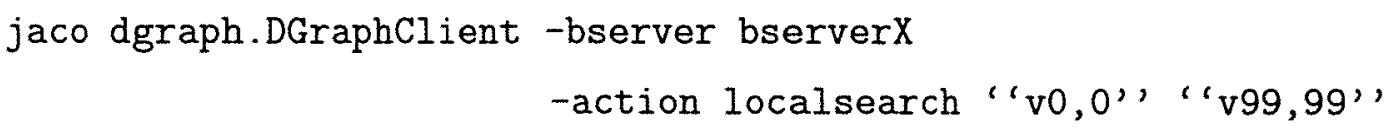

Há outros parâmetros usados na classe DgraphClient para facilitar os processos de simulação e testes, que podem ser encontrados no pacote da implementação disponibilizada. 


\section{Referências Bibliográficas}

[1] D. Alberts, G. Cattaneo, and G. F. Italiano. An empirical study of dynamic graph algorithms. ACM Journal of Experimental Algorithmics, 2:5, 1997.

[2] T. Cormen, C. Leiserson, R. Rivest, and C. Stein. Introduction to Algorithms. MIT Press, 2nd. edition, 2001.

[3] C. Demetrescu, D. Frigioni, A. Marchetti-Spaccamela, and U. Nanni. Maintaining shortest paths in digraphs with arbitrary arc weights: An experimental study. Lecture Notes in Computer Science, 1982:218-230, 2001.

[4] E. Dijkstra. A note on two problems in connection with graphs. Numerische Mathematik, 1:269-271, 1959.

[5] M. Dorigo and G. Di Caro. The ant colony optimization meta-heuristic. In New Ideas in Optimization, pages 11-32. McGraw-Hill, 1999.

[6] J. Edmonds and R. Karp. Theoretical improvements in algorithmic efficiency for network flow problems. Journal of the ACM, 19:248-264, 1972.

[7] J. Fawcett and P. Robinson. Adaptive routing for road traffic. IEEE Computer Graphics and Applications, 20(3):46-53, May/June 2000.

[8] M. Fowler. Patterns of Enterprise Application Architecture. Addison Wesley, 2002.

[9] D. Frigioni, A. Marchetti-Spaccamela, and U. Nanni. Incremental algorithms for singlesource shortest path trees. Proceedings of Foundations of Software Technology and Theoretical Computer Science, pages 113-224, December 1994.

[10] M. Dorigo G. Di Caro. Mobile agents for adaptive routing. Proceedings of the 31st Hawaii International Conference on System Sciences (HICSS'98), page 74, January.

[11] L. Kleinrock and F. Kamoun. Hierachical routing for large networks: Performance evalution and optimization. Computer Networks, 1(2):155-174, 1977.

[12] Y. Ko and N. Vaidya. A Routing Protocol for Physically Hierarchical Ad Hoc Networks. Technical Report TR97-010, 9, 1997. 
[13] P. Lauder, R. Kummerfeld, and A. Fekete. Hierachical network routing. Proceedings of TriComm'91, IEEE Conference on Communications Software, Chapel Hill, North Carolina, USA, pages 105-114, April 1991.

[14] D. Lea. Concurrent Programming in Java: Design Principles and Pattern. Addison-Wesley, 2nd. edition, 1999.

[15] C. Lee. An algorithm for path connectivity and its applications. IRE Transport on Electronic Computers, 10(3):346-365, September 1961.

[16] A. Loureiro and R. Mateus. Introdução à Computação Móvel. XI Escola de Computação, 1998.

[17] J. McQuillian. Adaptive routing algorithms for distributed computer networks. BBN Rep. 2831, Bolt Beranek and Newman Inc., Cambridge MA, May 1974.

[18] P. Narváez, K. Siu, and H. Tzeng. New dynamic algorithms for shortest path tree computation. IEEE/ACM Transactions on Networking, 8(6):734-746, December 2000.

[19] G. Ramalingam. Bounded incremental computation. Number 1089 in Lecture Notes in Computer Science. Springer-Verlag, 1996.

[20] G. Ramalingam and T. Reps. An incremental algorithm for a generalization of the shortest path problem. Journal of Algorithms, 21:267-305, 1996.

[21] G. Ramalingam and T. Reps. On the computational complexity of dynamic graph problems. Theoretical Computer Science, 158:233-277, 1996.

[22] A. Tanenbaum. Computer Networks. Prentice Hall, 2003.

[23] A. Tanenbaum and M. Steen. Distributed Systems - Principles and Paradigms. Prentice Hall, 2002. 